مجي آلفنون والندب وعلوم اللانسانيات واللاجتهاءع

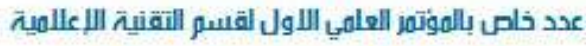

كلية التقنية الليدارية -جامعت السليمانية التقنية

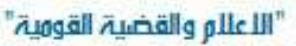

www jalhss.com ISSN online: 2414-3383 ISSN print 2616-3810

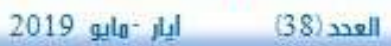

\title{
Identity and New Media Identity in the Web from Web1 to Web3
}

(Analytical theoretical research of the media in the Web era)

\author{
Dr. Bahat Haseeb Qaradakhy \\ Department of Media Technique \\ College of Management Techniques \\ Erbil Polytechnic University \\ bahat.ali@epu.edu.iq
}

\author{
Hardawan Mahmud \\ Department of Media \\ College of Arts \\ University of Salahaddin \\ hardawan@su.edu.krd
}

\begin{abstract}
The new media occupies a wide range of different areas of our daily lives, one of that is the question of national identity and culture. If we focus on the development of the new media and the Internet, we will find that there are many questions and concerns about the Kurdish identity and its culture have come into being, with this development, ringing like bells of dangers, want to alert the media, educational and cultural institutions to do more scientific efforts to study those fears.

In this theoretical and analytical research, the researchers attempt to shed light on the effects of the new media on the issue of nationalism, identity and culture, through the method of observation and theoretical analysis.

The aim of the research is to show these vital issues and to identify future risks, as well as to stimulate interest of the relevant governmental and civil institutions to give serious attention to those issues.
\end{abstract}




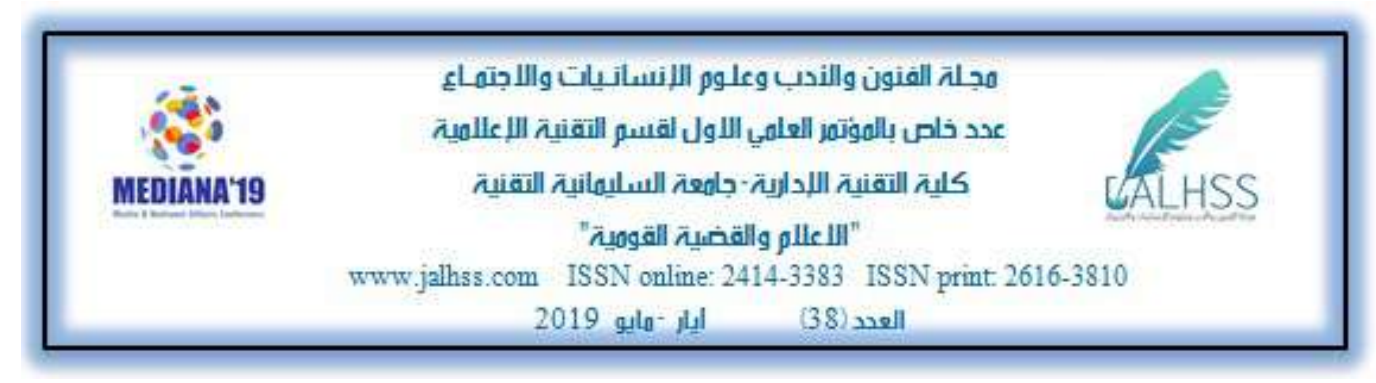

\section{بِرسى شوناس لله ميدياى نويّدا

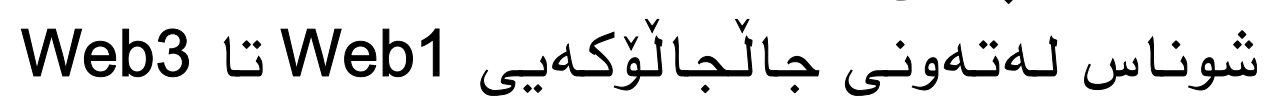

تويّزينهوهيهكى تيؤريى شيكارييه بؤ ميدياى سهردهمى ويّبـهكان

م. هـردهوان مهحمود كاكهشيّخ

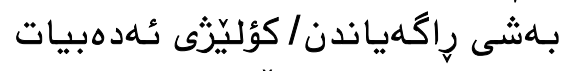

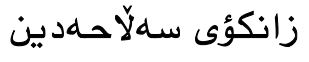

hardawan@su.edu.krd

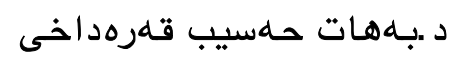

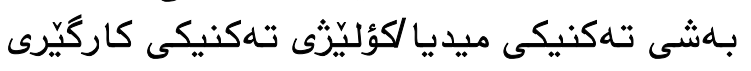

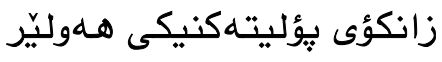 \\ bahat.ali@epu.edu.iq
}

بوخته

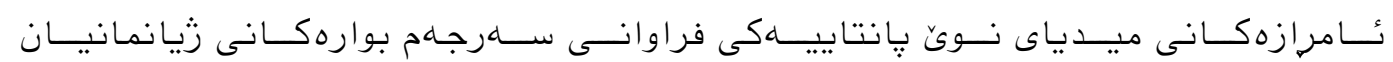

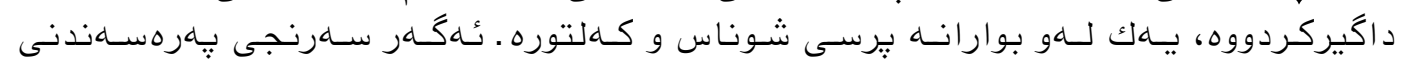

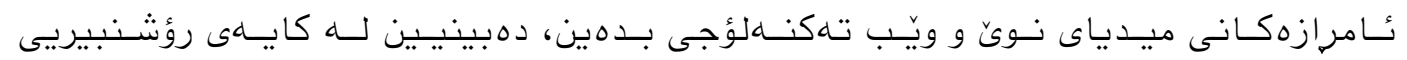

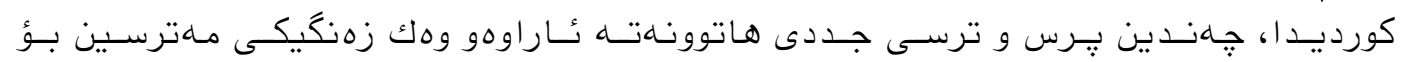

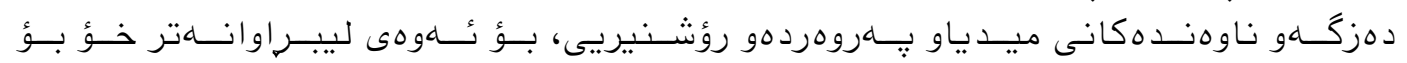

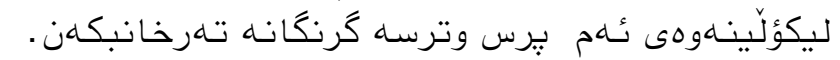

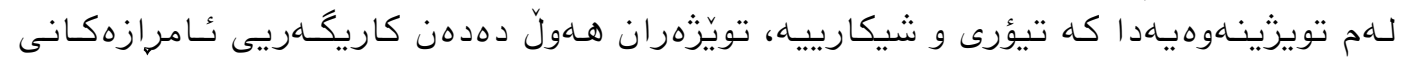

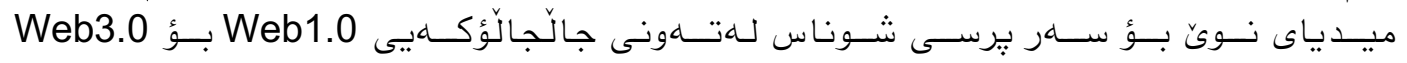

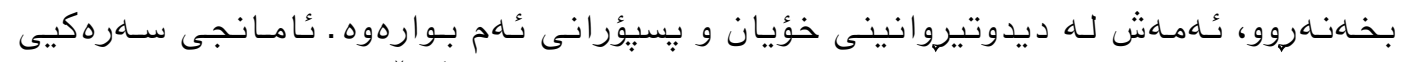

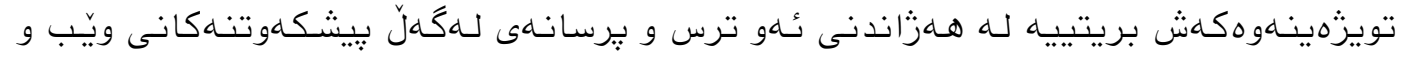

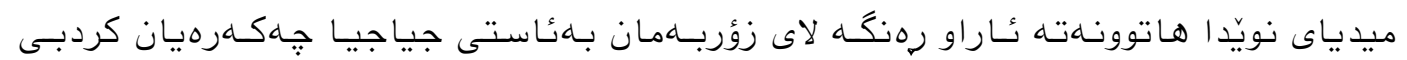

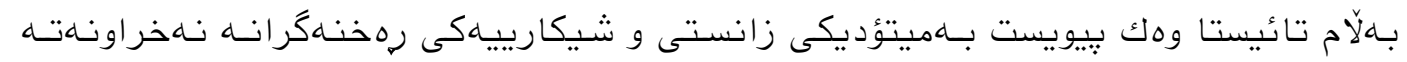

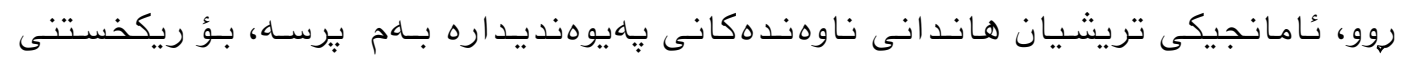

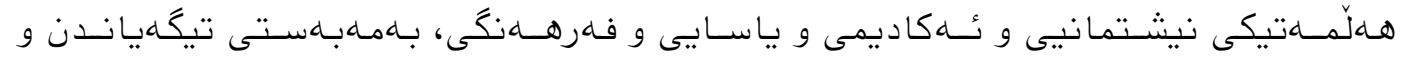

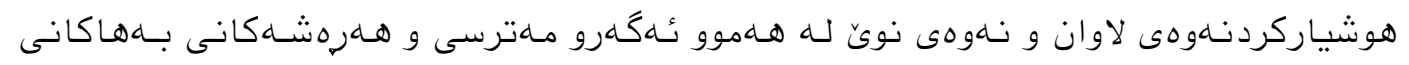




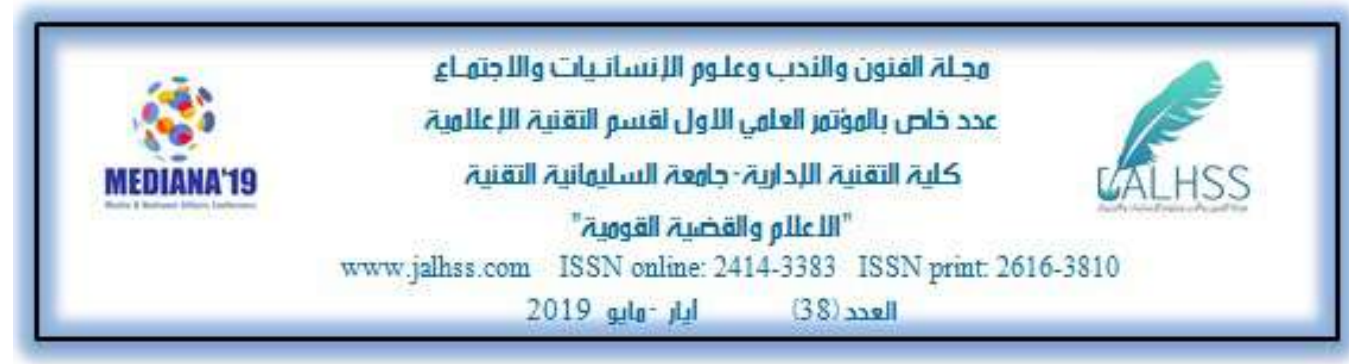

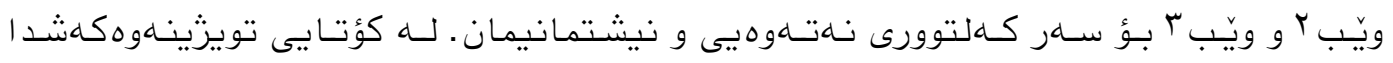

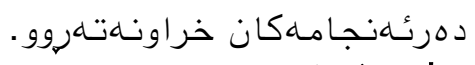

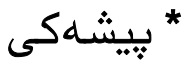

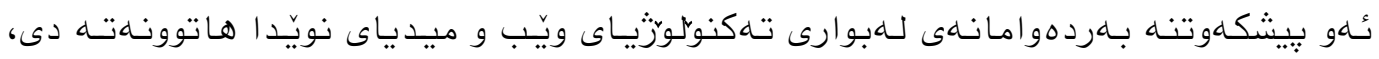

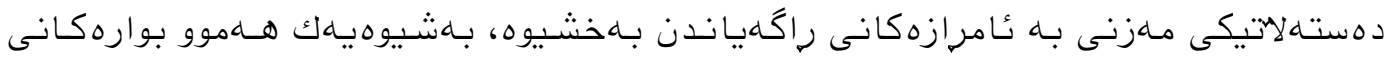

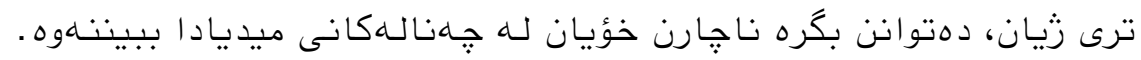

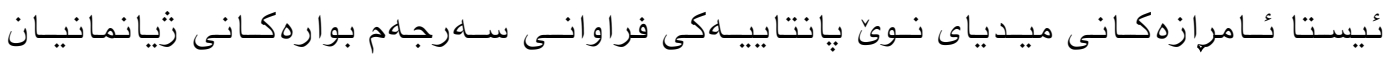

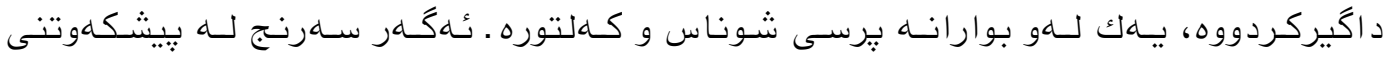

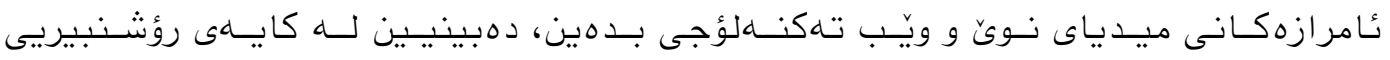

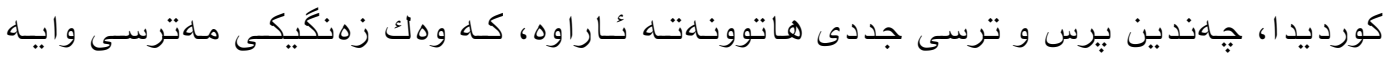

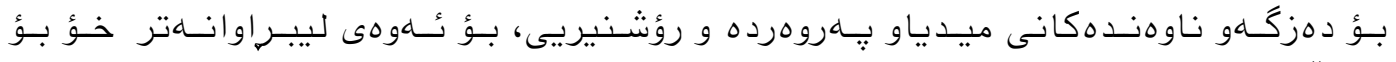

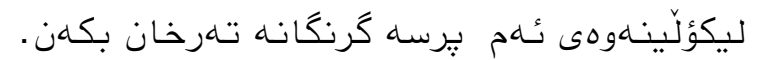

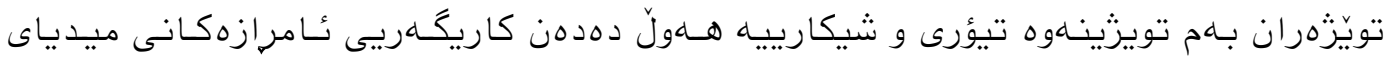

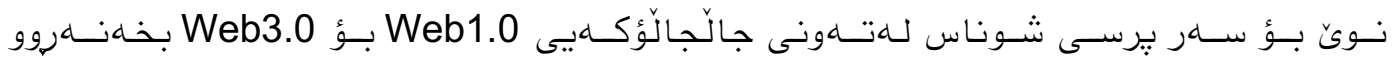

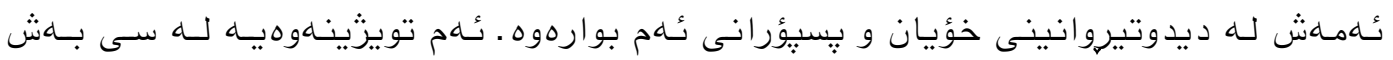

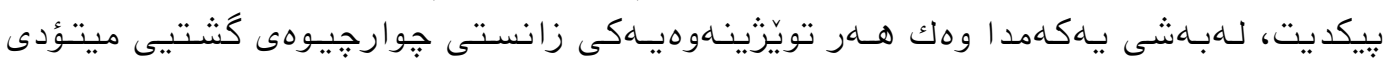

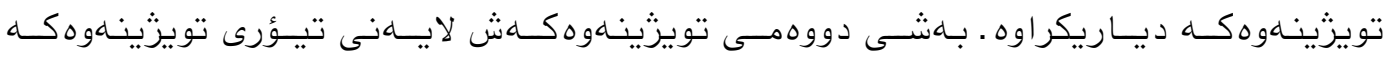

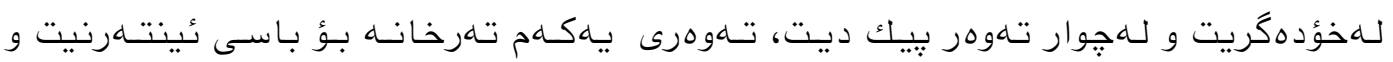

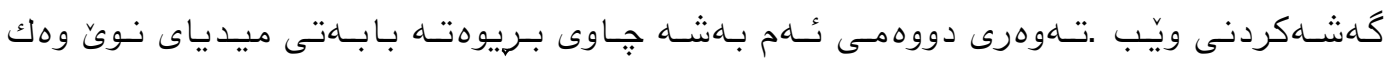

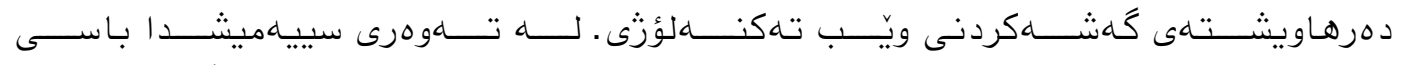

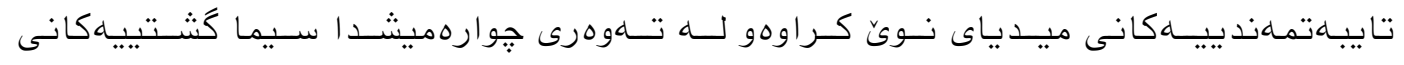

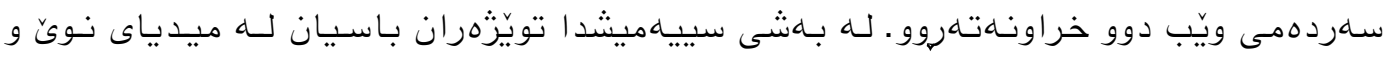

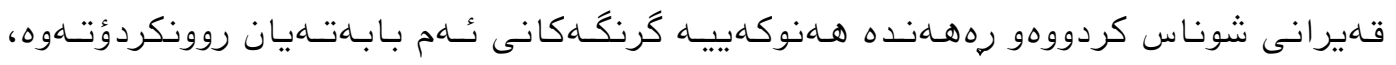

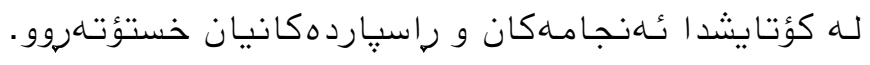




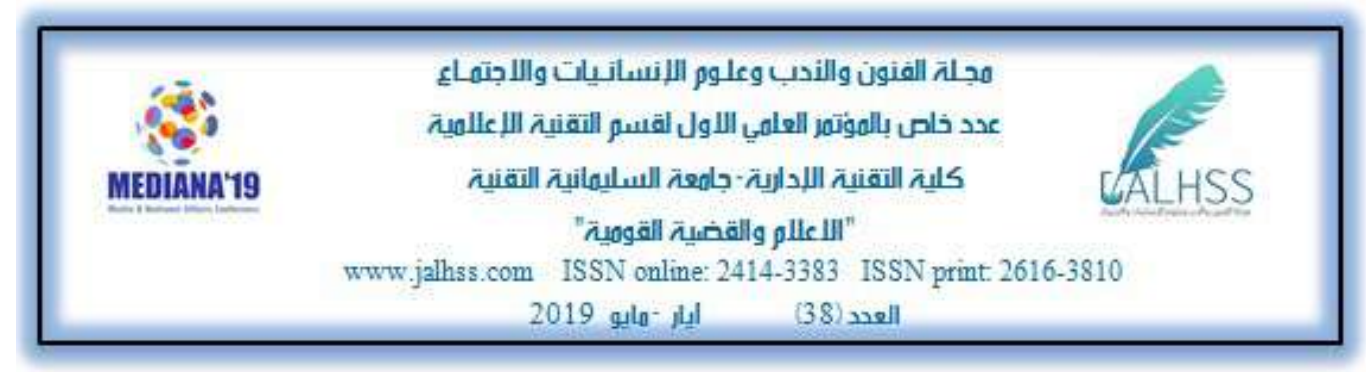

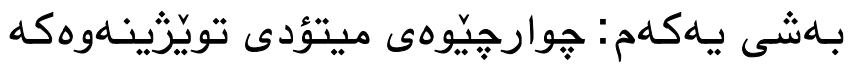

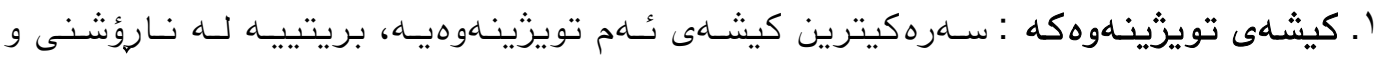

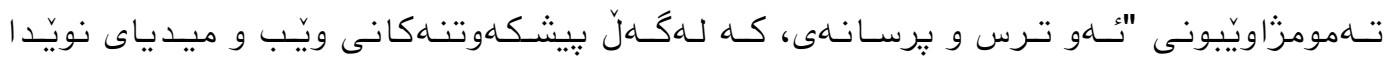

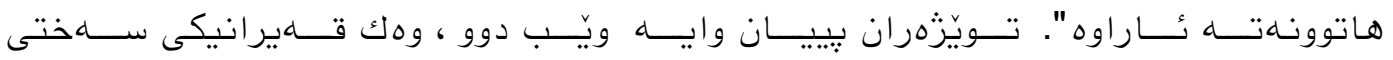

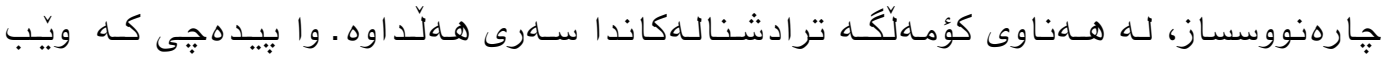

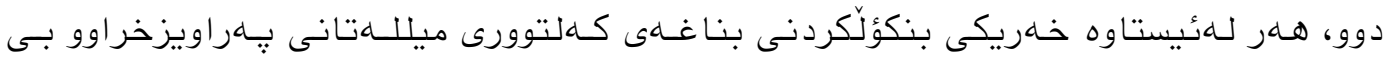

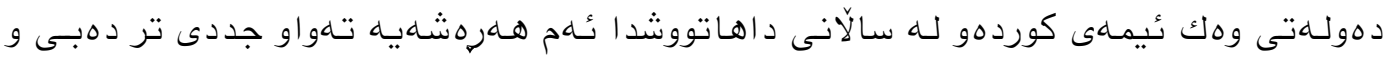

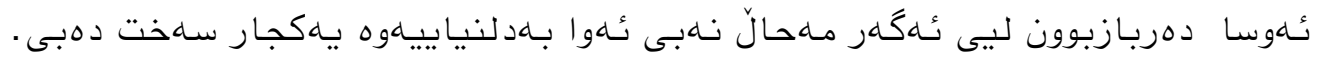

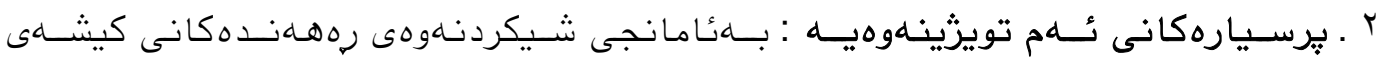

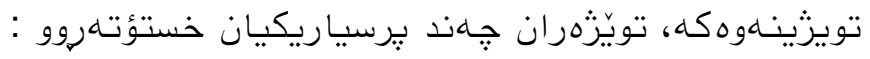

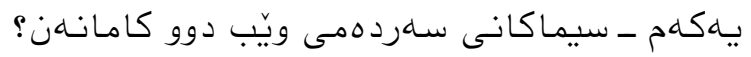

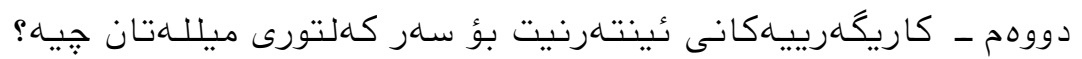

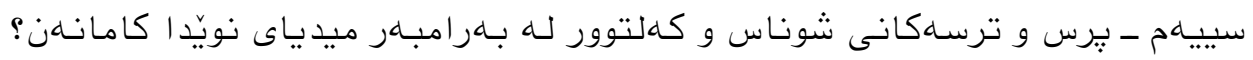

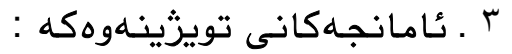

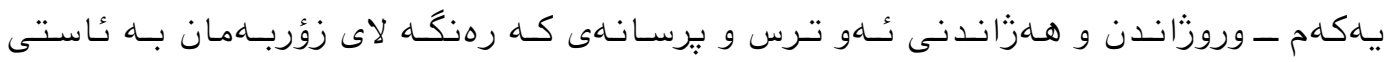

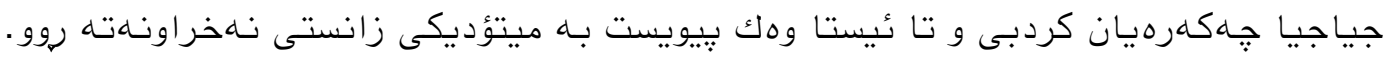

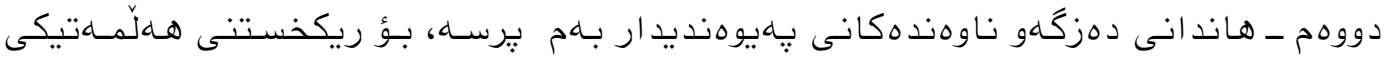

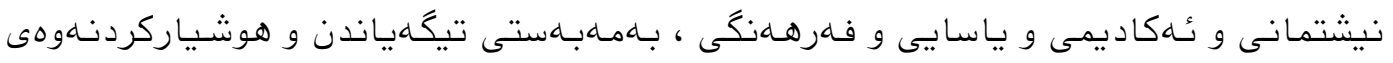

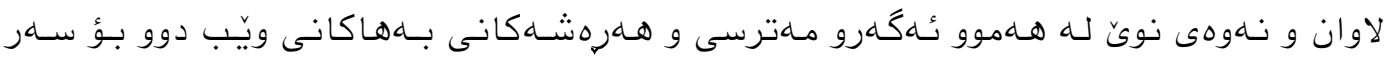

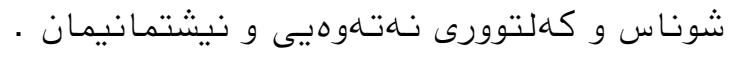

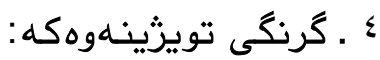

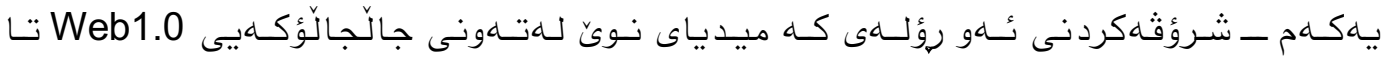

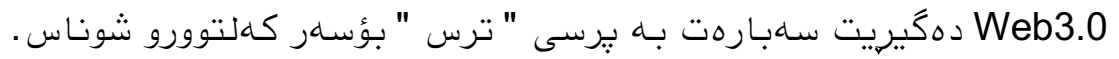

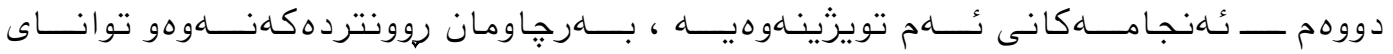

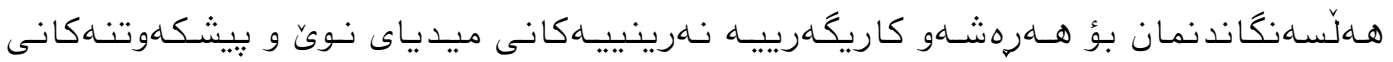

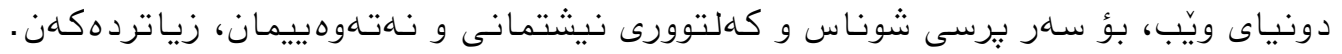

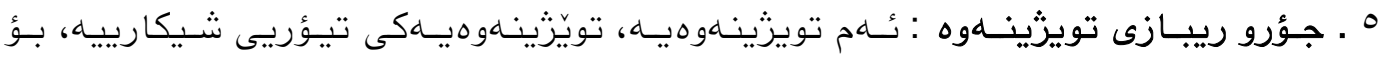

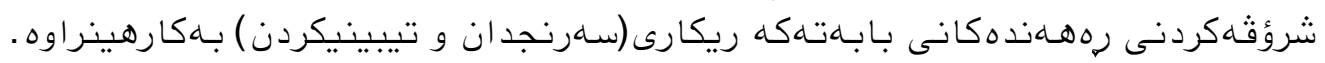




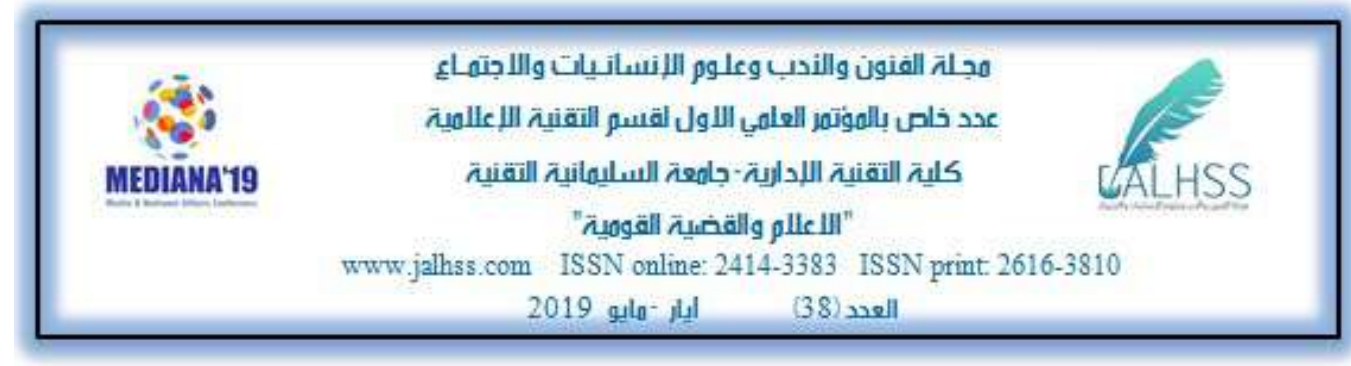

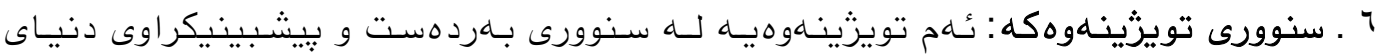

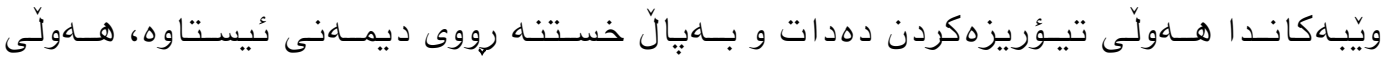

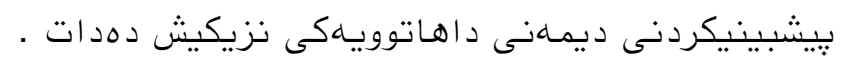

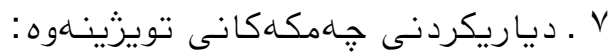

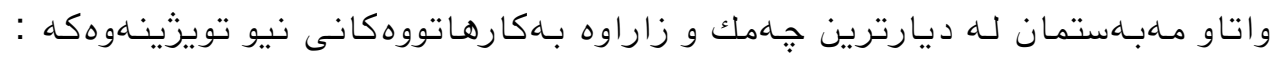

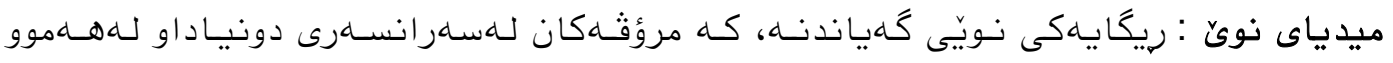

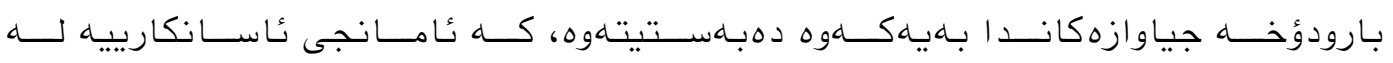

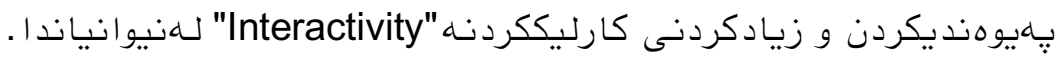

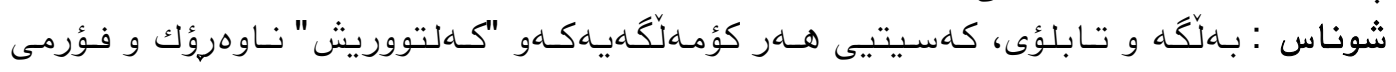
ئسهو شوناسهيه.

\section{بـهـى دووهم: توّرهاكانى ئينتهرنيت وكَشهكردنيان}

يهكهم : ئينتهرنيت و كهشهكردنى ويّب

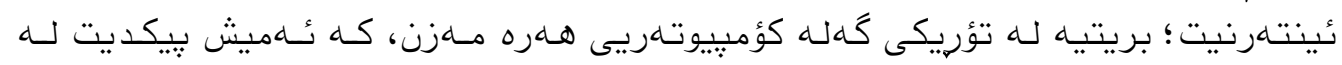

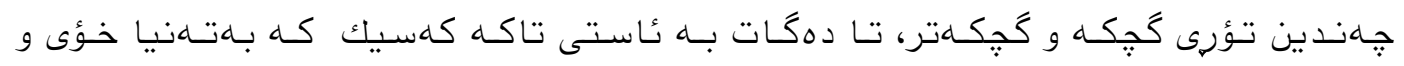

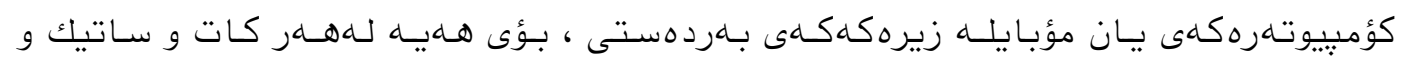

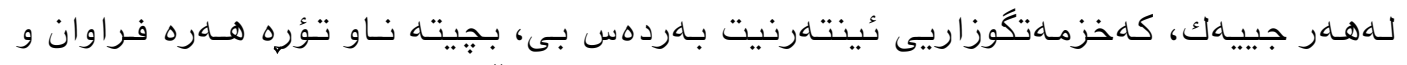

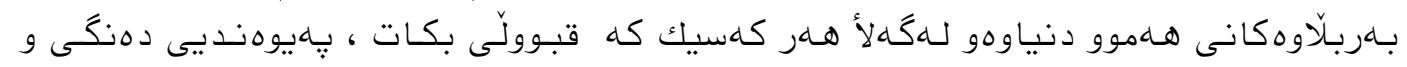

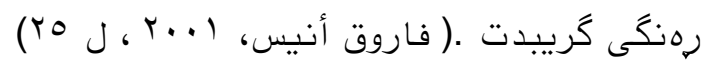

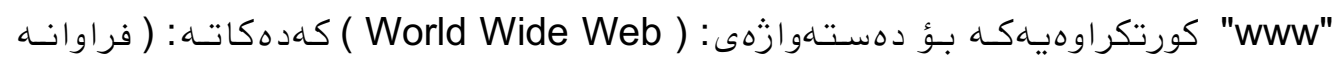

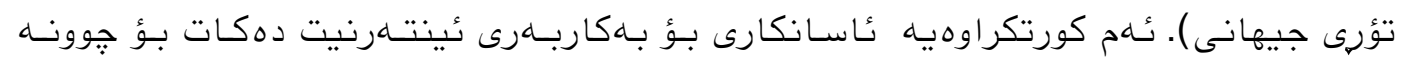

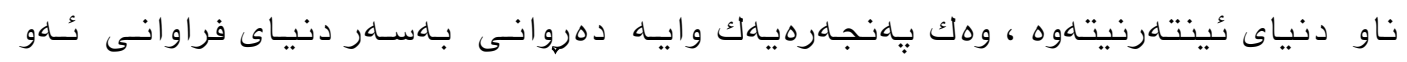

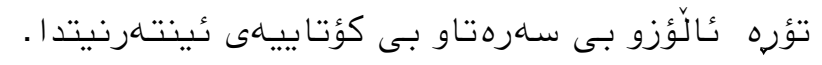

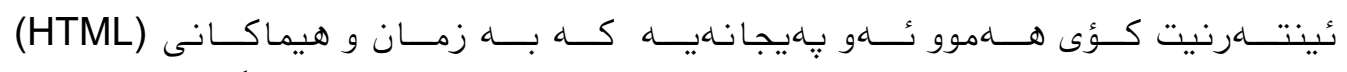

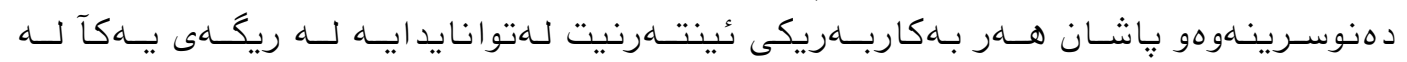

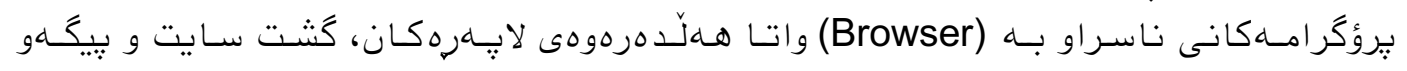

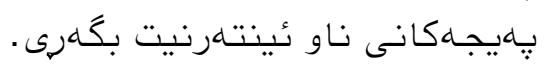




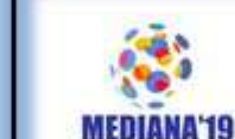

MEDIĀMA'19
مجِلحَ الفنون والندب وعلوم اللإنسانيات واللاجتهاءي

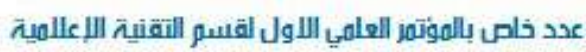

كلية التقنية الليدارية-جامعة السليهانية التقنية

"

www.jalhss.com ISSN online: 2414-3383 ISSN print 2616-3810

2019 العدايد

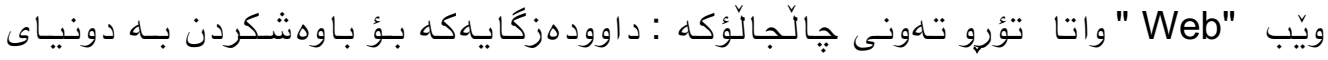

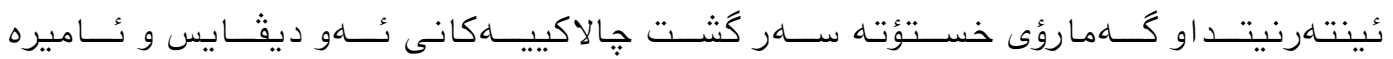

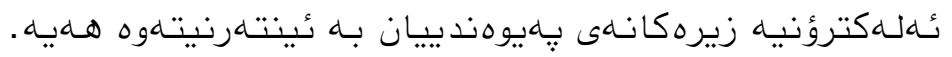

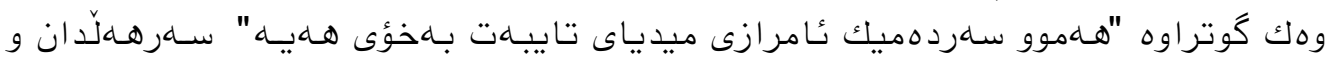

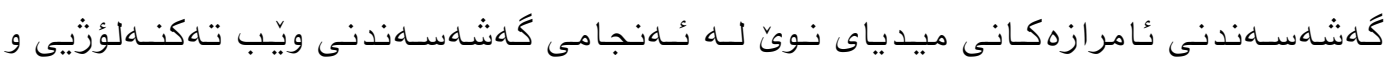

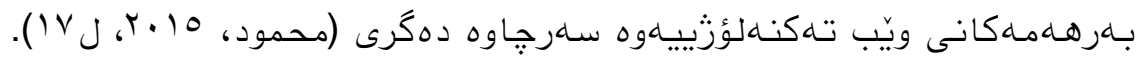

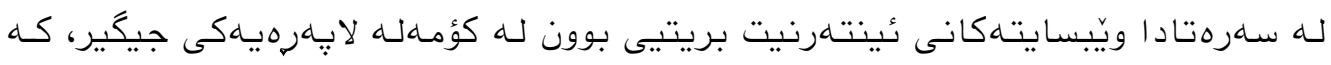

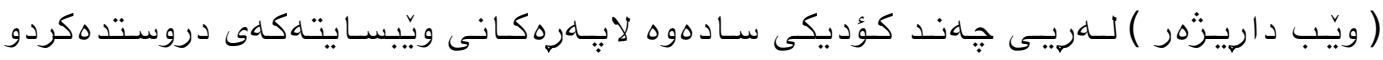

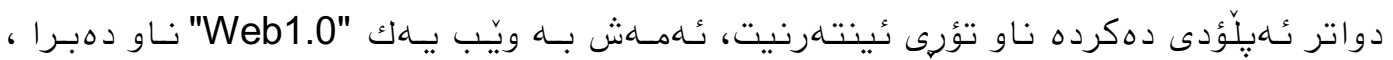

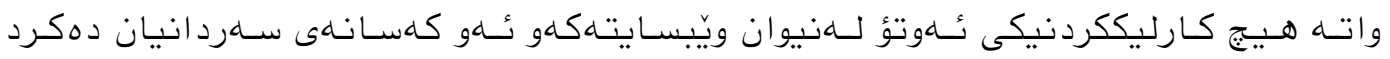

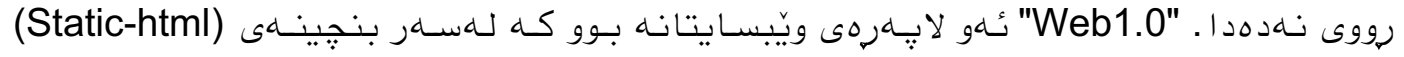

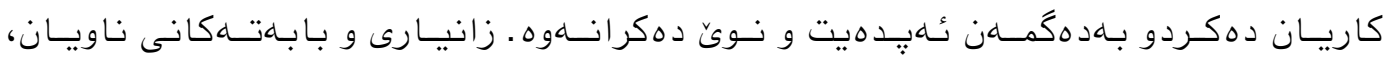

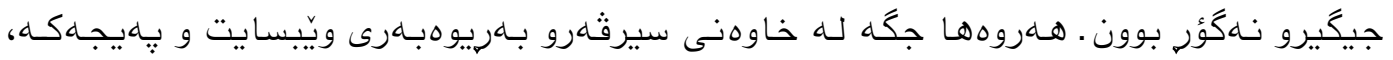

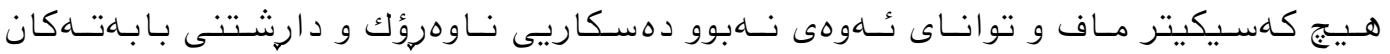

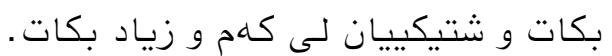

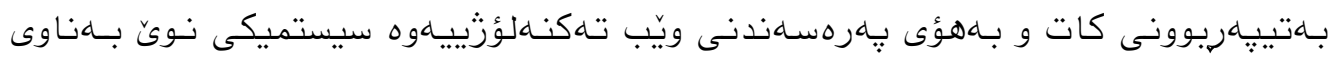

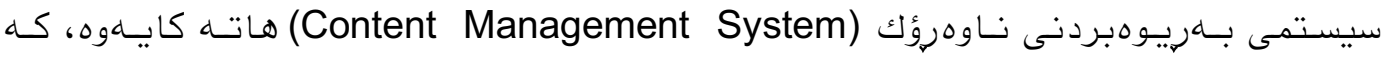

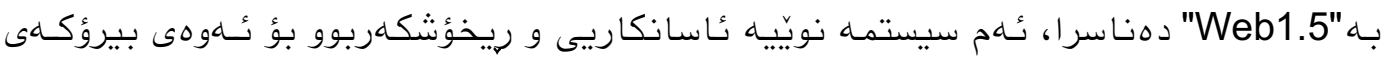

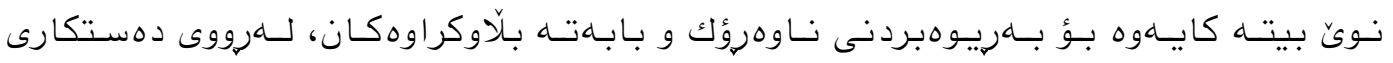

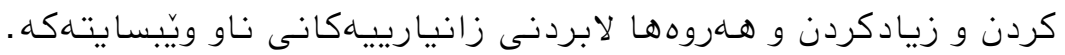

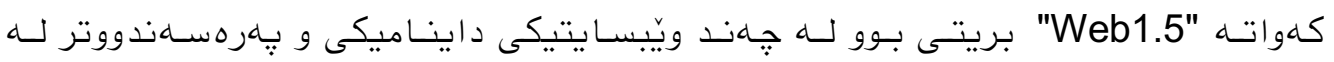

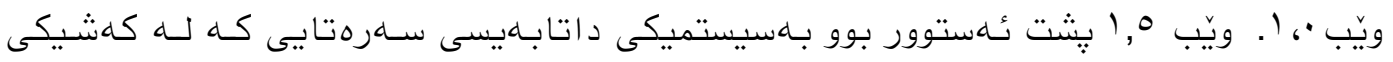

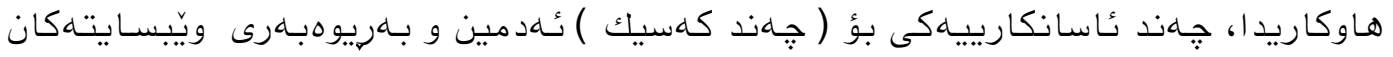

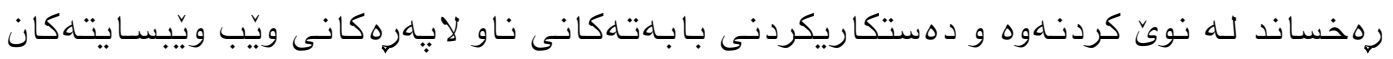

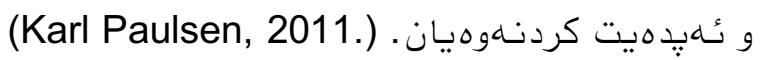

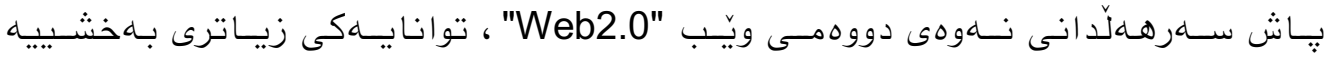

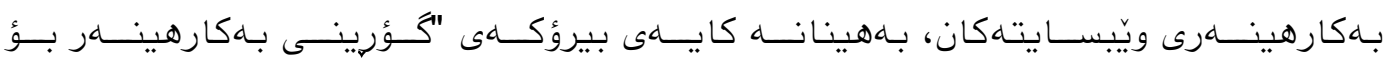

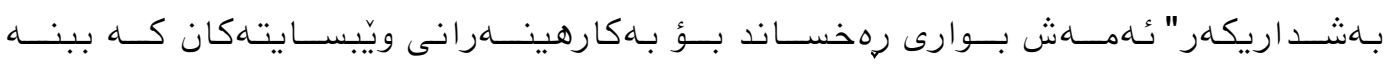

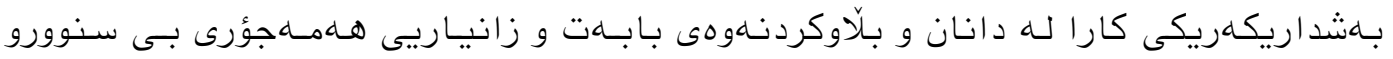
بعى سانسؤر. 


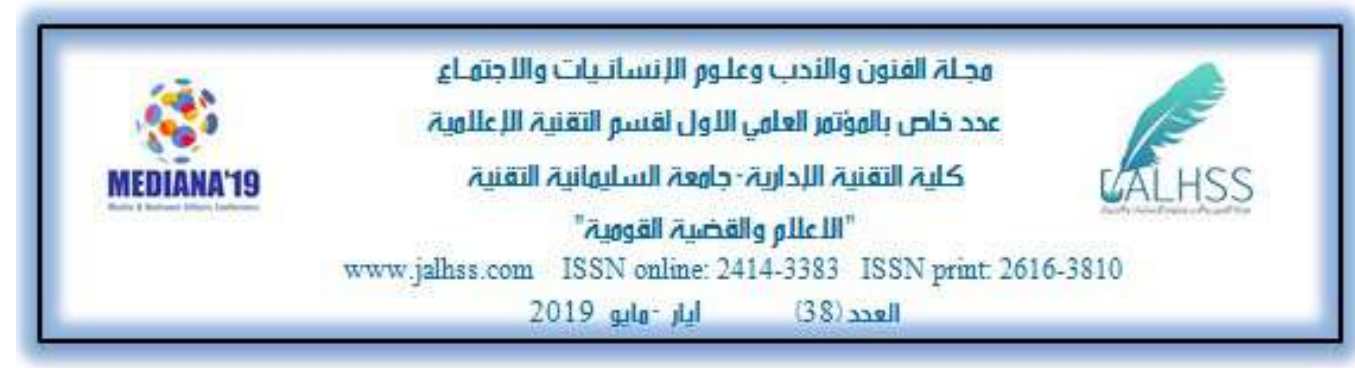

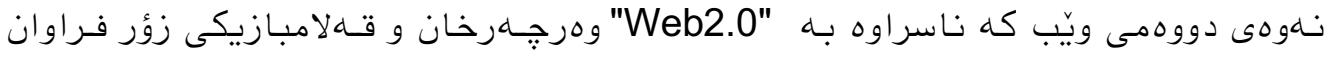

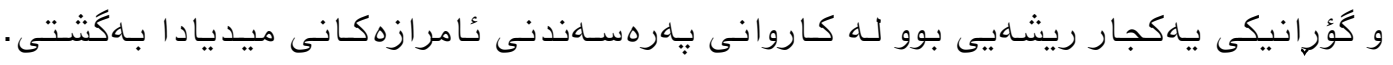

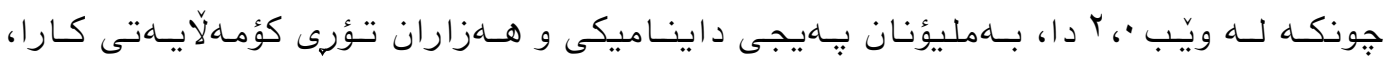

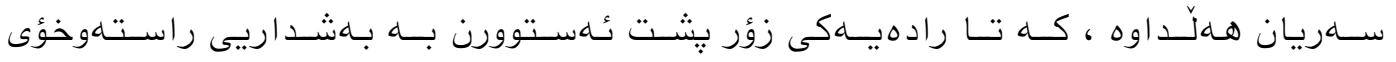

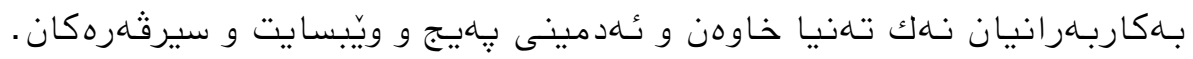

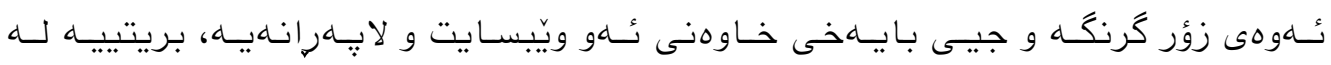

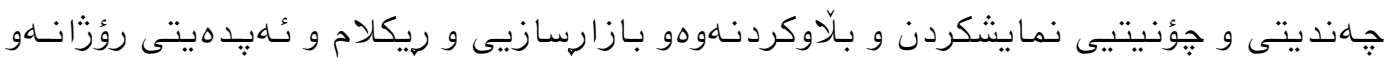

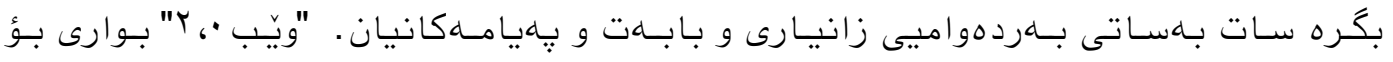

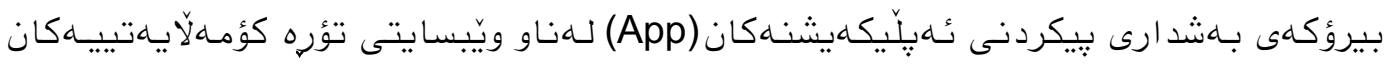

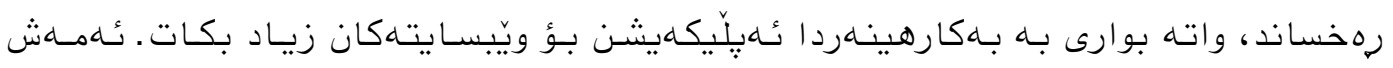

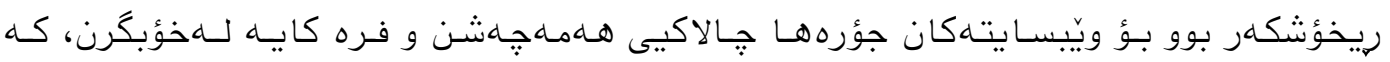

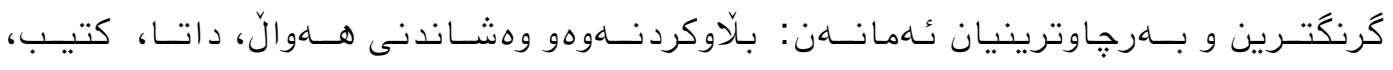

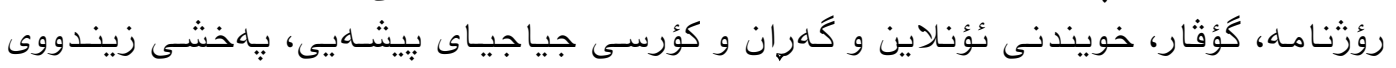

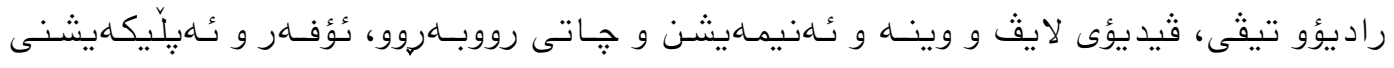

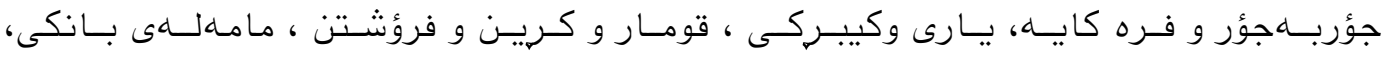

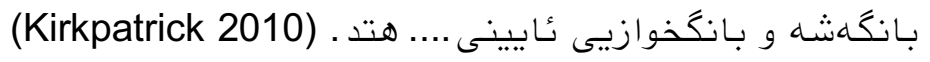

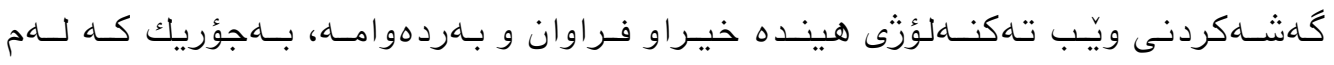

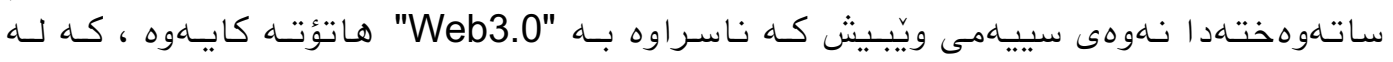

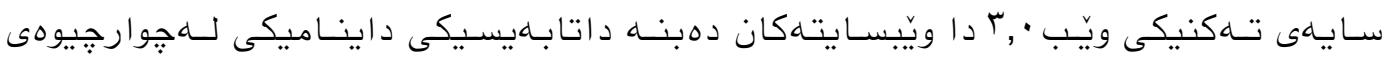

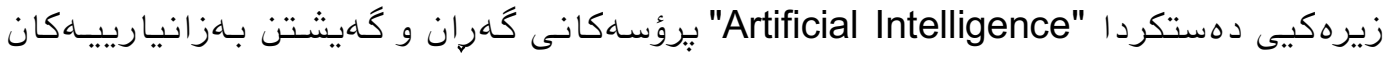

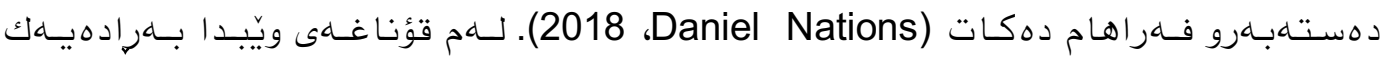

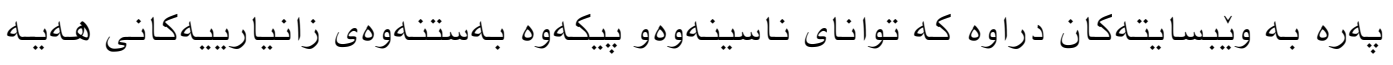

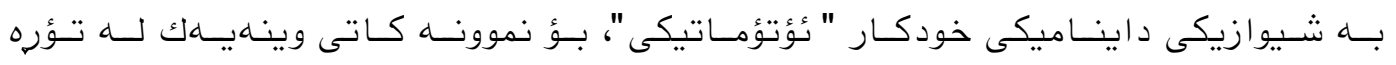

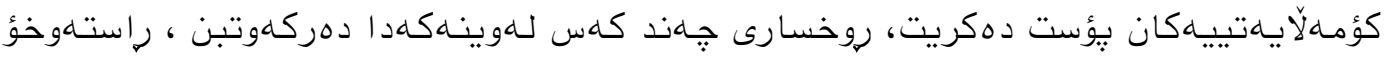

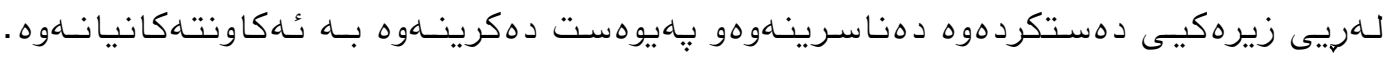

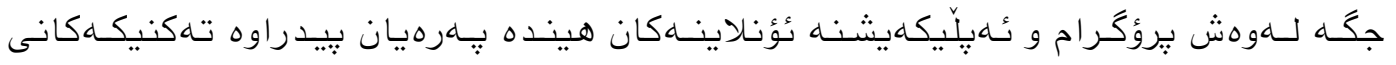

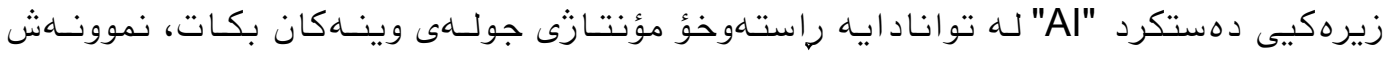

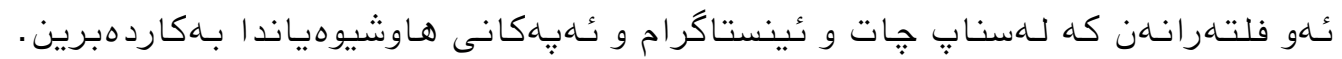

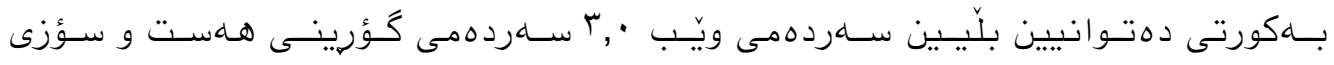

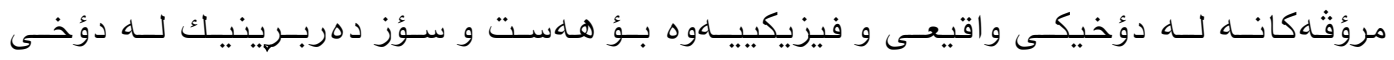




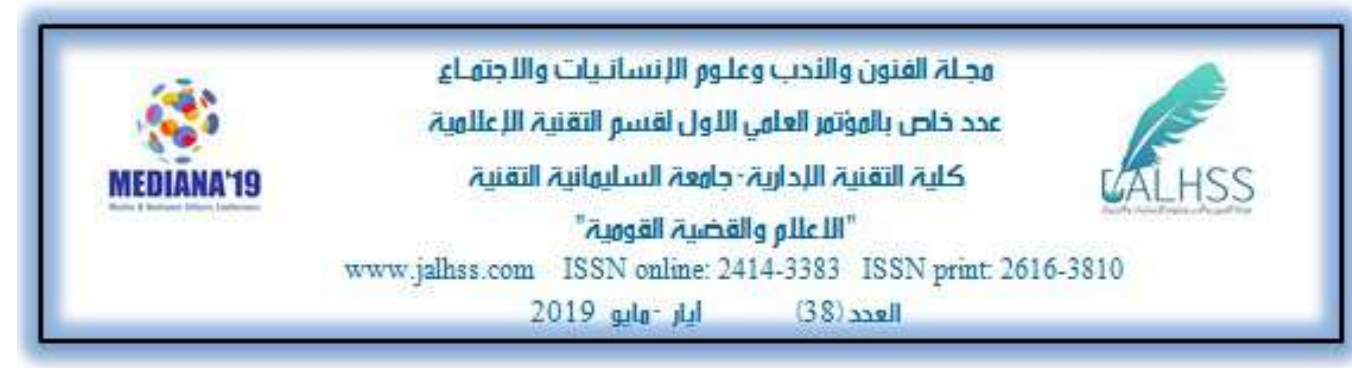

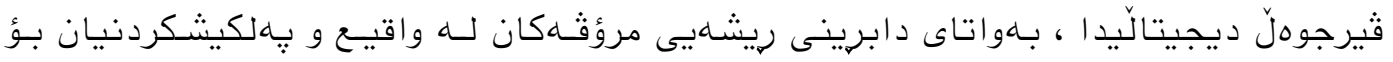

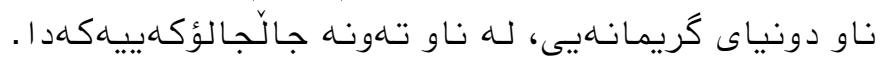

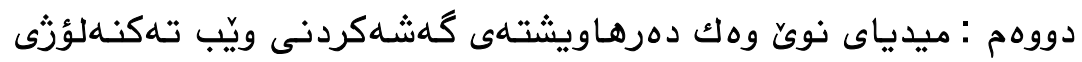

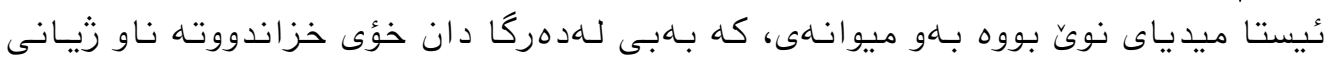

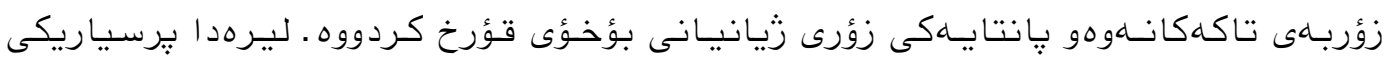

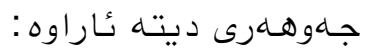

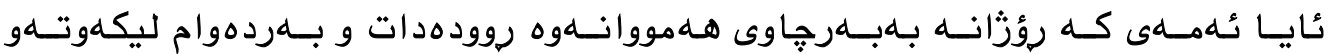

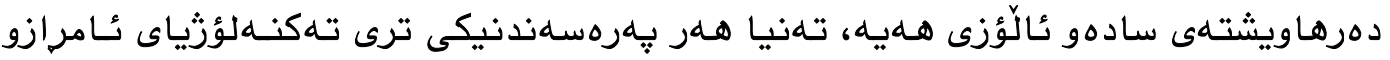

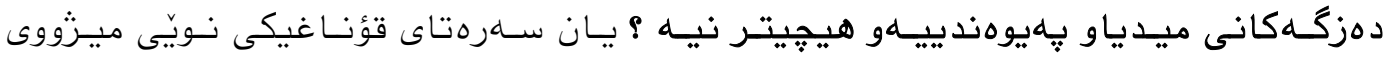

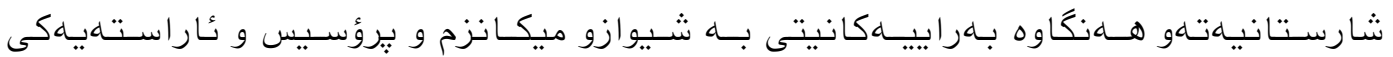

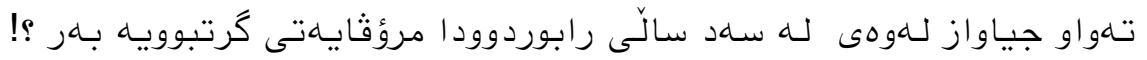

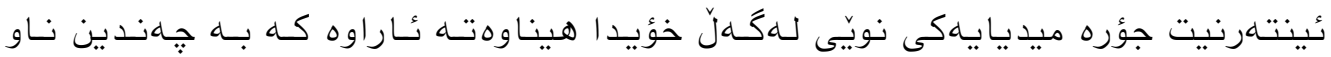

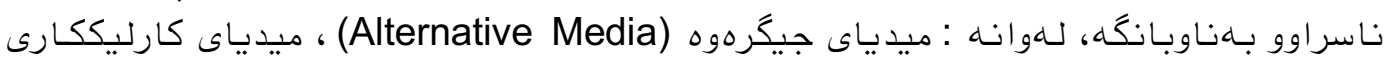
(Interactive Media)

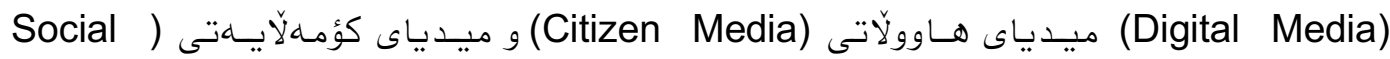
(Media

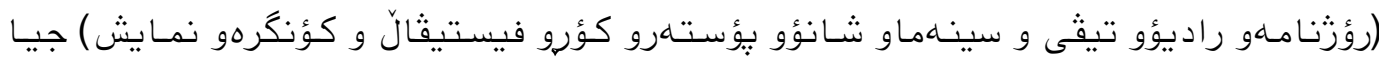

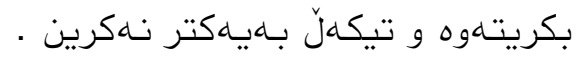

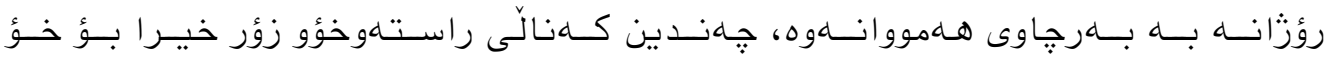

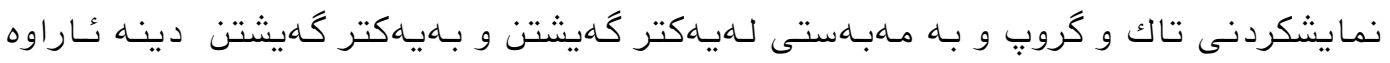

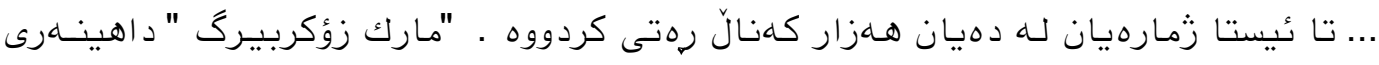

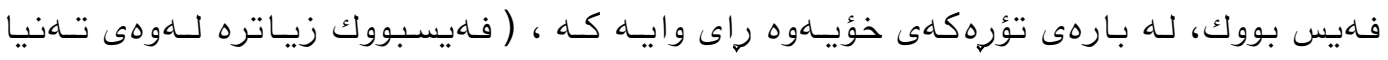

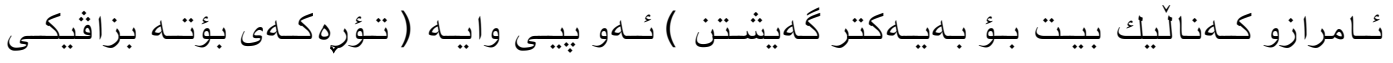

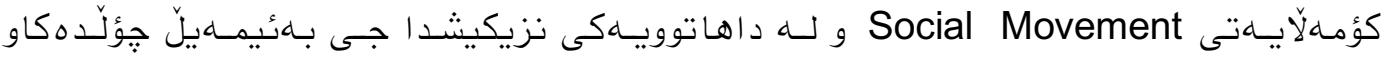

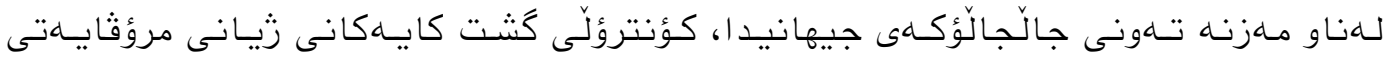

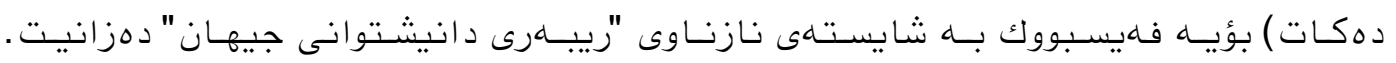

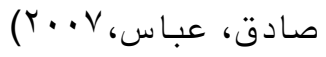

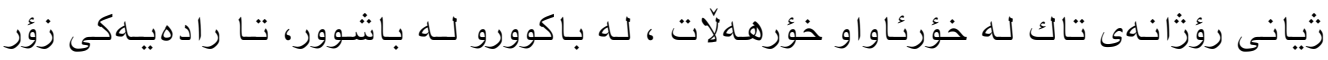

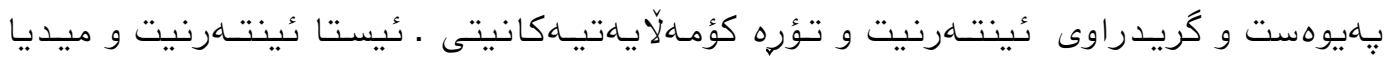

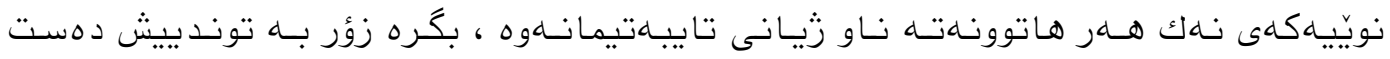




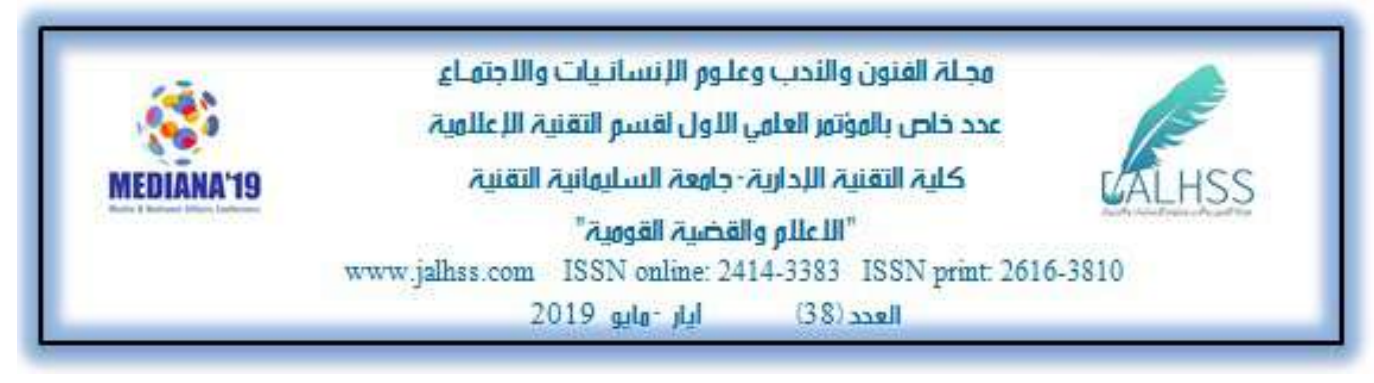

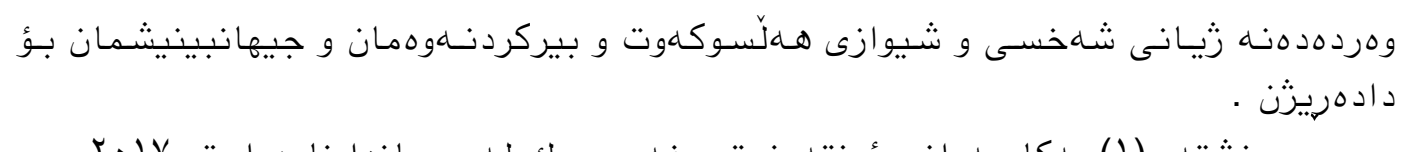

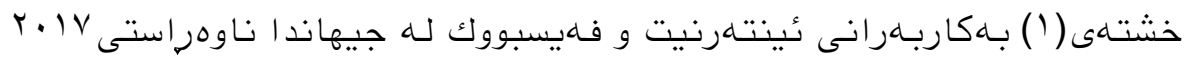

\section{Facebook, Internet and World Population Comparison - June 30, 2017}

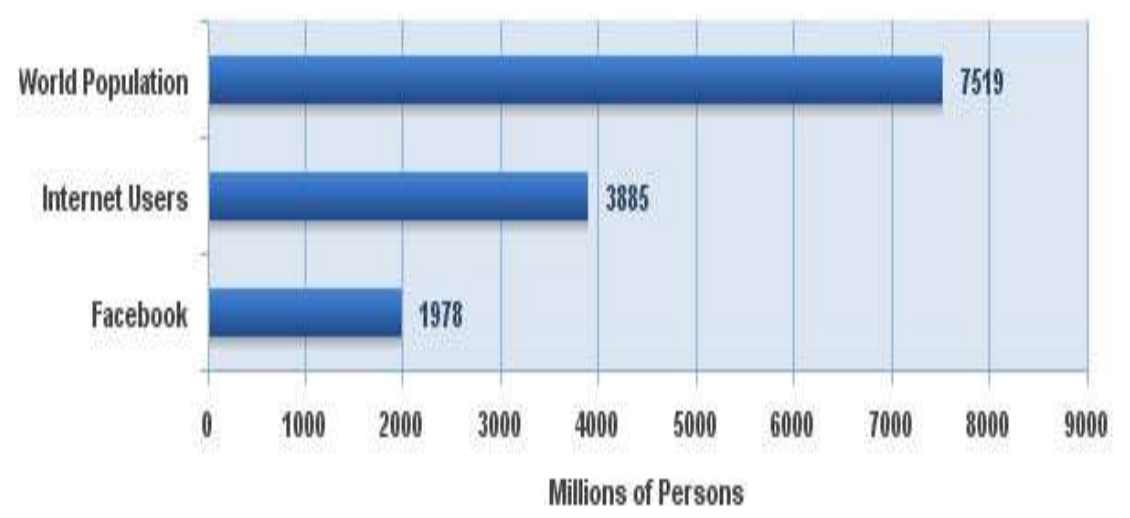

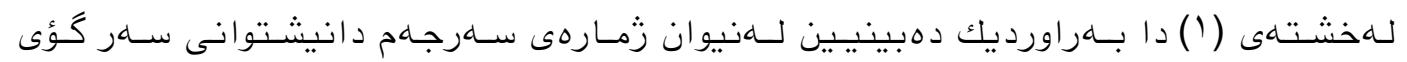

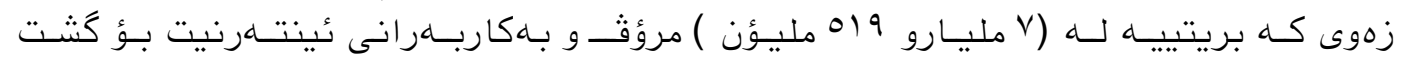

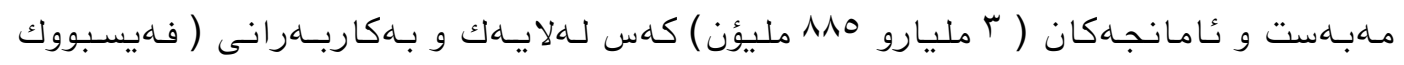

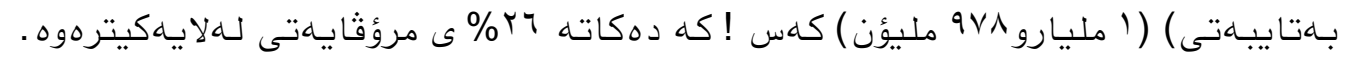

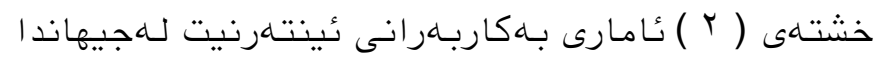




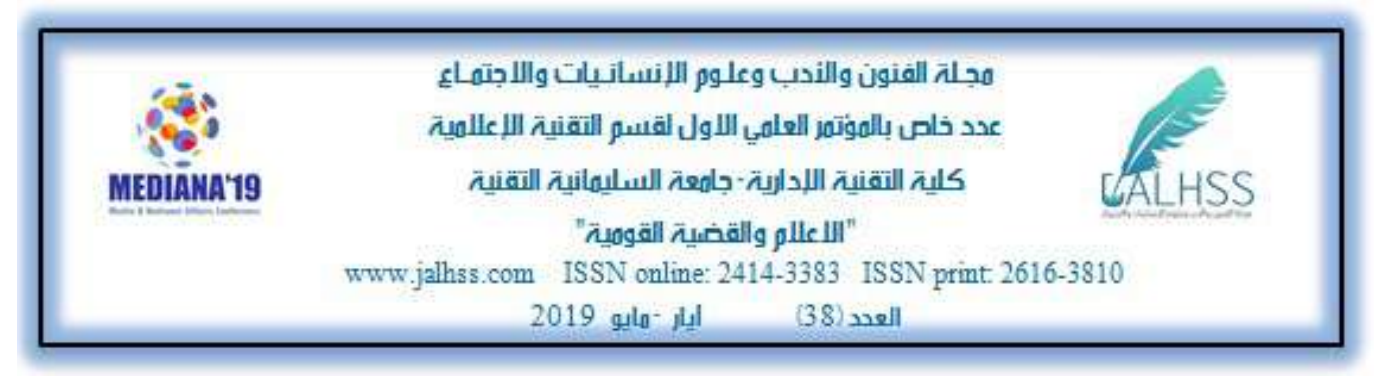

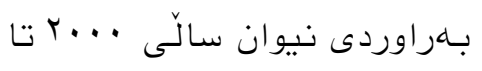

$$
\begin{aligned}
& \text { r.11 }
\end{aligned}
$$

\begin{tabular}{|c|c|c|c|c|c|c|}
\hline \multicolumn{7}{|c|}{ WORLD INIERNET USAGE AND POPULATION STATISTCS } \\
\hline World Regions & $\begin{array}{l}\text { Population } \\
\text { (2011 Est.) }\end{array}$ & \begin{tabular}{|c|} 
Internet Users \\
Dec.31, 2000 \\
\end{tabular} & $\begin{array}{l}\text { Intemet Usais } \\
\text { Mat.31,2011 }\end{array}$ & $\begin{array}{c}\text { Penetration } \\
\text { (5. Population) }\end{array}$ & $\begin{array}{c}\text { Growth } \\
20002011\end{array}$ & $\begin{array}{l}\text { Users } \\
\text { of Table }\end{array}$ \\
\hline Alrica & $1,037,524,050$ & $4,514,400$ & 118.609 .620 & $11.4 \%$ & $2527.4 \%$ & $5.7 \%$ \\
\hline Asia & $3,879,740,877$ & $114,304,000$ & 922.329 .554 & $23.8 \%$ & $7069 \%$ & $440 \%$ \\
\hline Emope & $816,426,346$ & $105,056,099$ & $476,213,935$ & 5838 & $353.1 \%$ & $22.7 \%$ \\
\hline Middle Eas & $216,258,843$ & $3,284,800$ & $68.553,666$ & $31.7 \%$ & $1987.0 \%$ & $33 \%$ \\
\hline Henth America & $347,394,870$ & 108.096 .800 & $272,066,000$ & $783 \%$ & $151.7 \%$ & $130 \%$ \\
\hline Latin America Carib. & $597,263,165$ & $18,068,919$ & $215,939,400$ & $32 \%$ & $1,037.4 \%$ & $103 \%$ \\
\hline Qseania / Anstralia & $35,426,995$ & $7,620,480$ & 21.293 .830 & 6018 & $179.4 \%$ & $10 \%$ \\
\hline WORLD TOTAL & $6,960,065,154$ & $360,965,492$ & 2.095 .006 .005 & $30.2 \%$ & $400.4 \times 6$ & $100.0 \%$ \\
\hline
\end{tabular}

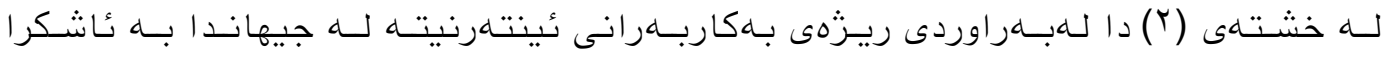

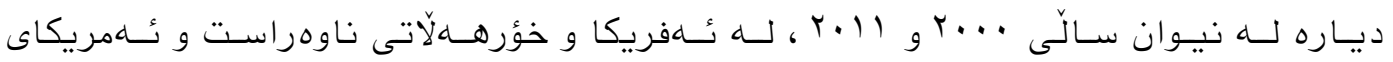

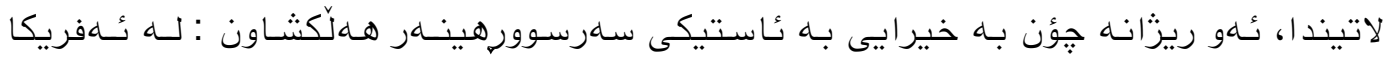

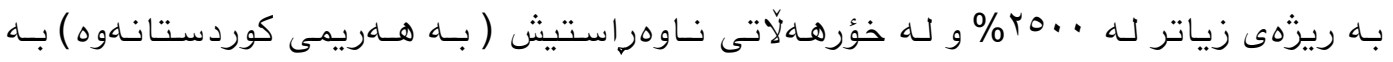

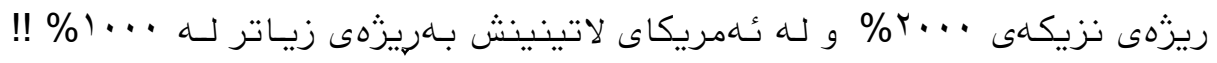

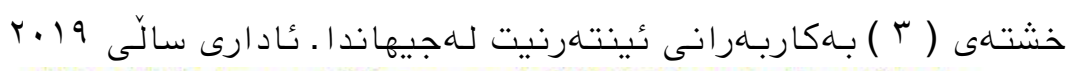

\section{World Internet Users and 2019 Population Stats}

\begin{tabular}{|c|c|c|c|c|c|c|}
\hline \multicolumn{7}{|c|}{$\begin{array}{l}\text { WORLD INTERNET USAGE AND POPULATION STATISTICS } \\
\text { MARCH, } 2019 \text { - New Update }\end{array}$} \\
\hline World Regions & $\begin{array}{l}\text { Population } \\
\text { (2019 Est.) }\end{array}$ & $\begin{array}{l}\text { Population } \\
\% \text { of World }\end{array}$ & $\begin{array}{c}\text { Internet Users } \\
25 \text { Mar } 2019\end{array}$ & $\begin{array}{c}\text { Penetration } \\
\text { Rate (\% Pop.) }\end{array}$ & $\begin{array}{c}\text { Growth } \\
2000-2019\end{array}$ & $\begin{array}{l}\text { Internet } \\
\text { Users \% }\end{array}$ \\
\hline Africa & $1,320,038,716$ & $17.0 \%$ & $474,120,563$ & $35.9 \%$ & $10,402 \%$ & $10.9 \%$ \\
\hline Asia & $4,241,972,790$ & $54.7 \%$ & $2,190,981,318$ & $51.7 \%$ & $1,817 \%$ & $50.4 \%$ \\
\hline Europe & $866,433,007$ & $11.2 \%$ & $718,172,106$ & $82.9 \%$ & $583 \%$ & $16.5 \%$ \\
\hline Latin America / Caribbean & $658,345,826$ & $8.5 \%$ & $438,248,446$ & $66.6 \%$ & $2,325 \%$ & $10.1 \%$ \\
\hline Middle East & $258,356,867$ & $3.3 \%$ & $170,039,990$ & $65.8 \%$ & $5,076 \%$ & $3.9 \%$ \\
\hline North America & $366,496,802$ & $4.7 \%$ & $326,561,853$ & $89.1 \%$ & $202 \%$ & $7.5 \%$ \\
\hline Oceania / Australia & $41,839,201$ & $0.5 \%$ & $28,437,577$ & $68.0 \%$ & $273 \%$ & $0.7 \%$ \\
\hline WORLD TOTAL & $7,753,483,209$ & $100.0 \%$ & $4,346,561,853$ & $56.1 \%$ & $1,104 \%$ & $100.0 \%$ \\
\hline
\end{tabular}

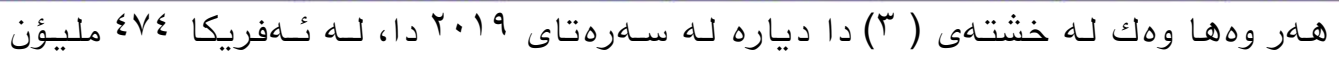

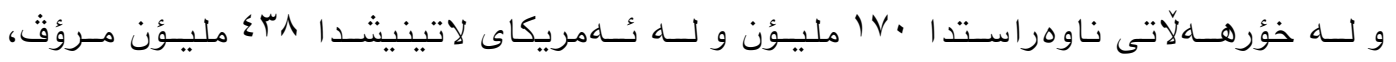




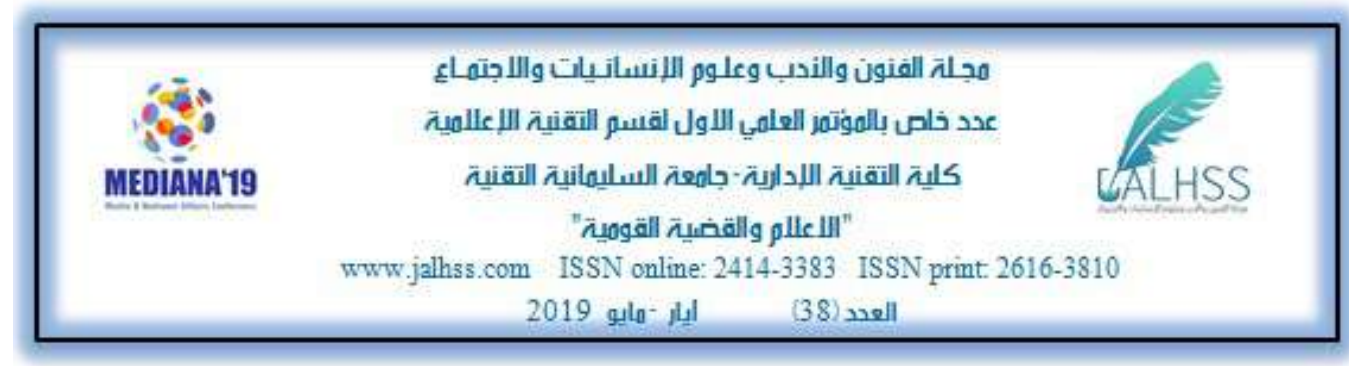

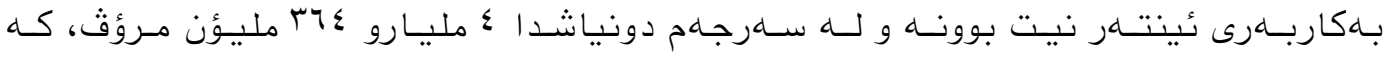

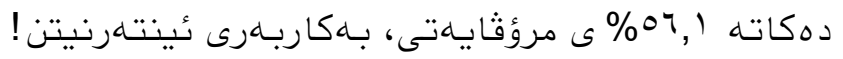

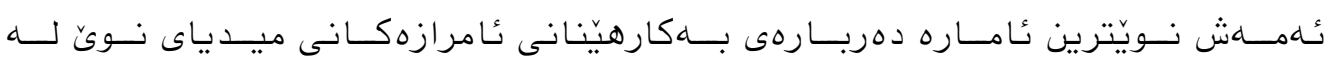

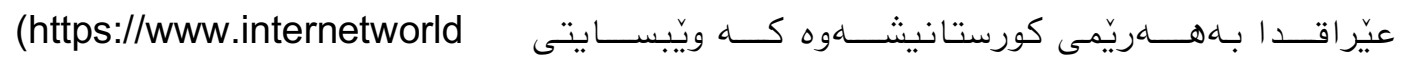

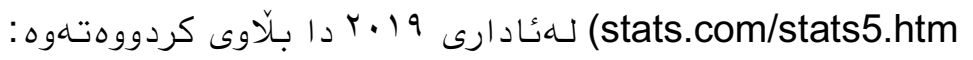

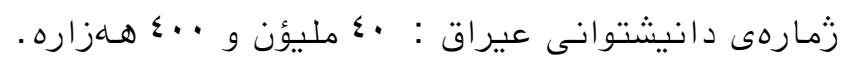

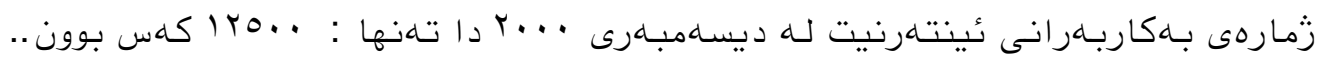

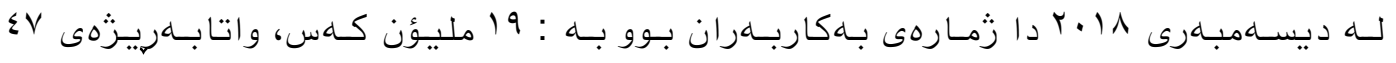
\% مانى دانيشتوان.

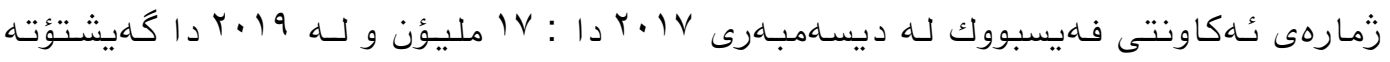

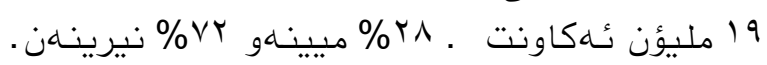

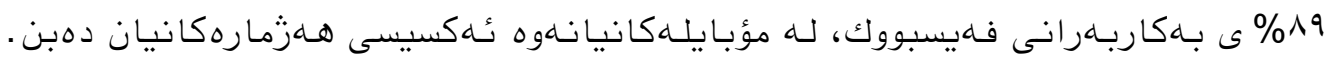

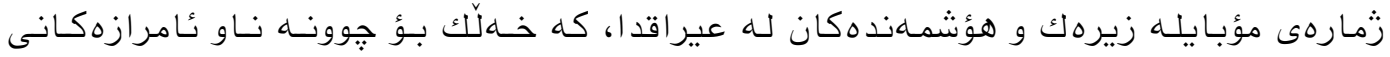

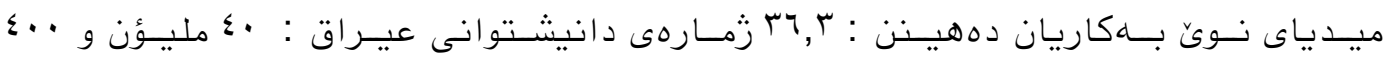
هـ همازماره.

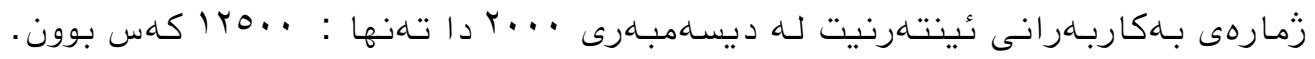

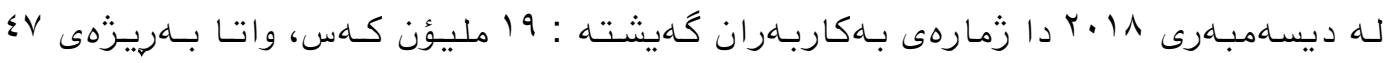
\% مارى دانيشتوان.

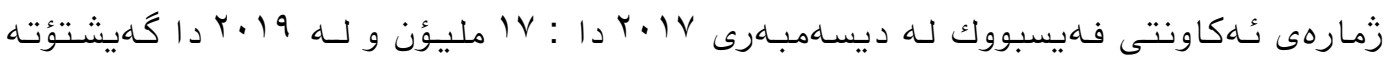

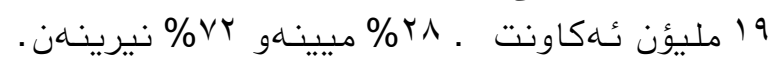

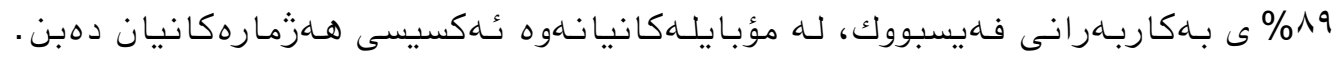

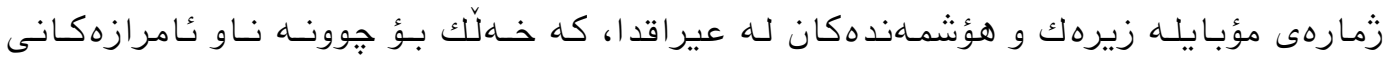

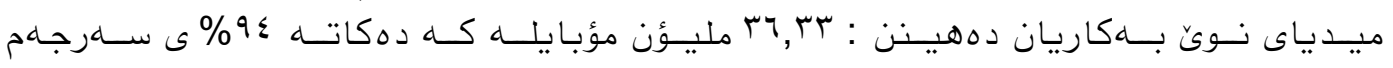

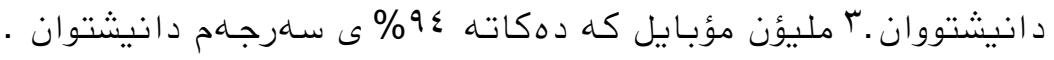

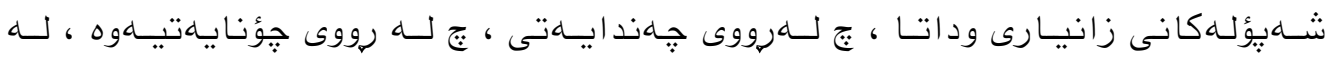

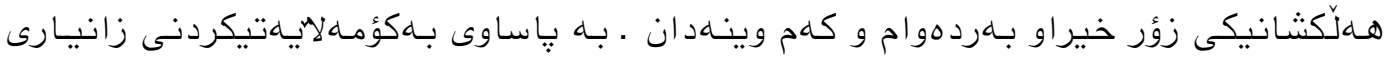

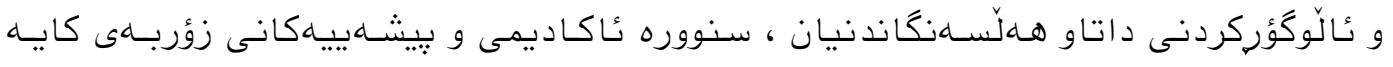

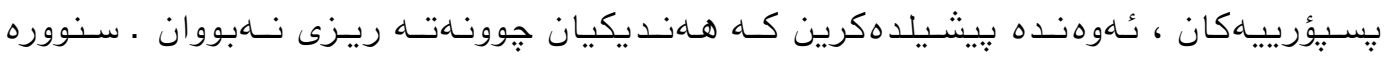

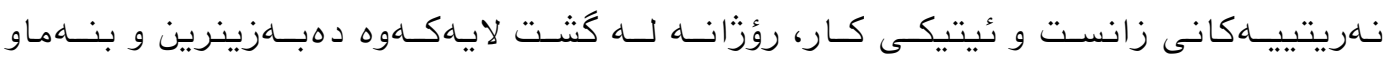

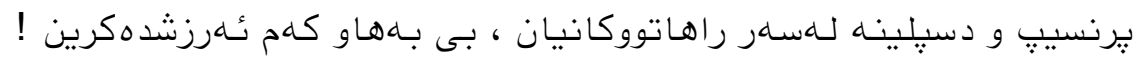




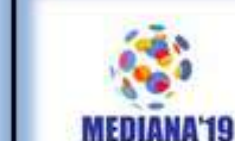

MEDIĀMA'19
مجِ آلفنون والندب وعلوم اللإنسانيات واللاجتهاء

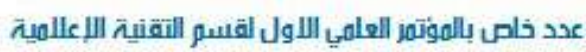

كلية التقنية الليدارية-جامعة السليهانية التقنية

"

www.jalhss.com ISSN online: 2414-3383 ISSN print 2616-3810

2019 العدايد

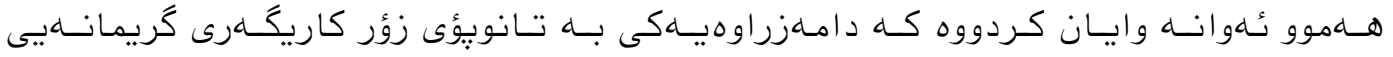

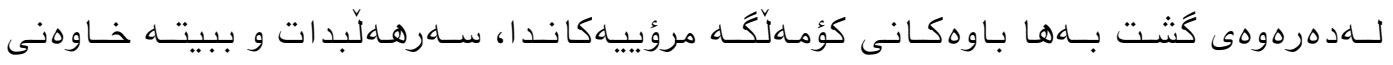

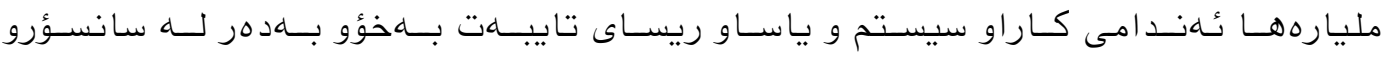

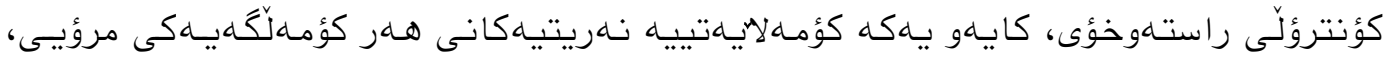

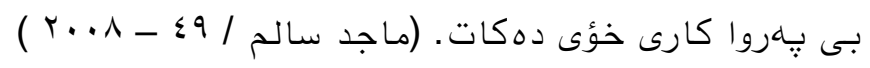

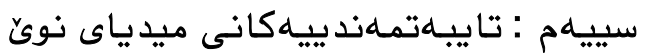

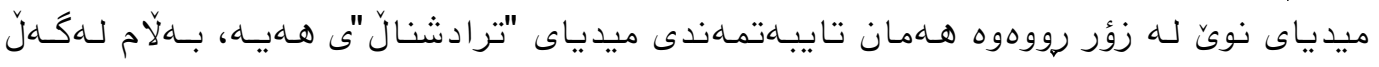

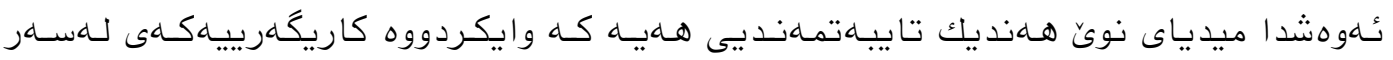

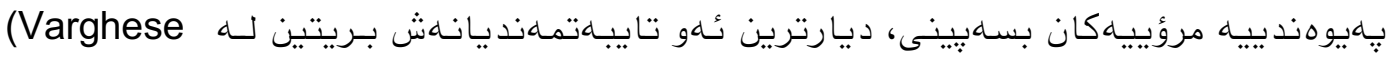

:(P.A. 2016

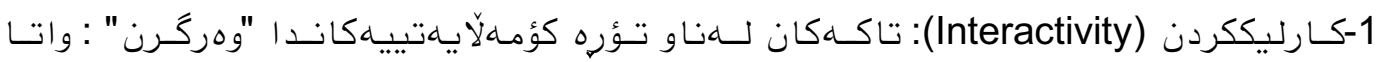

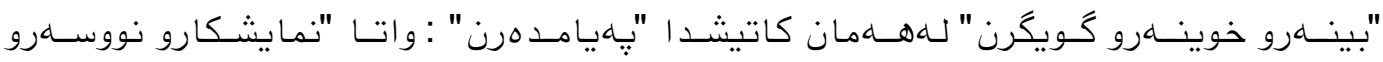

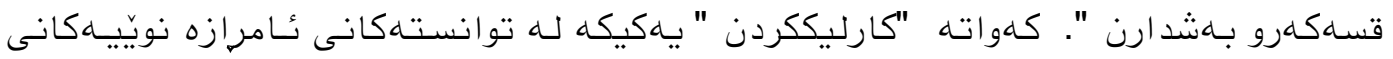

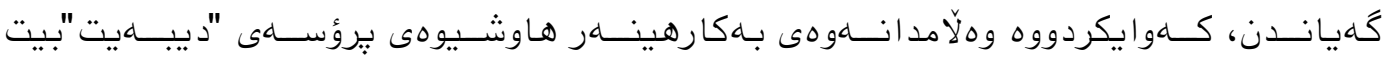

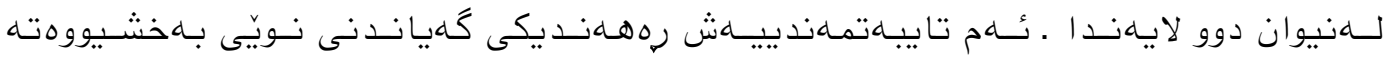

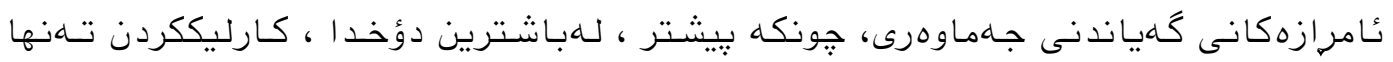

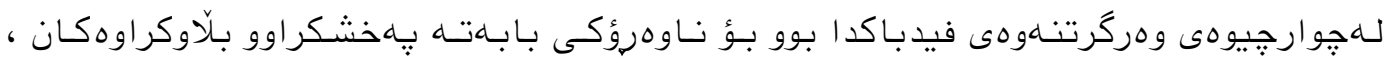

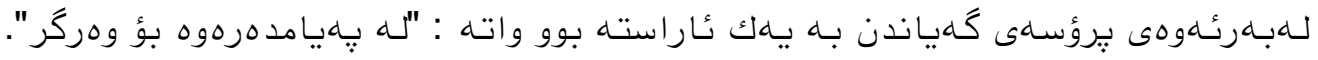

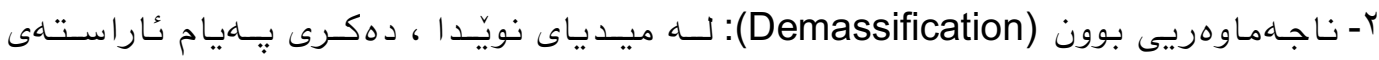

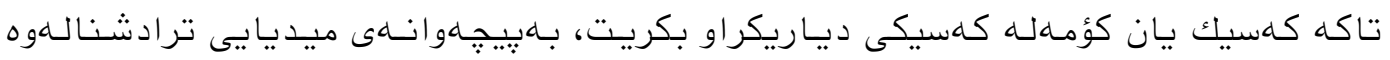

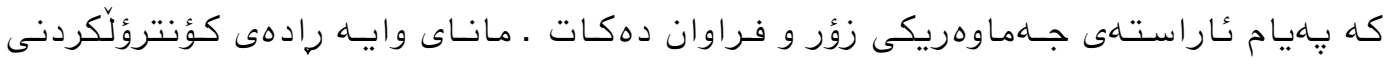

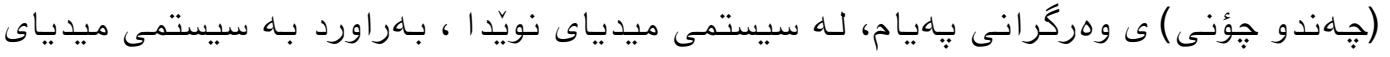

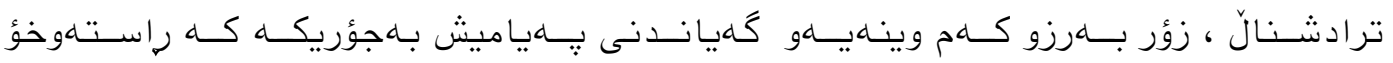

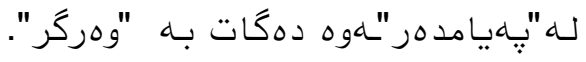

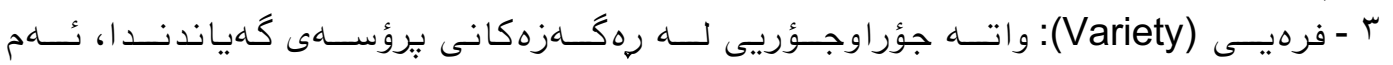

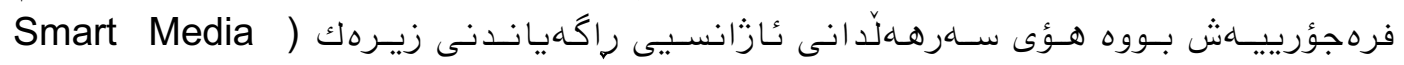

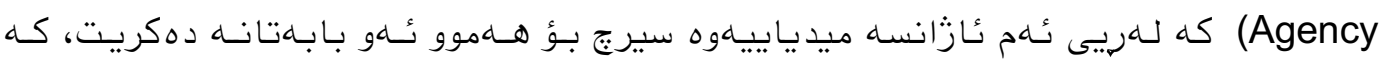

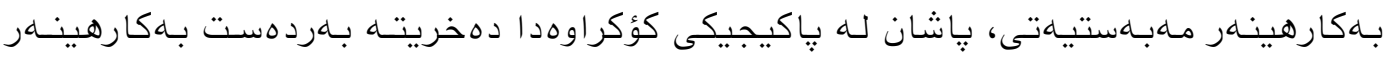

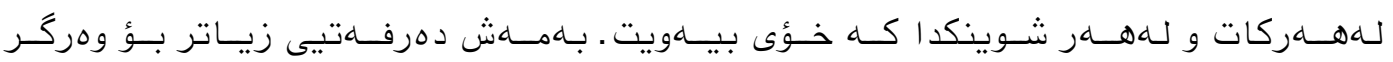




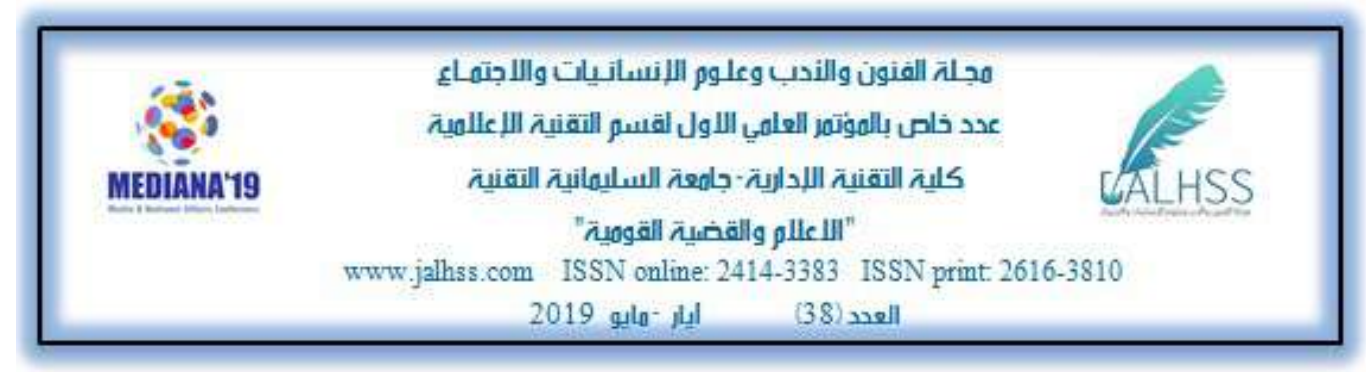

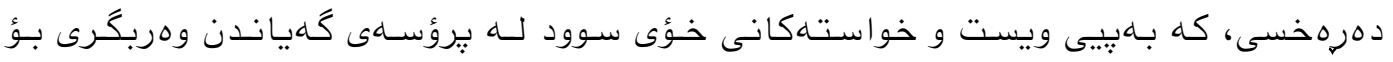

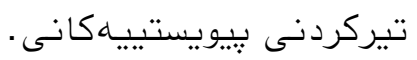

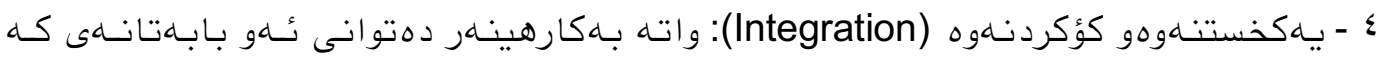

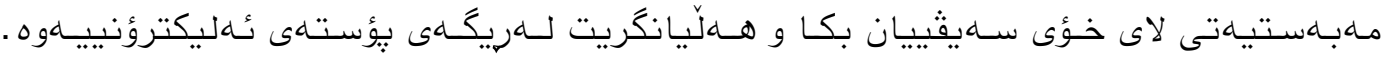

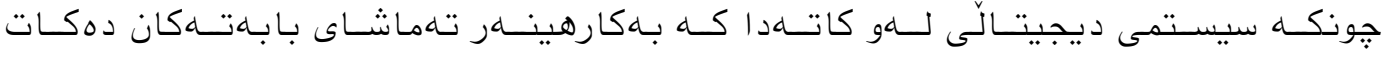

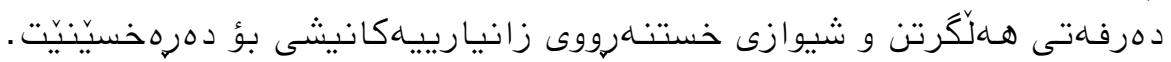

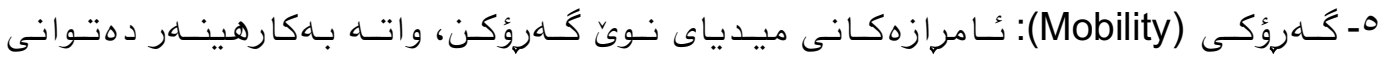

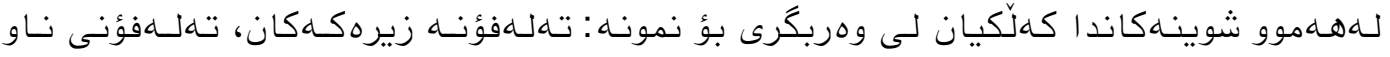

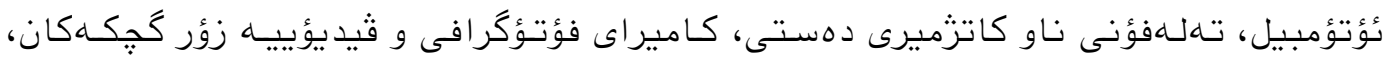

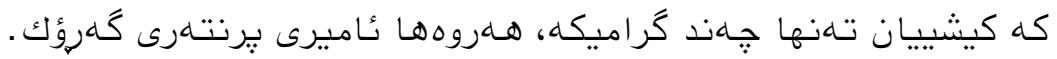

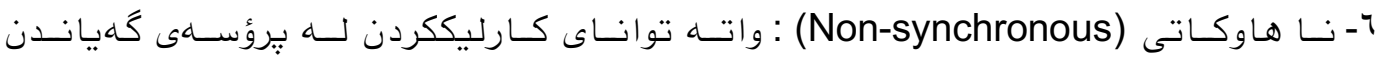

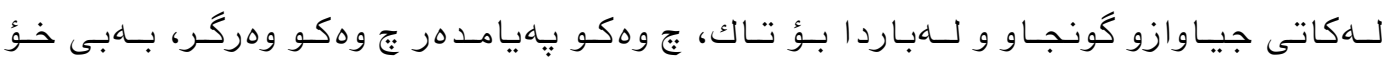

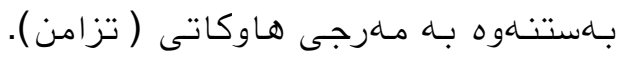

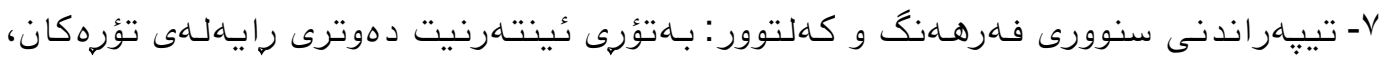

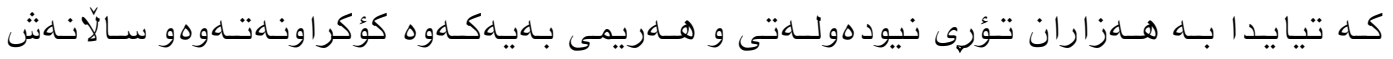

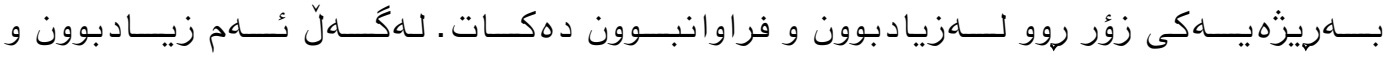

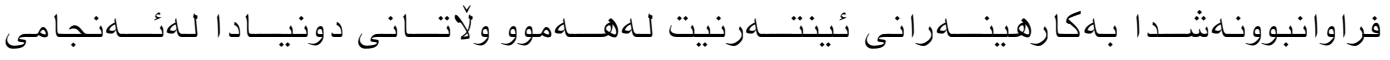

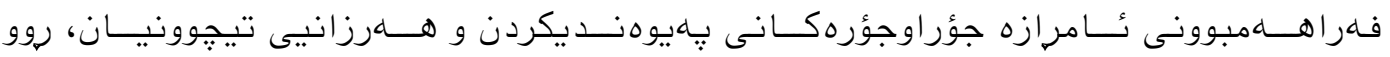

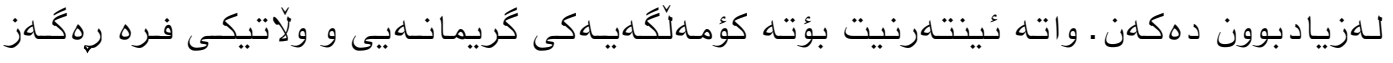

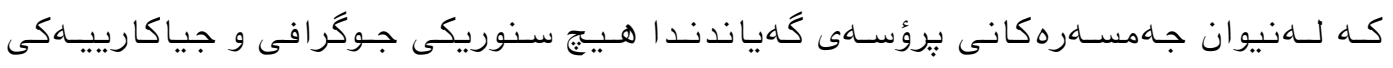

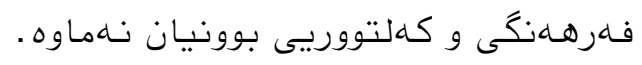

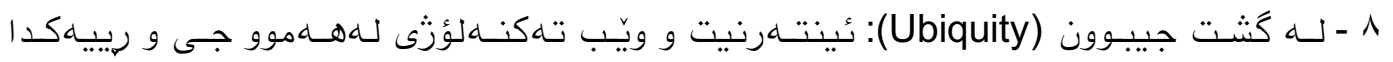

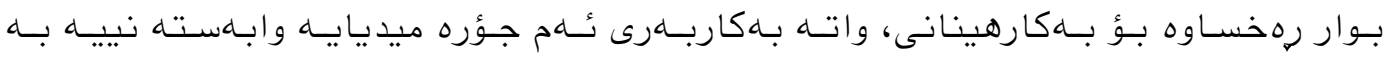

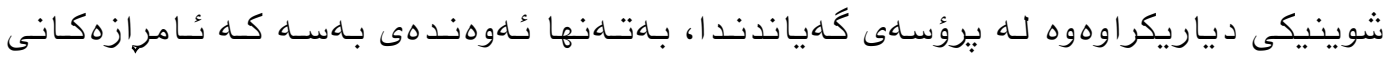

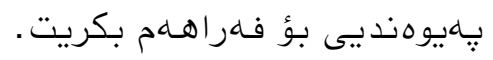

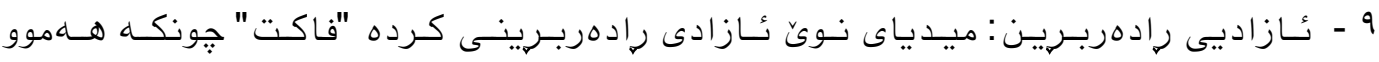

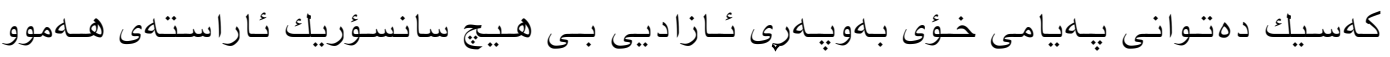

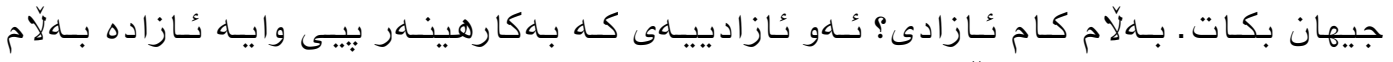

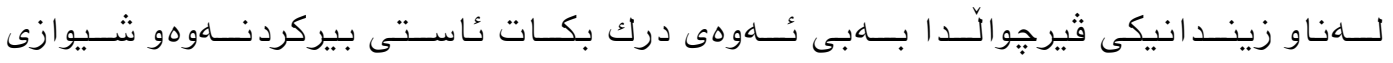

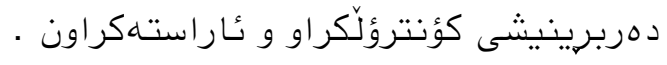




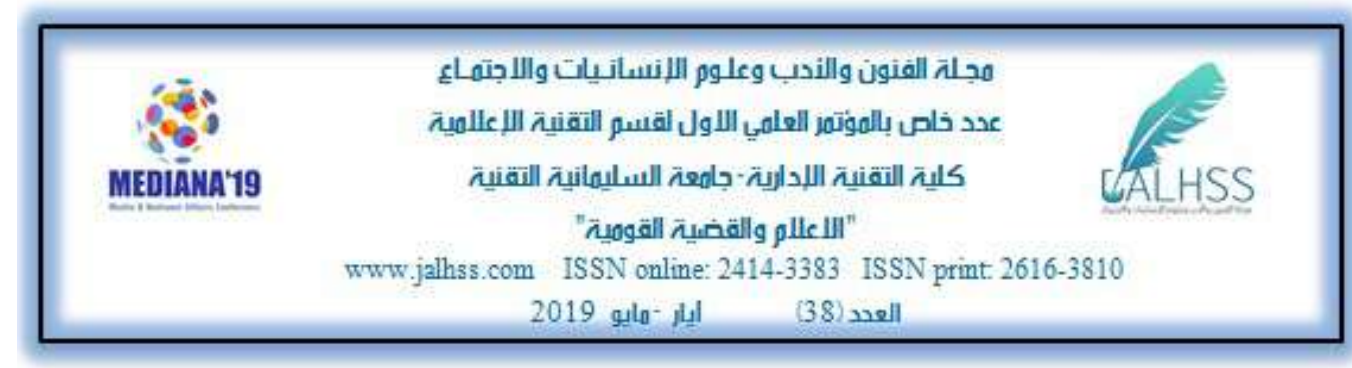

$$
\text { جوارهم : سيما كشتييهذكانى سهردهمى ويّب دوو: }
$$

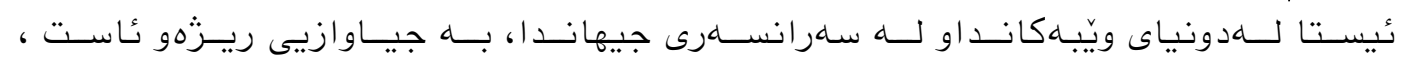

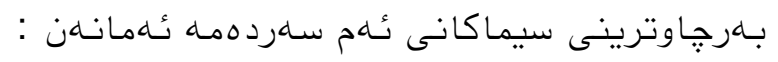

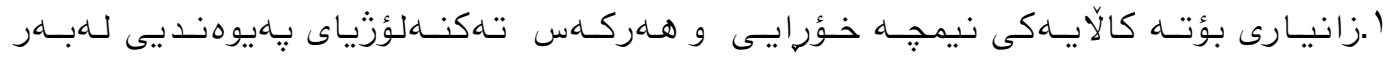

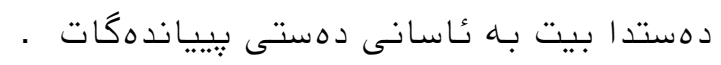

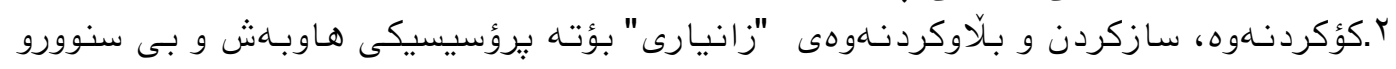
كشتخير

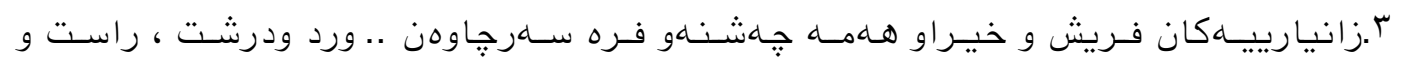

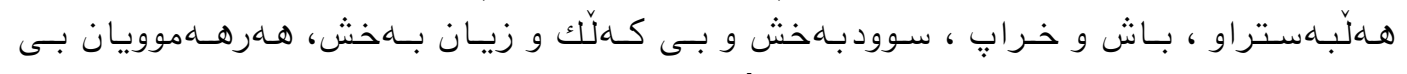

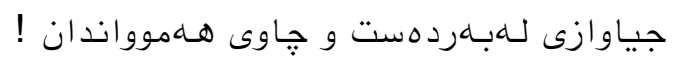

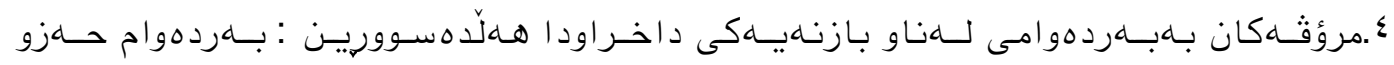

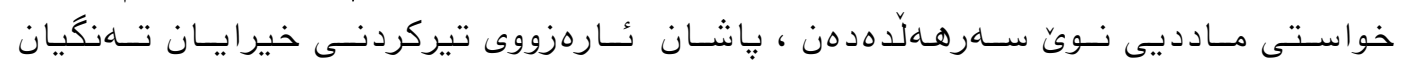

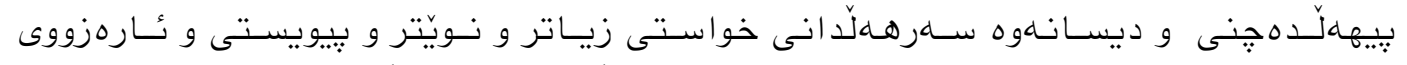

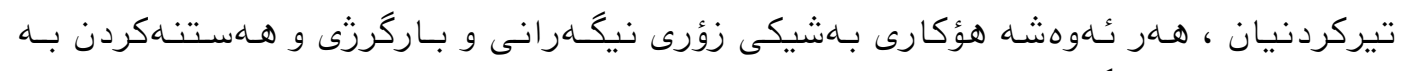

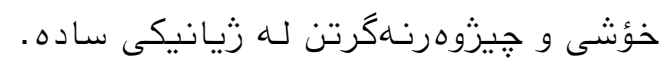

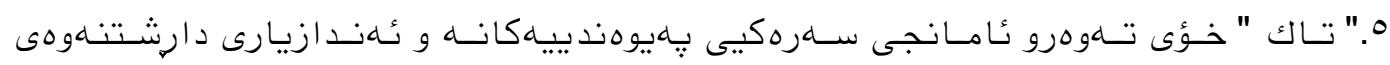

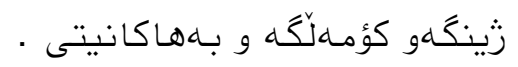

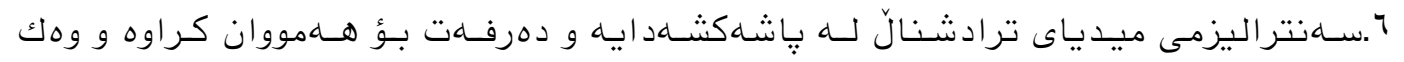

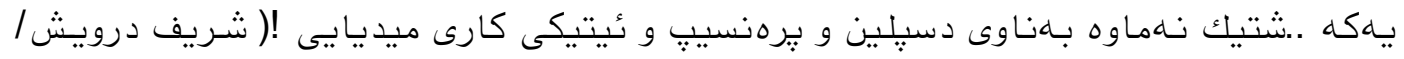
$(r \cdot V / 70$

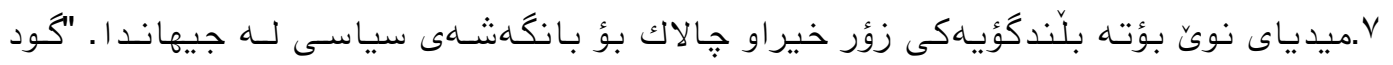

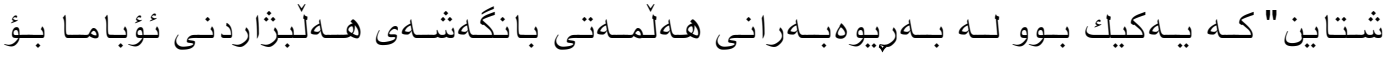

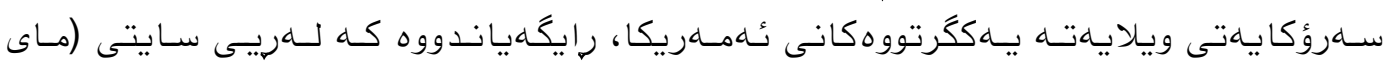

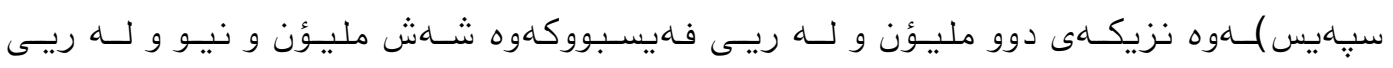

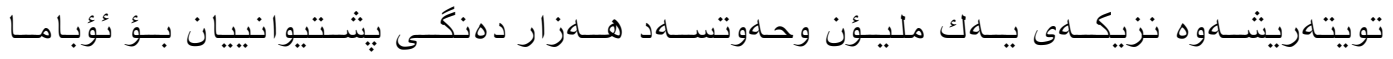

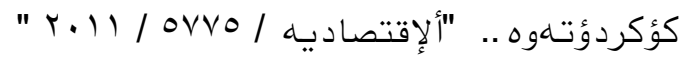




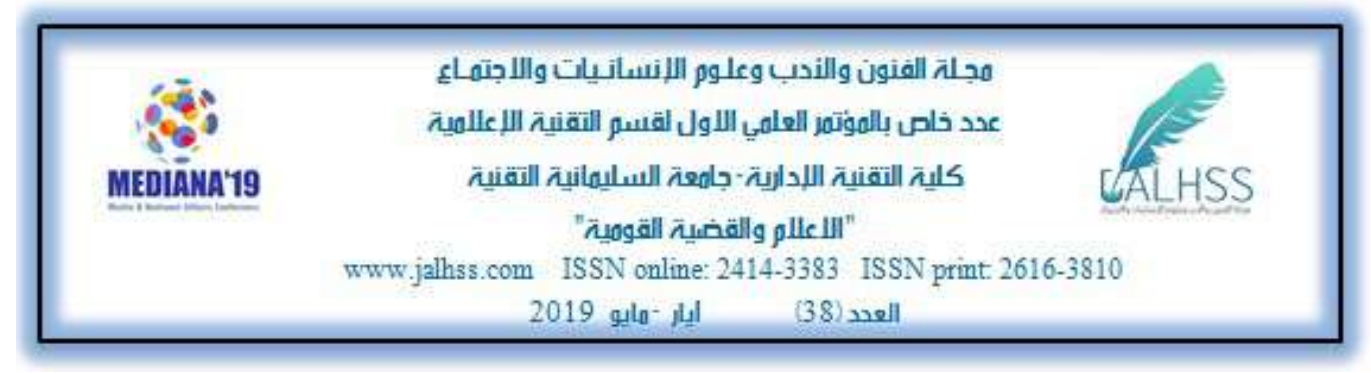

\section{بـهشى سييهم : ميدياى نوى وقهيرانى شوناس}

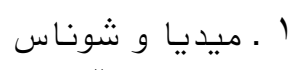

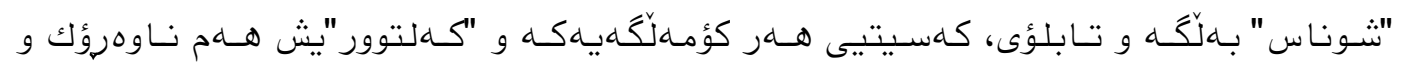

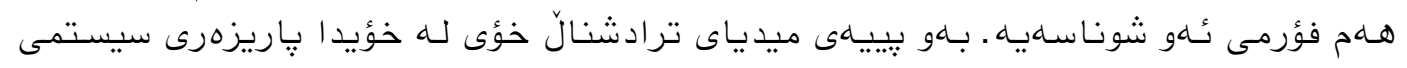

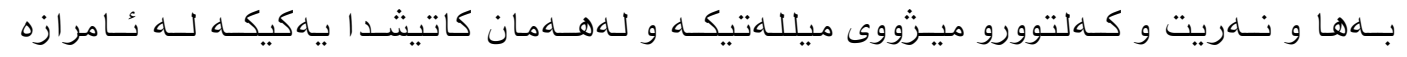

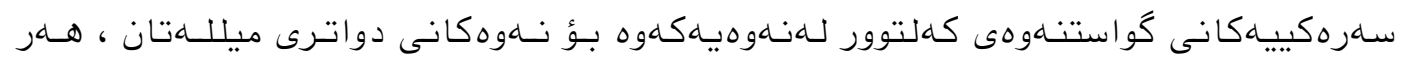

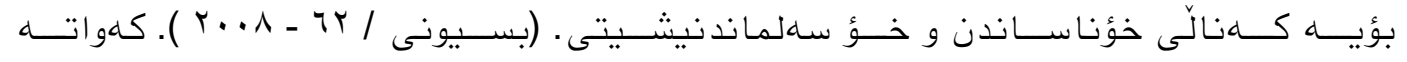

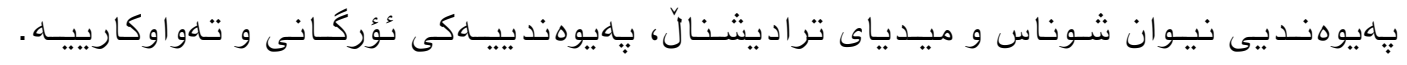

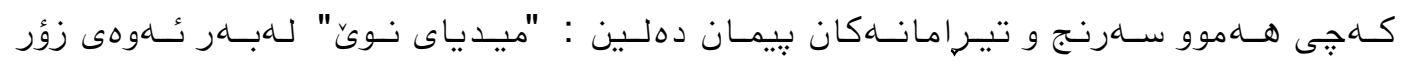

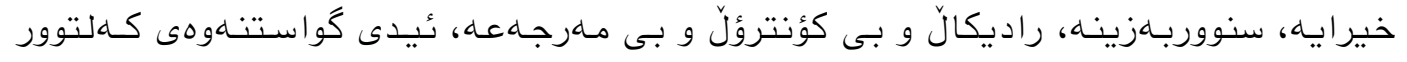

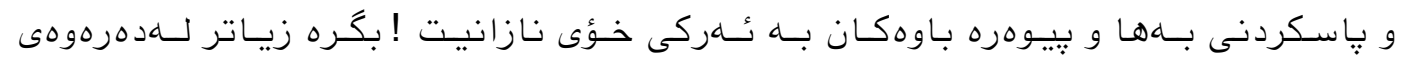

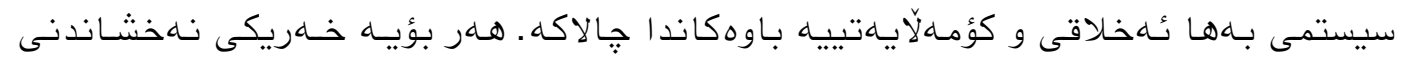

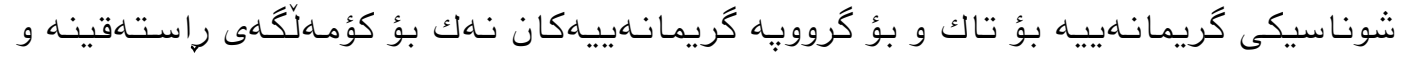

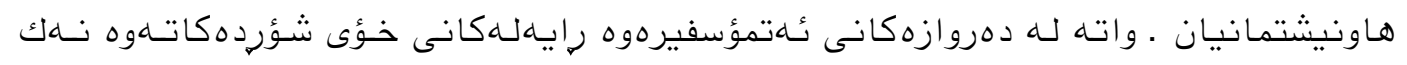

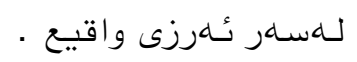

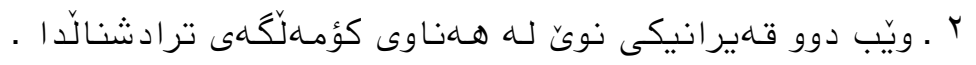

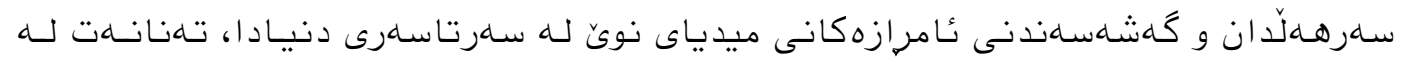

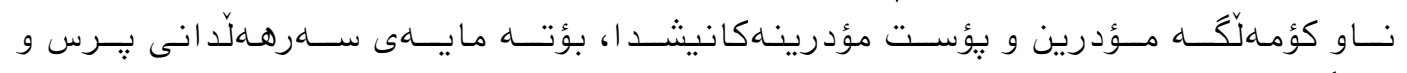

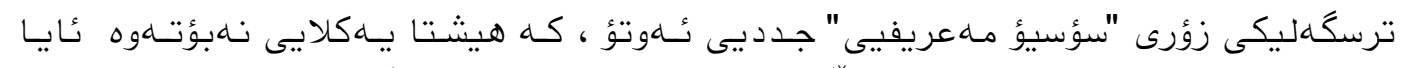

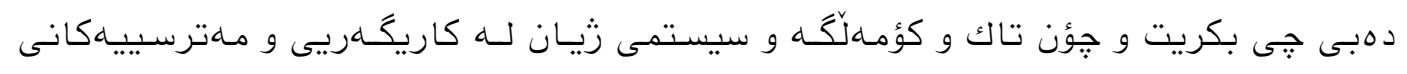

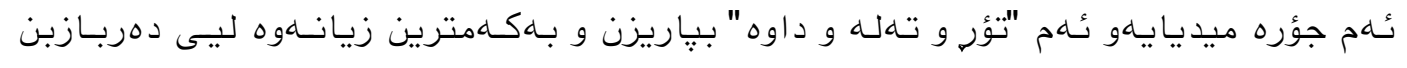
و و باريزراو بن.

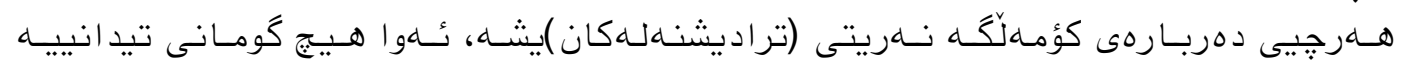

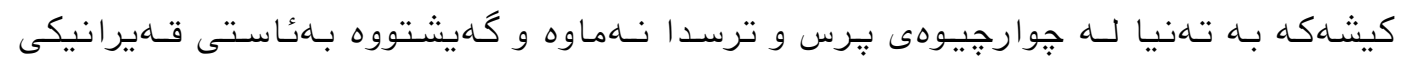

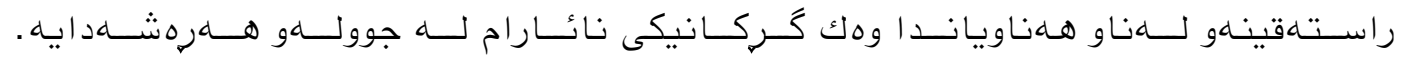

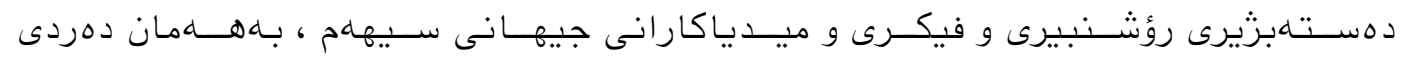

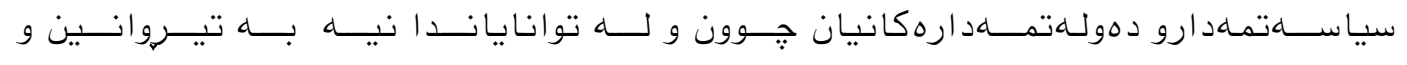

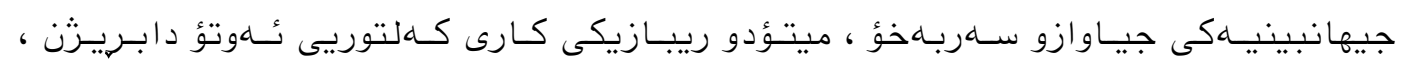

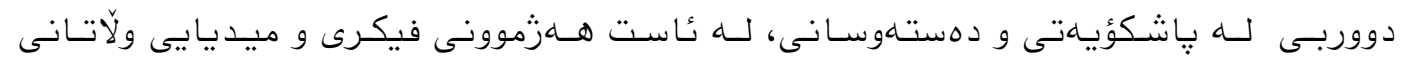




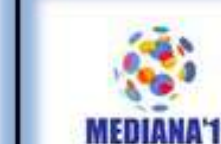

MEDIĀMA'19
محِ آلفنون والندب وعلوم اللإنسانيات واللاجتهاء

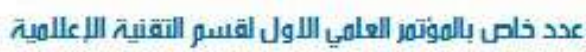

كلية التقنية الليدارية-جامعة السليهانية التقنية

"

www.jalhss.com ISSN online: 2414-3383 ISSN print 2616-3810

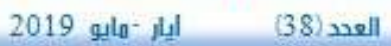

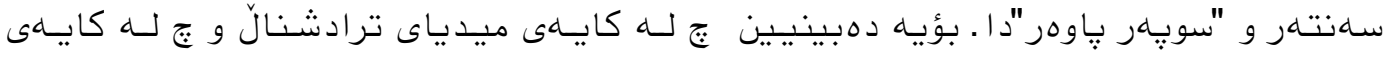

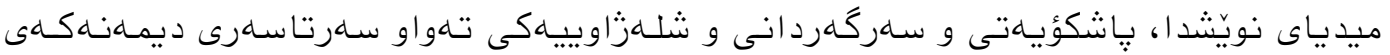
تلهنيوه.

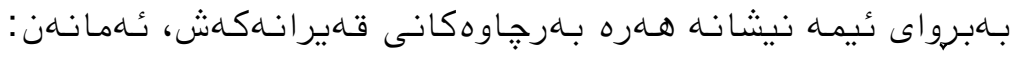

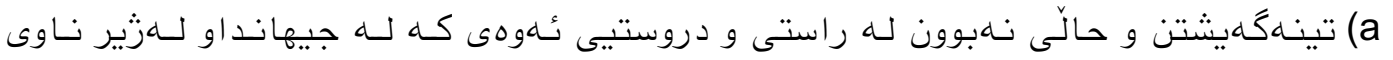

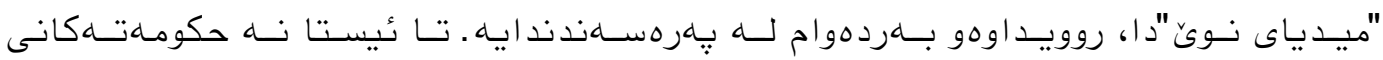

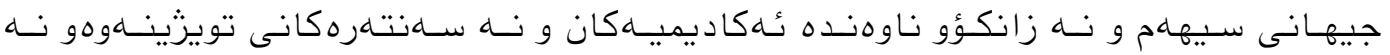

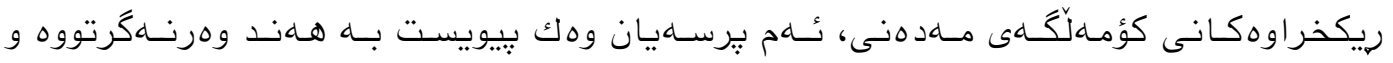

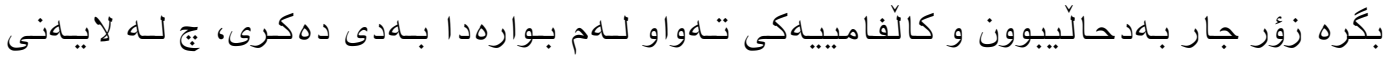

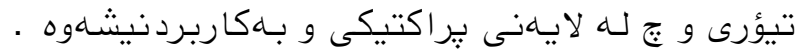

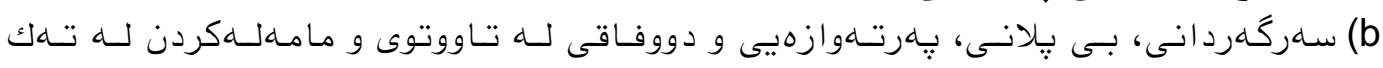

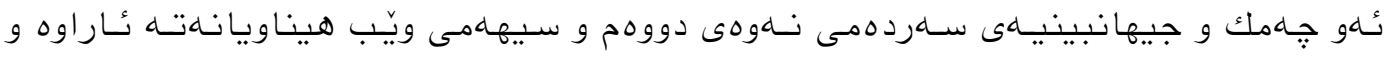

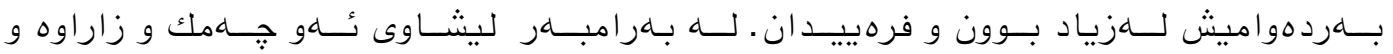

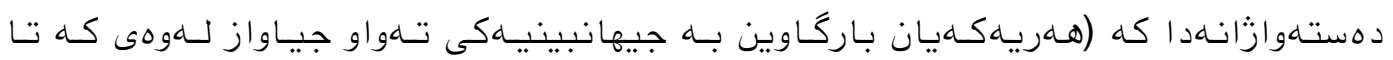

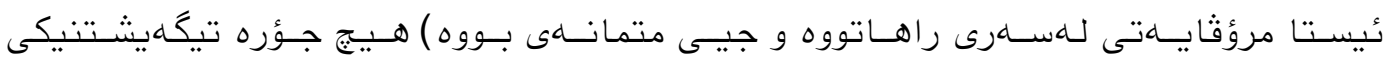

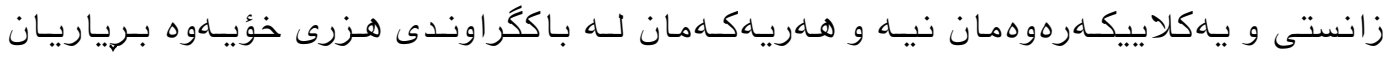

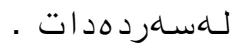

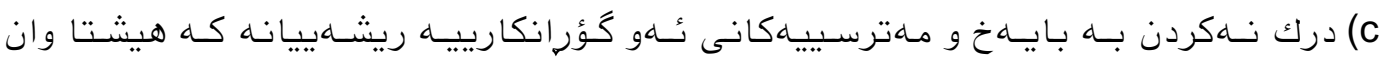

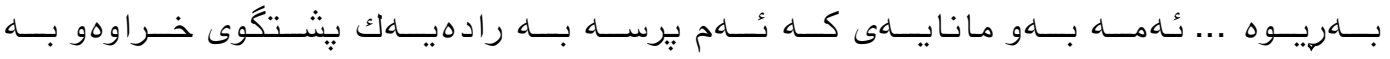

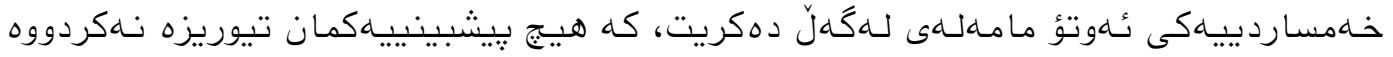

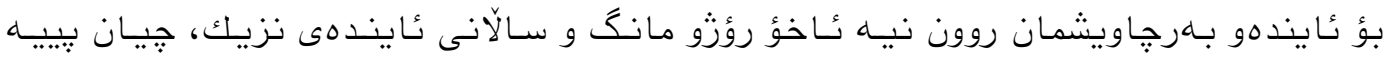

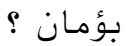

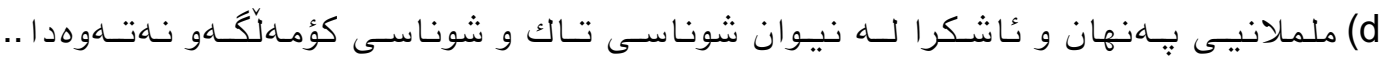

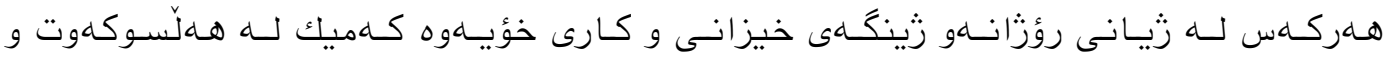

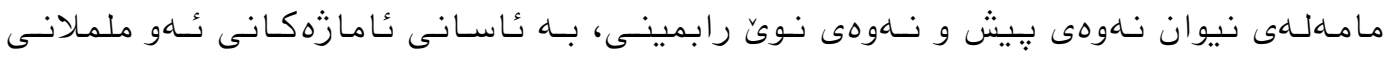

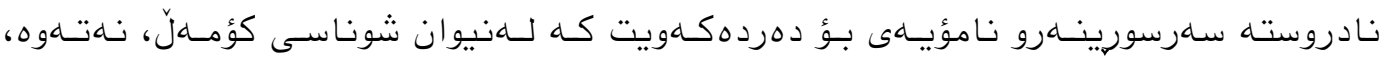

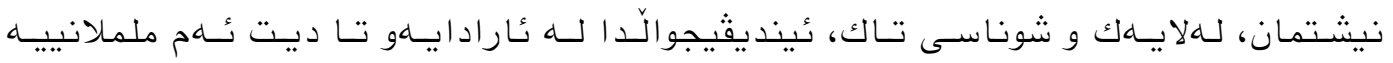

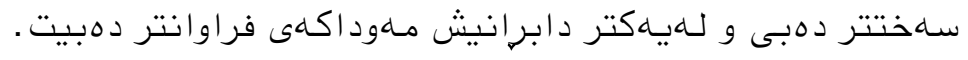




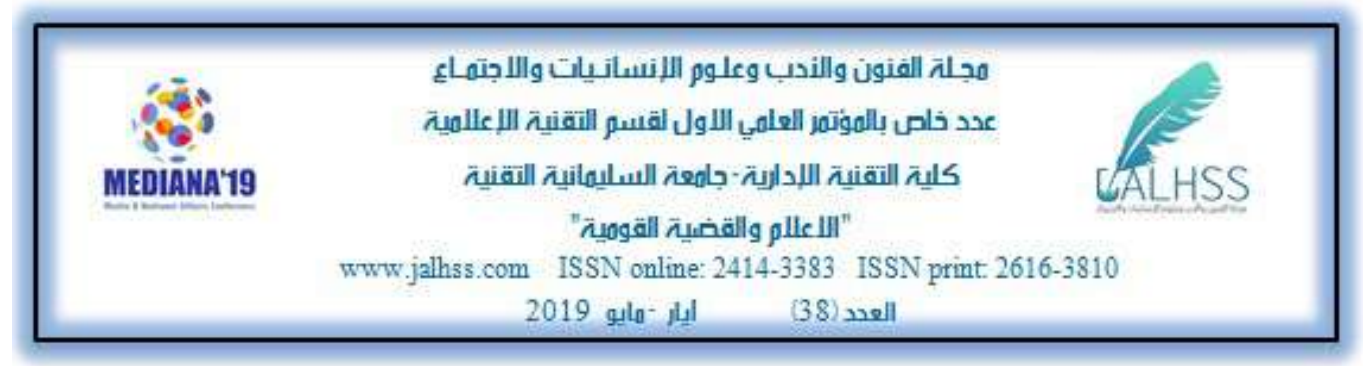

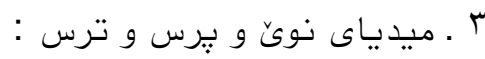

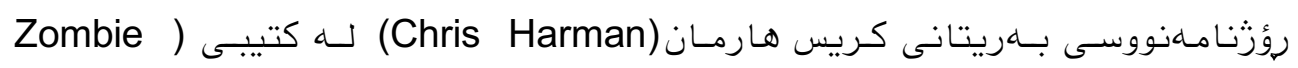

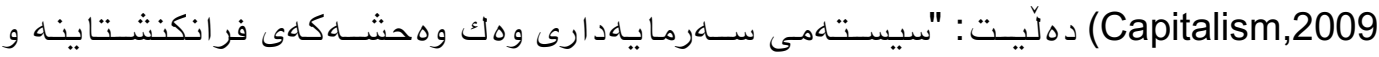

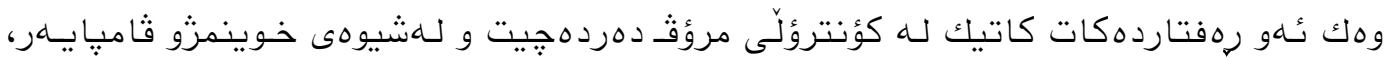

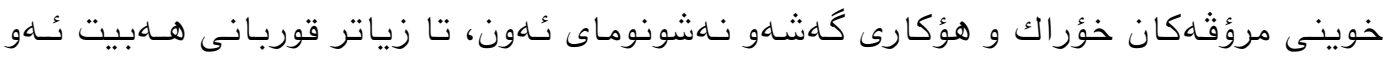

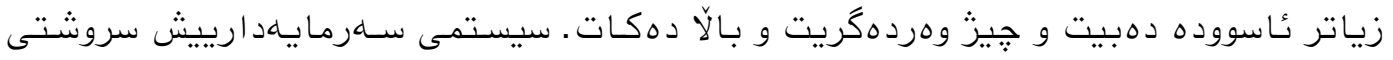

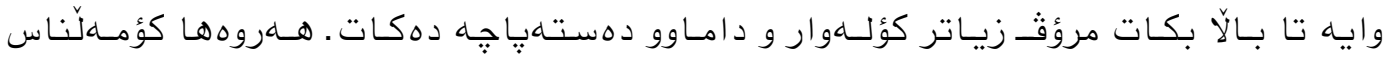

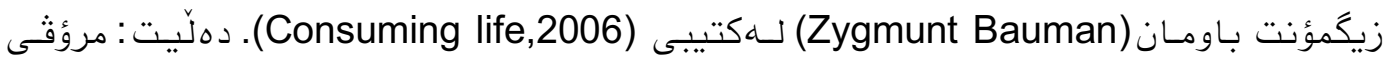

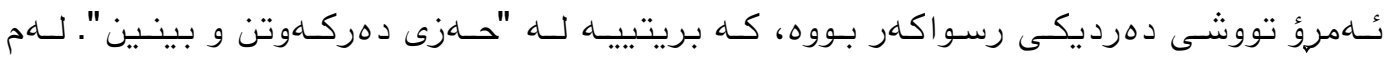

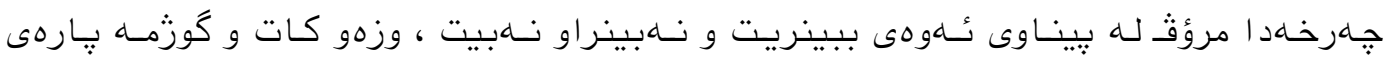

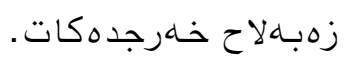

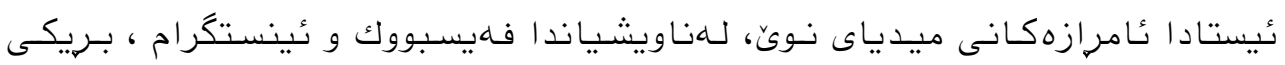

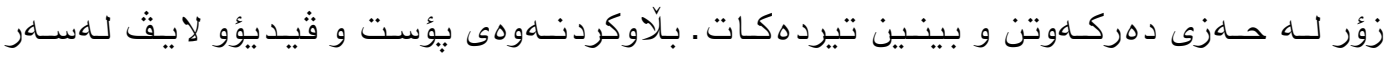

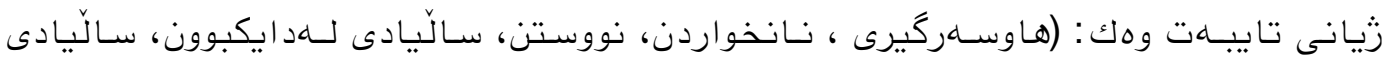

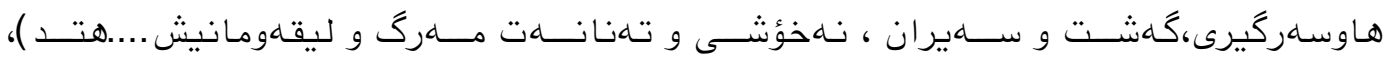

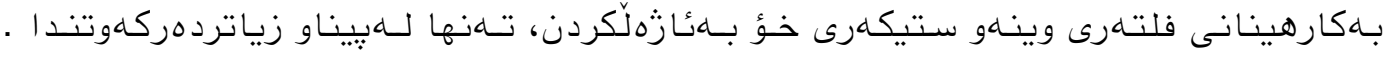

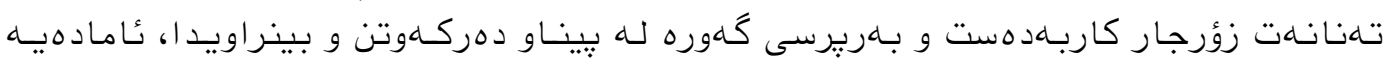

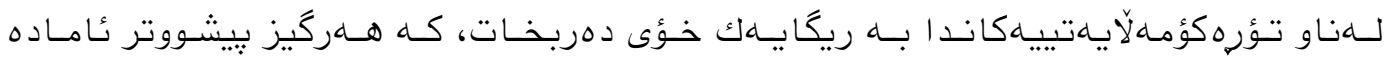

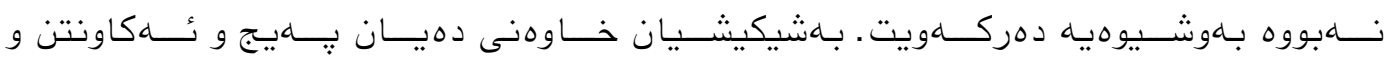

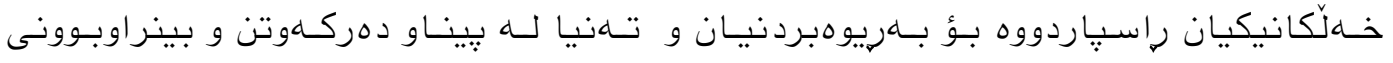

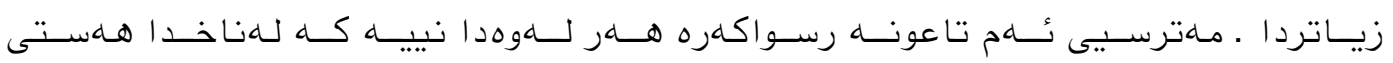

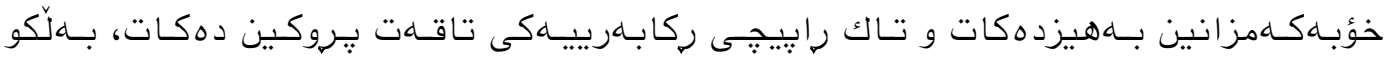

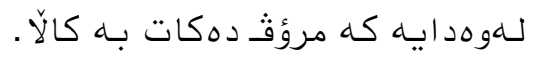

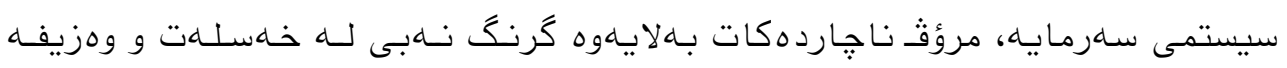

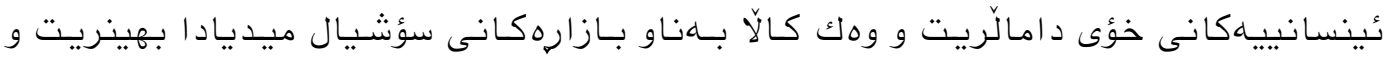

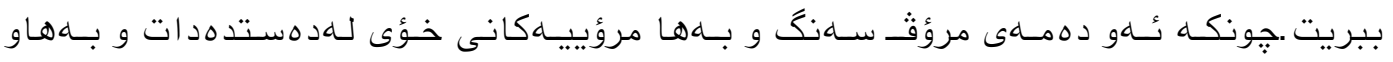

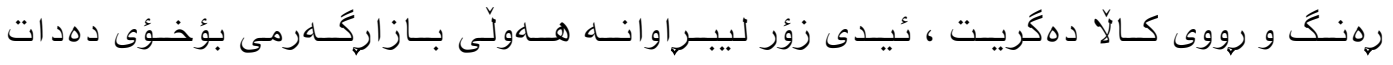

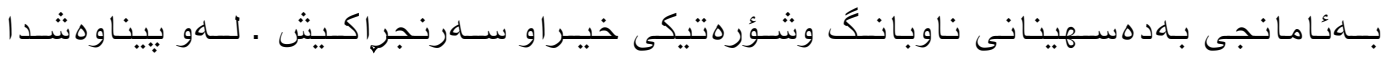

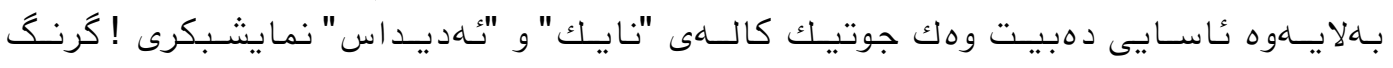

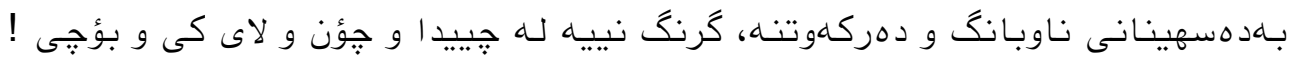




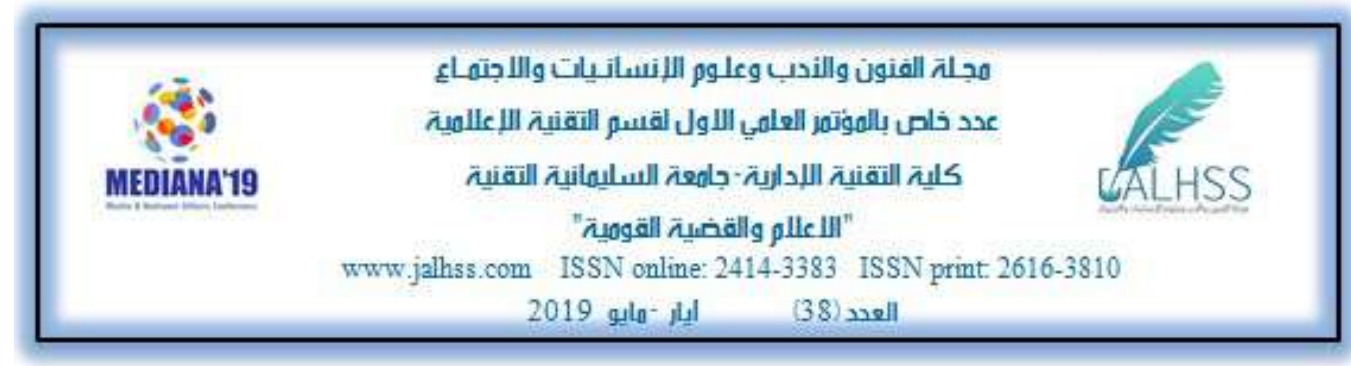

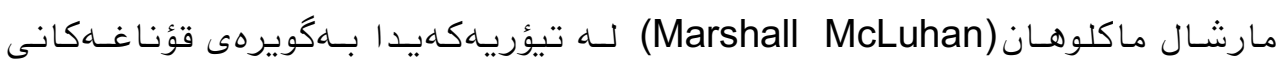

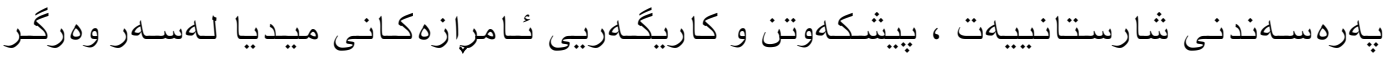

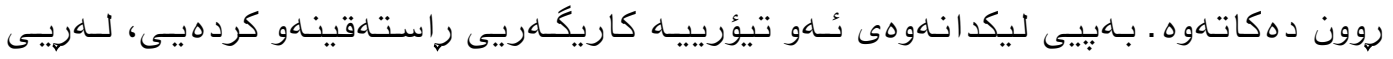

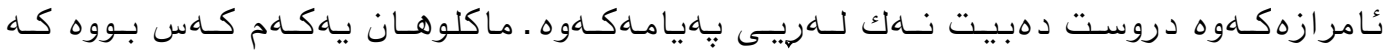

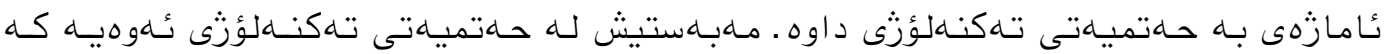

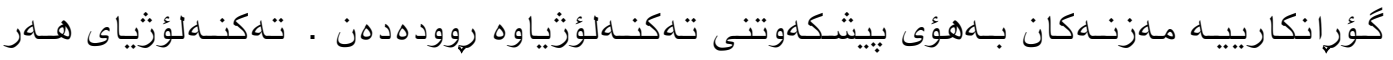

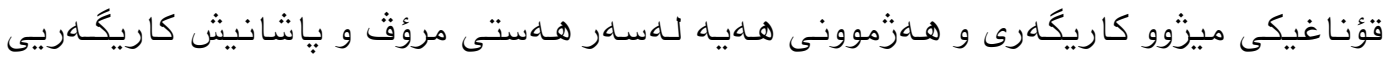

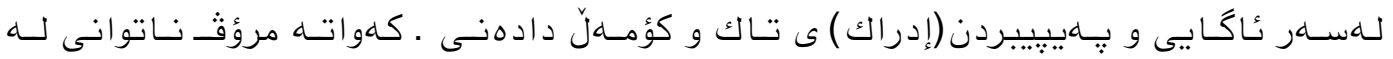

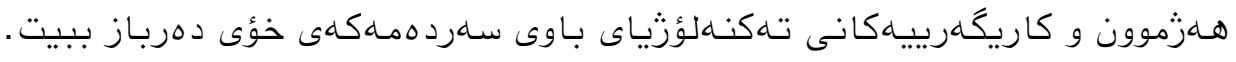

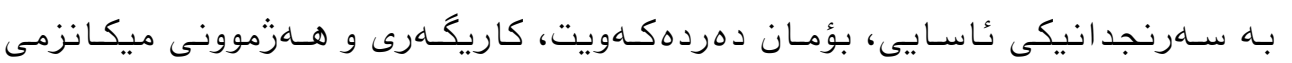

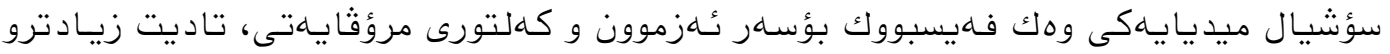

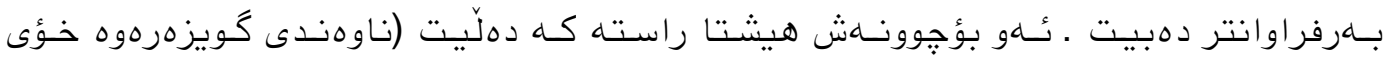

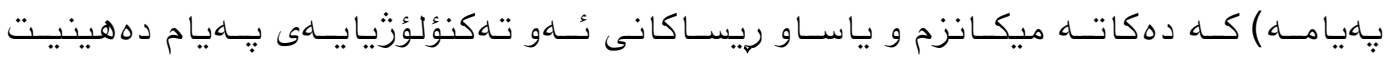

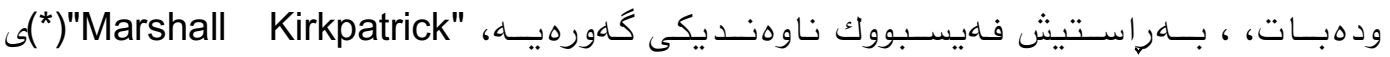

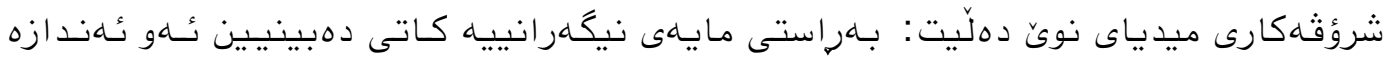

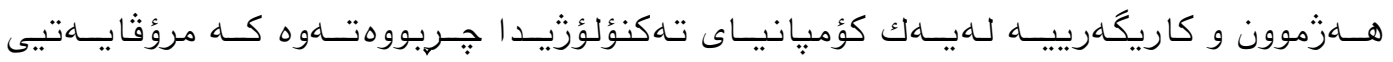

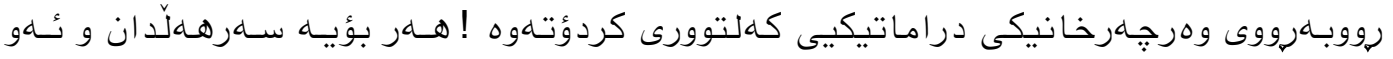

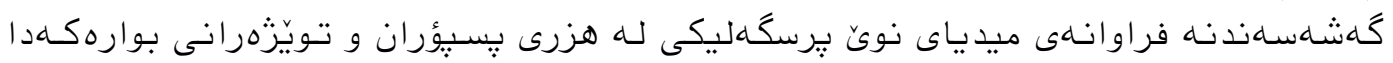

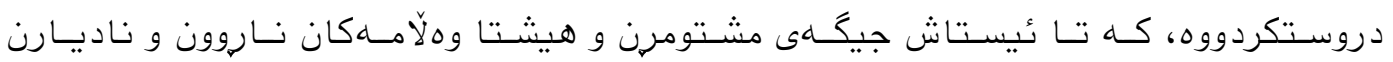

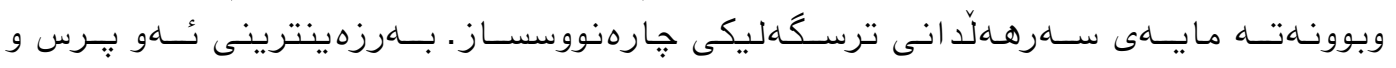
ترسانهيش ئهمانهان : :برسهكان:

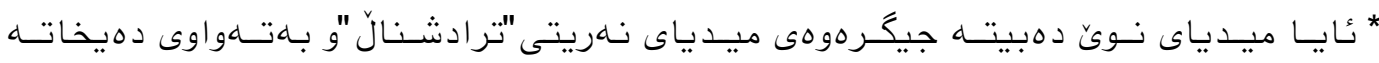

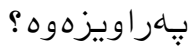

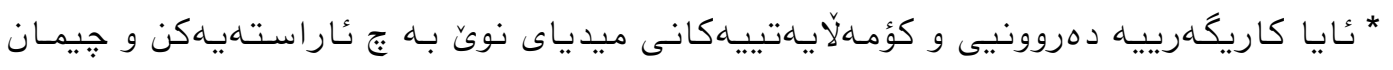

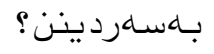

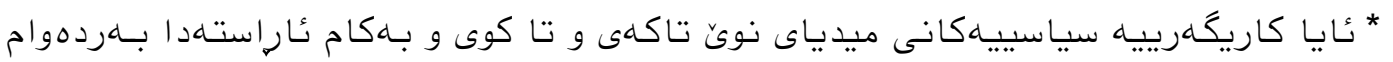
دهبن؟

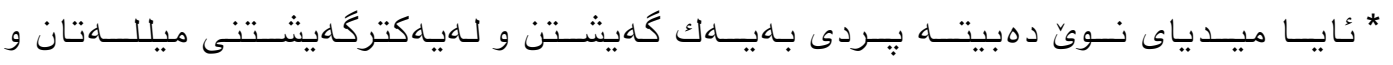

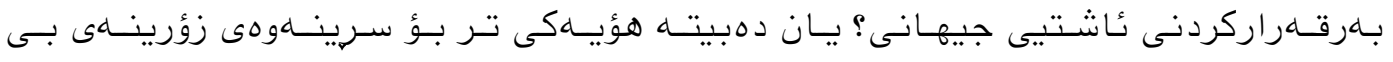


isi
محِ آلفنون والندب وعلوم اللإنسانيات واللاجتهاء

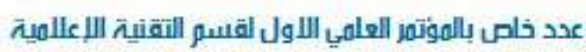

كلية التقنية الليدارية-جامعة السليهانية التقنية

"

www.jalhss.com ISSN online: 2414-3383 ISSN print: 2616-3810

2019 العيد

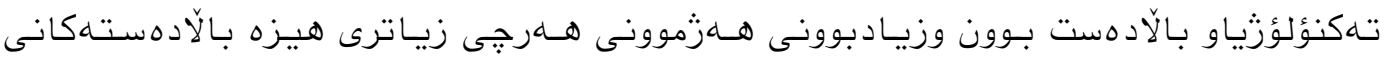

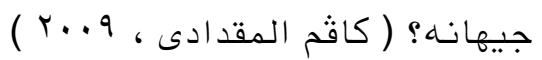

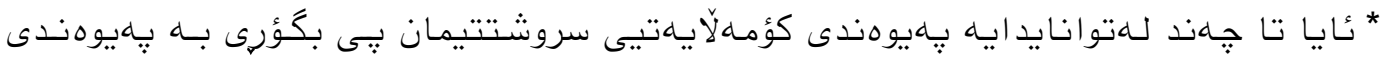

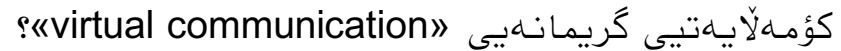

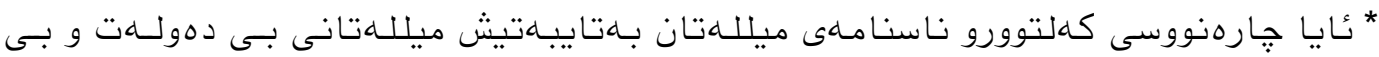

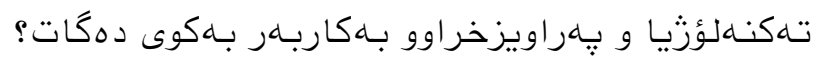

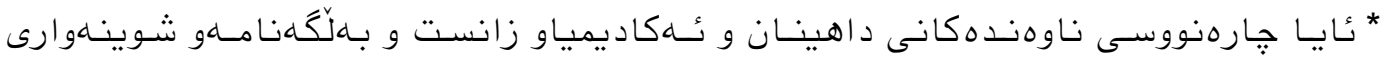

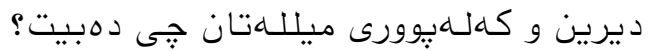

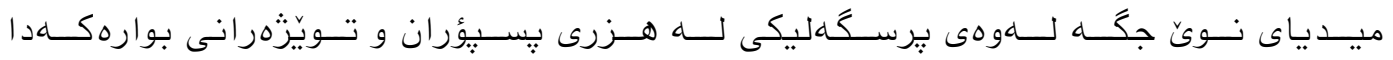

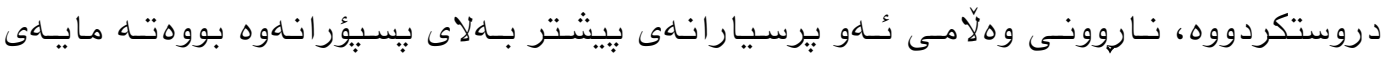

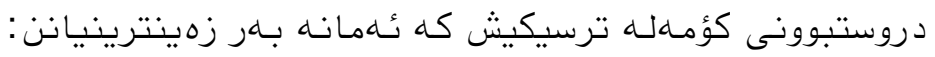
ترسهكان:

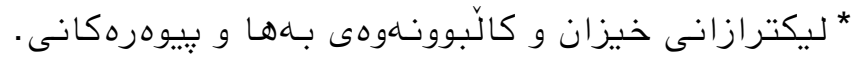

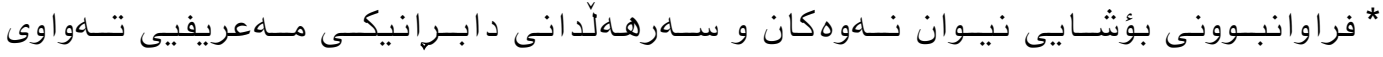
نيو انيان.

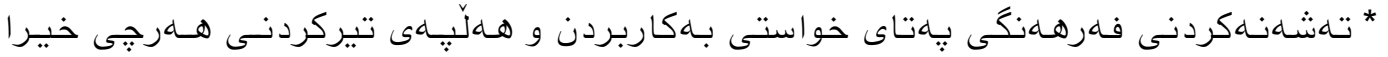

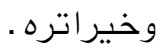

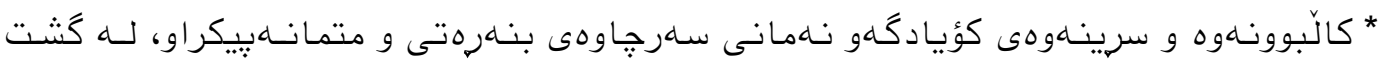

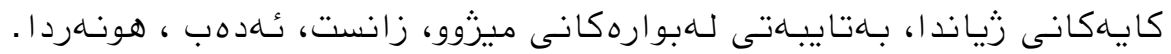

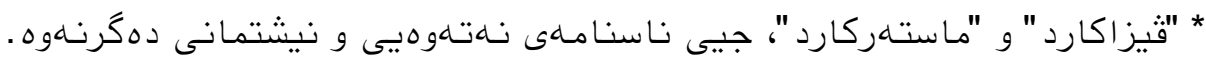

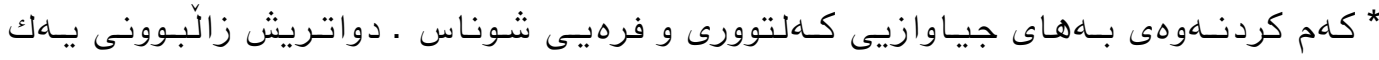

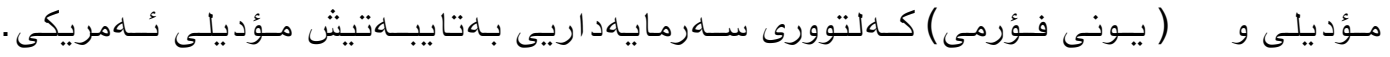

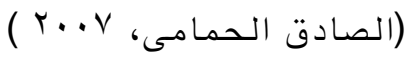

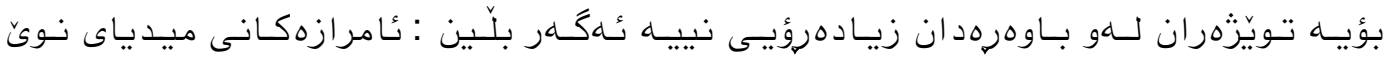

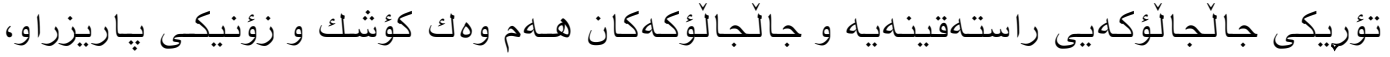

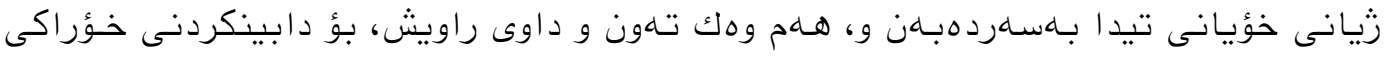

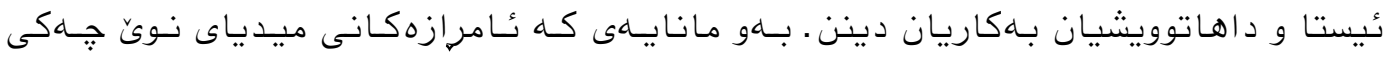

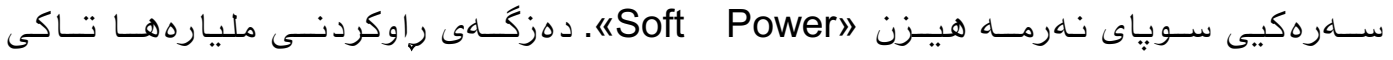

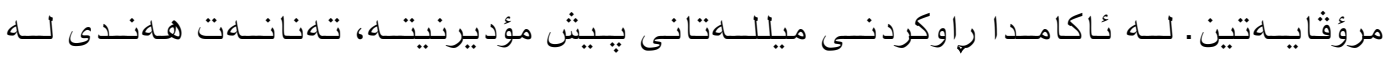

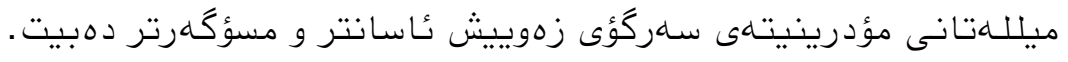




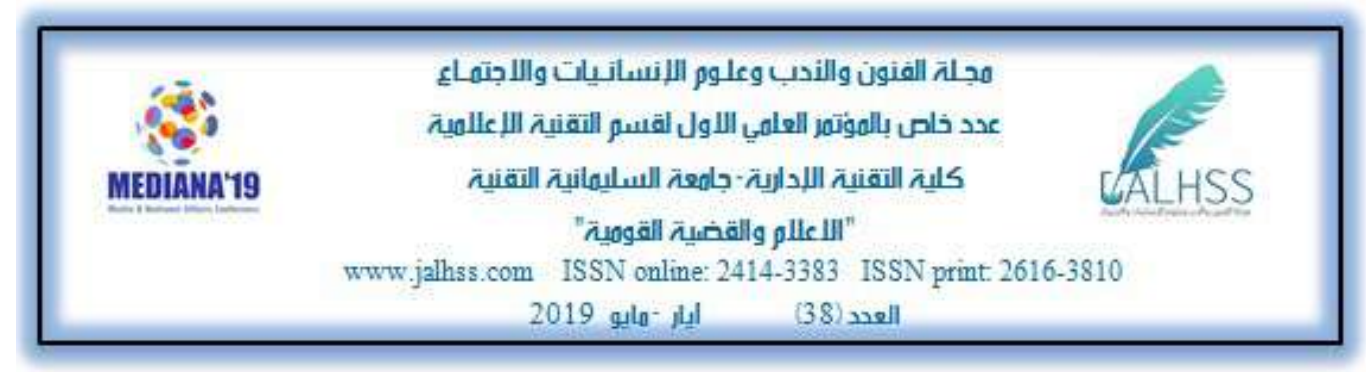

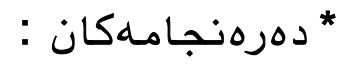

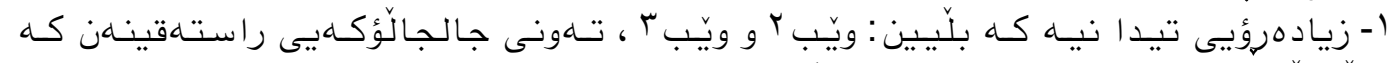

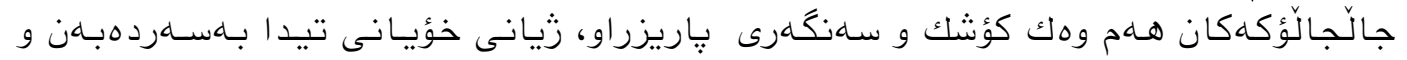

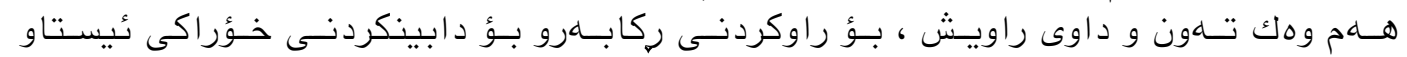
داهـاتوويشيان بـهكارى دين دون.

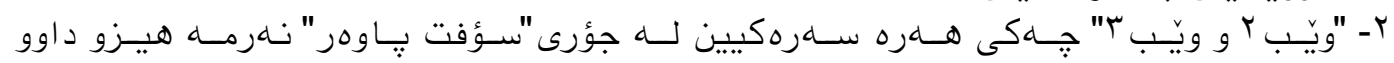

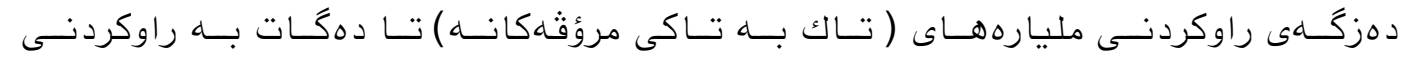

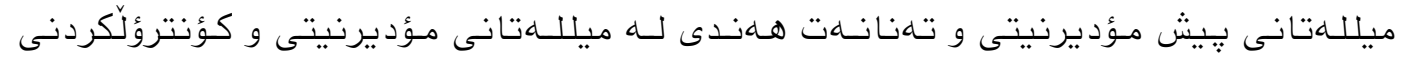

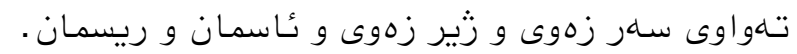

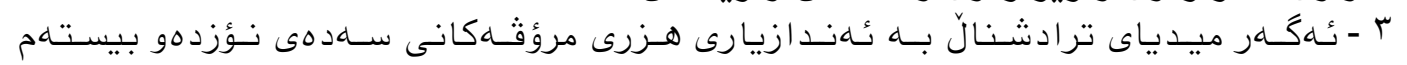

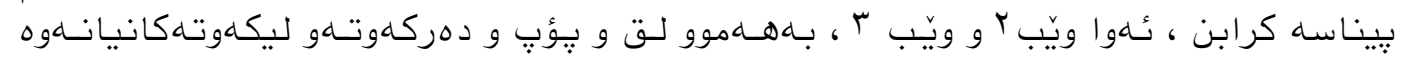

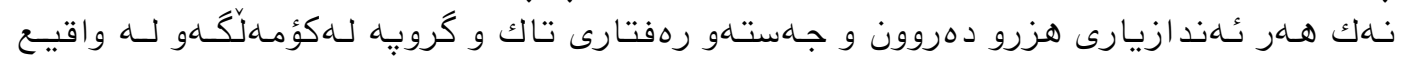

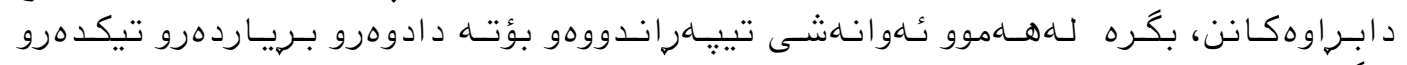

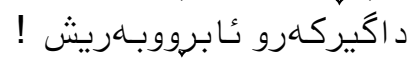

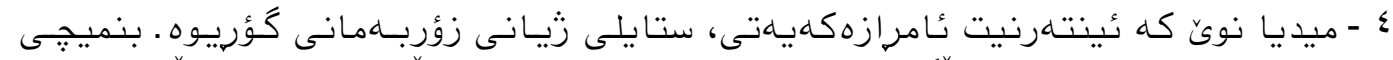

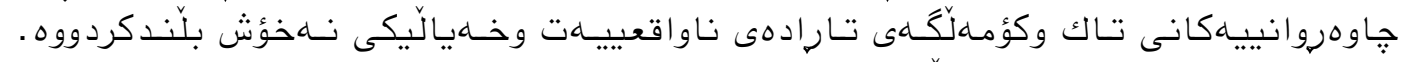

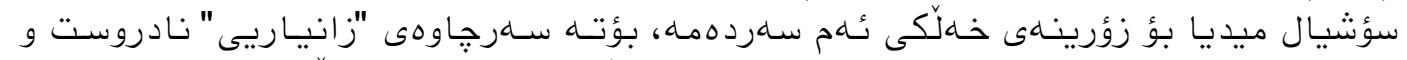

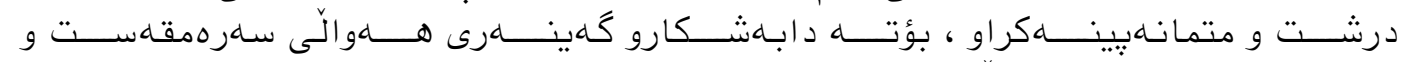

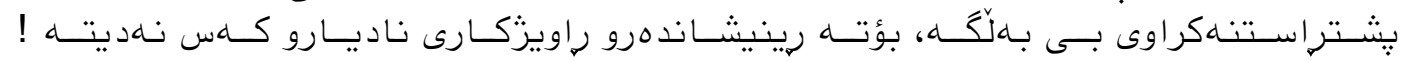

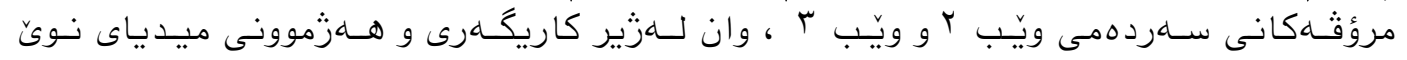

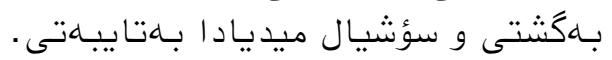

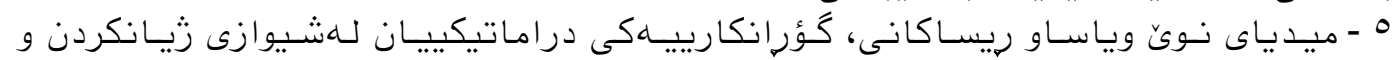

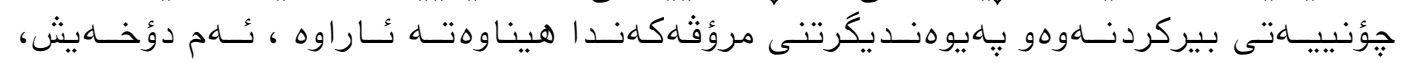

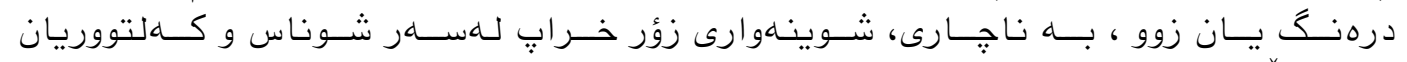

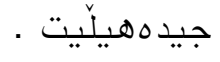

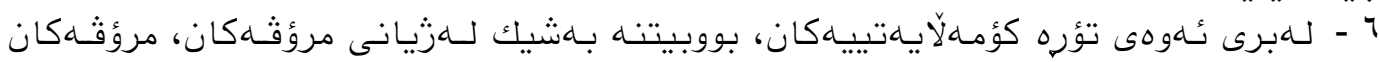

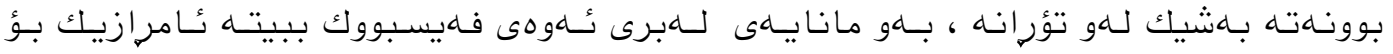

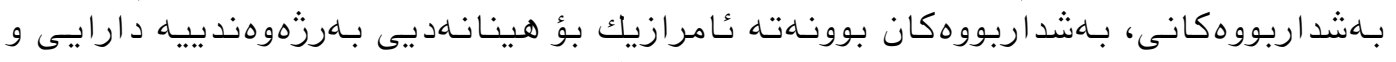

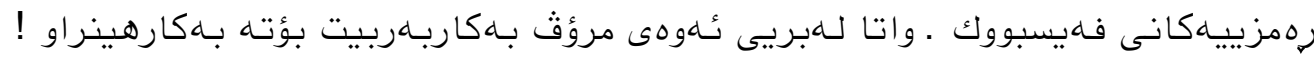

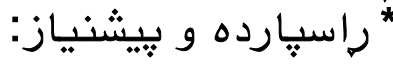

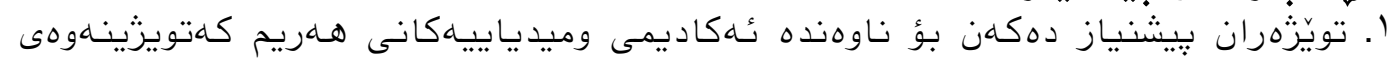

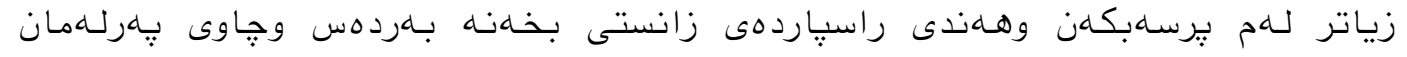
وحكومهات. 


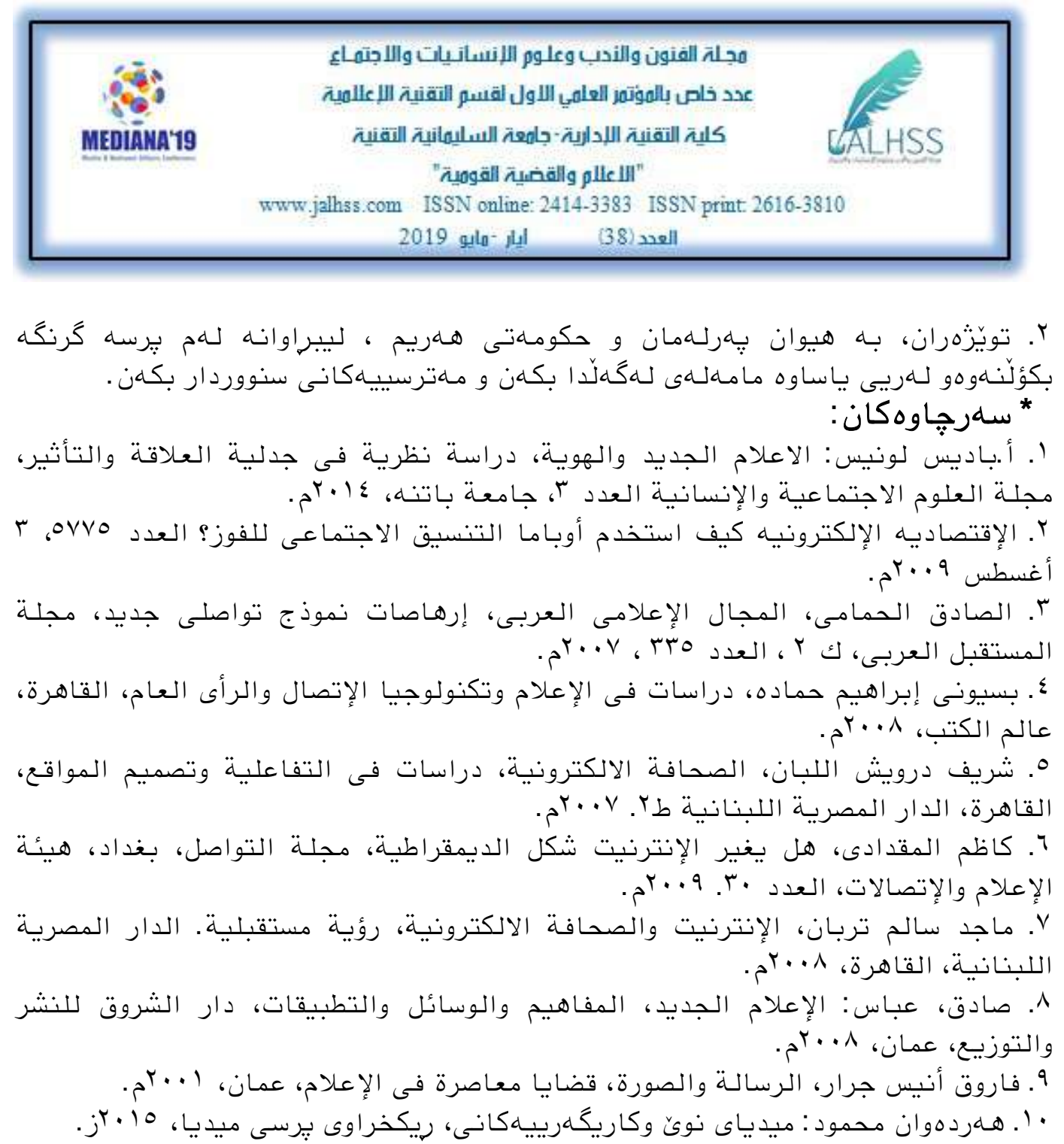

11.- Kirkpatrick، David. The Facebook Effect: the inside Story of the Company That Is Connecting the World. New York: Siman \& Schuster ، 2010

ir - Daniel Nations :Is Web 3.0 Really a Thing ،September 06، 2018

13- Karl Paulsen, Moving Media Storage Technologies: Applications \& Workflows for Video and Media S2011. Page 381

14- Varghese P.A., The characteristic of new media,2016.

15- https://www.lifewire.com/what-is-web-3-0-3486623

16 - https://www.internetworldstats.com/stats.htm

17 - https://www.oscarte.iq/2018/04/we-are-social-hootsuite-2018.html

18 - https://www.slideshare.net/wearesocial 


\title{
British Press Policy in the Fortune-Teller towards the Kurdish People \\ (Journal of Tegashtny Rasty and Peshkawtn-Model $৭ \uparrow r_{-} \mid q \backslash \wedge$ )
}

\author{
Assist. Prof. Dr. Yahia Omar Reshawy \\ Department of Technical media \\ College of Technical administrators \\ Sulaimani Polytechnic University \\ Iraq
}

\author{
Assist.Prof. Dr.Bahaddinn Ahmad Mhamad \\ Department of Technical media \\ College of Technical administrators \\ Sulaimani Polytechnic University \\ Iraq
}

\begin{abstract}
This media research that is about journalism policy of English authorities in Iraq and Sulaimaniespically after the first world war in (1914-1918). We have taken (Tegaishtnirasti-Peshkawtn) newspapers as a sample that has been published by Englishmen in Iraq and sulaimaniespically written in Kurdish language from-191^) (19rt
\end{abstract}

Its a descriptive research, in which both descriptive and historical methods have been used.

The importance of the research is that it talks about publishing newspapers in Iraq in Kurdish language by Englishmen in that historical stage in the mentioned city.

Also the purpose of doing our research is to find out the true aim of Englishmen behind publishing that newspaper, then to shed light on English journalism policy in the city through technical journalism publication analysis on all the covers of the entire copies of the mentioned newspaper.

This study is divided in to five sections: The first section is dedicated for the research frame, while the second one is about the relation between media and politics, the third section deals with the press policy and forms of media in the kurdish newspaper (TegaishtniRasti _ understanding the truth) whereas the forth section is about Sulaimanya city's condition especially during the first world war and the fifth and last section deals with the press policy and forms of media in the Kurdish newspaper (Peshkawtn - progress) and at the end conclusions and results. 


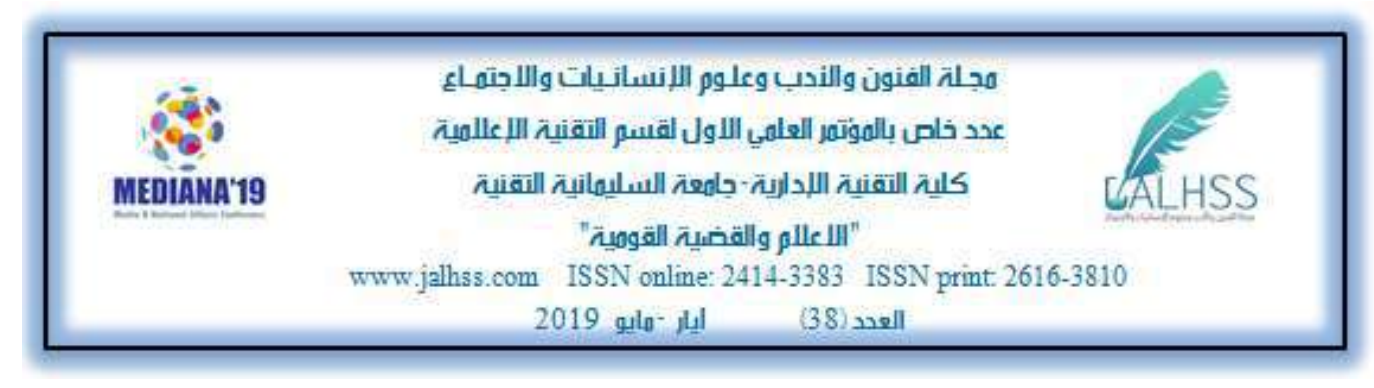

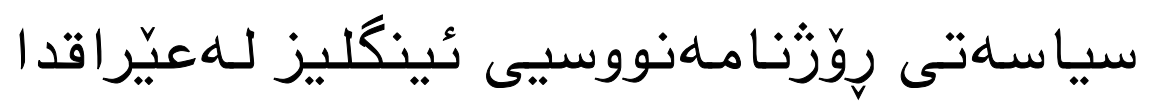

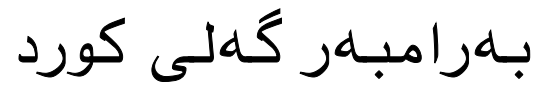

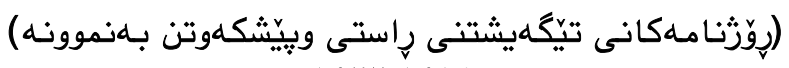 \\ 19Yr-1911
}

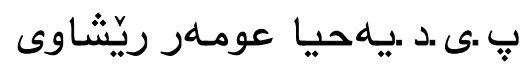

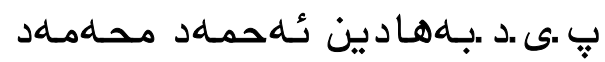

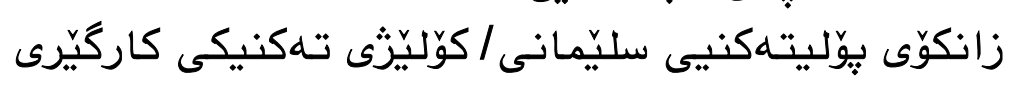 \\ بـهى تهكنيكى ميديا
}

بو ختونه

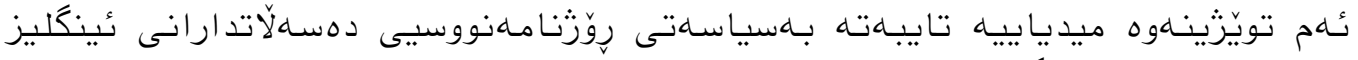

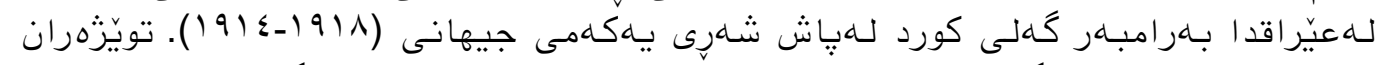

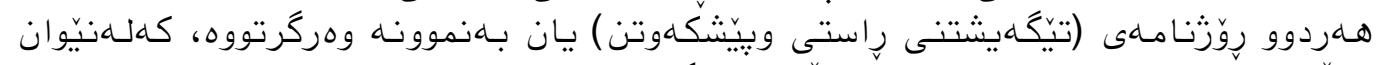

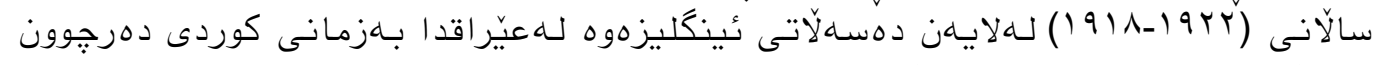

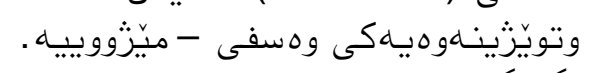

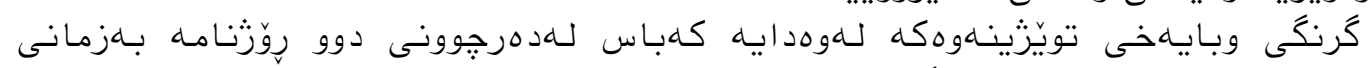

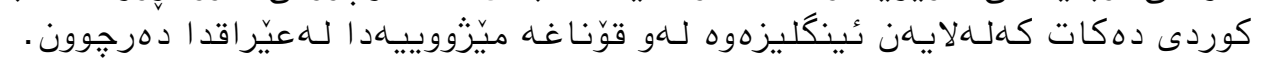

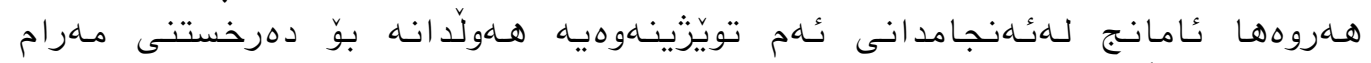

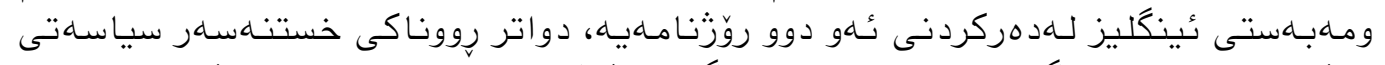

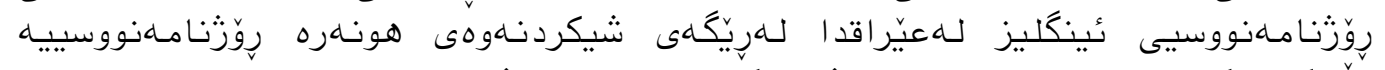

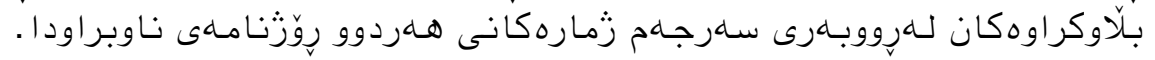

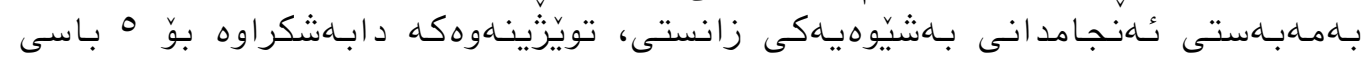

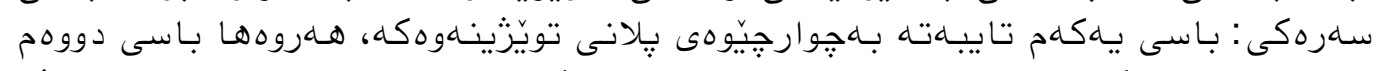

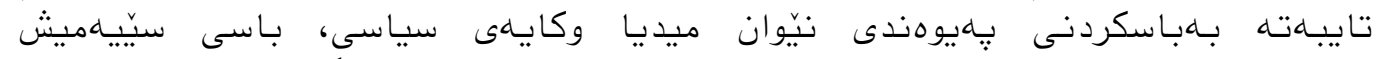

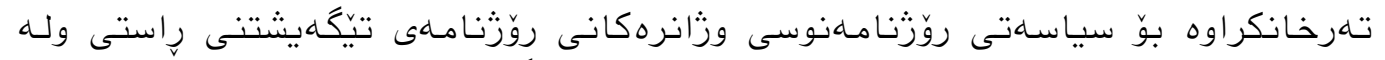

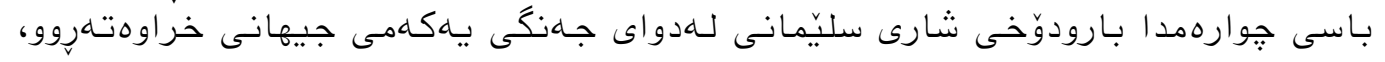

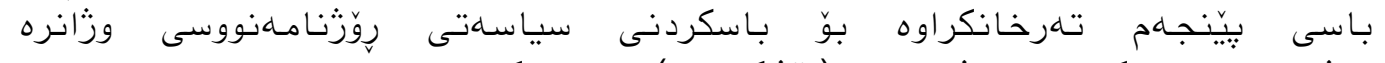

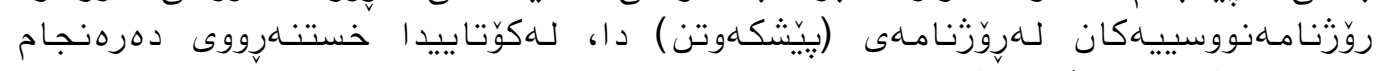

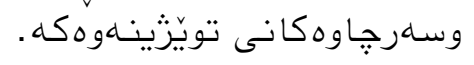




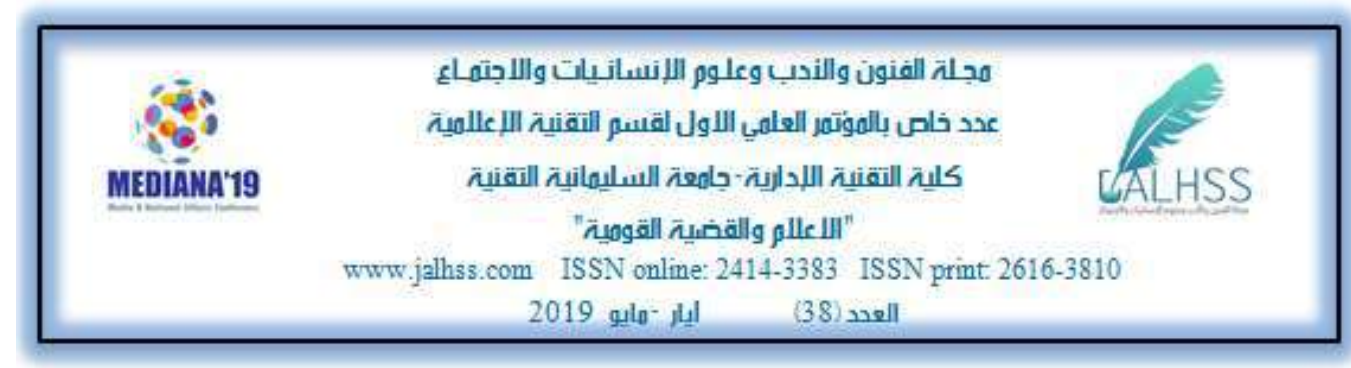

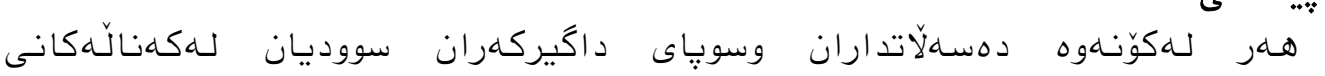

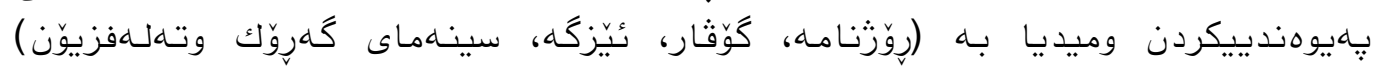

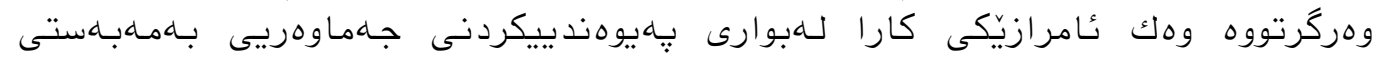

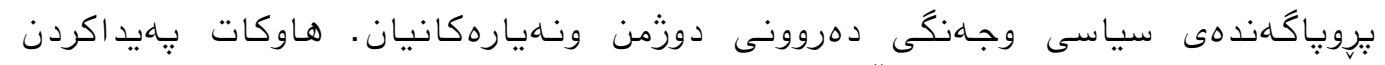

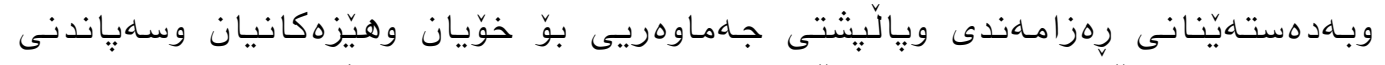

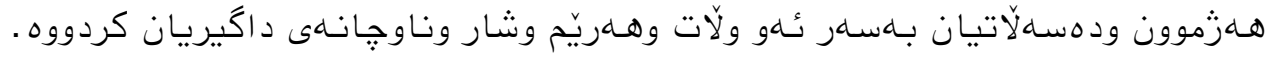

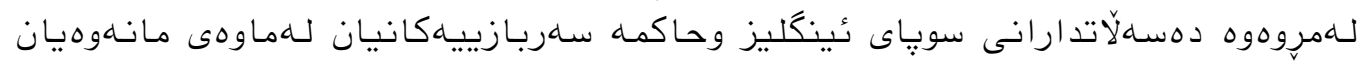

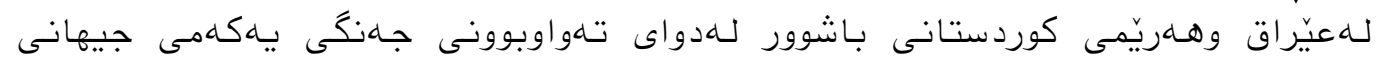

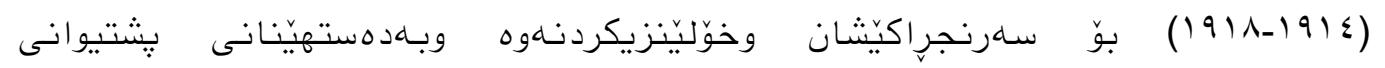

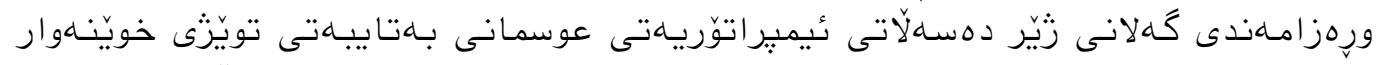

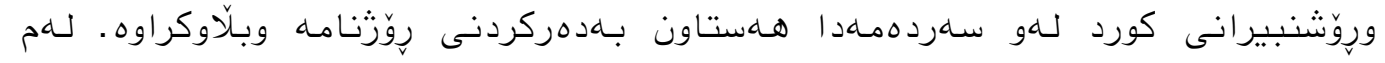

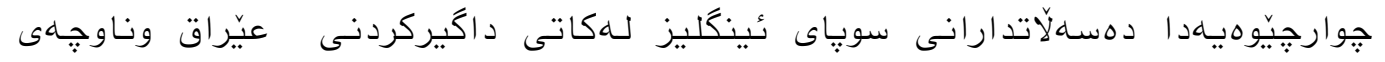

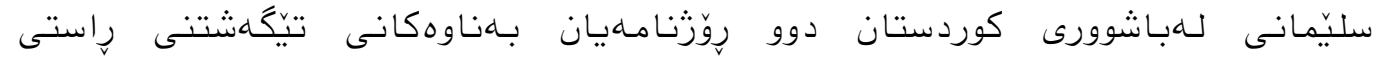

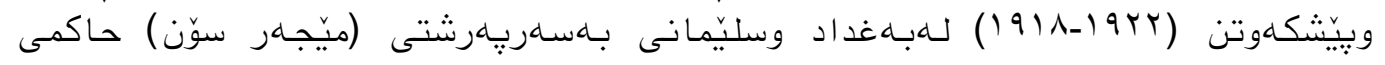

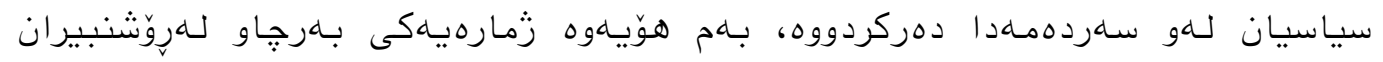

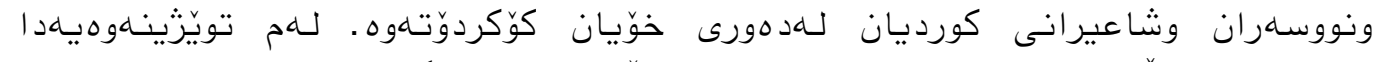

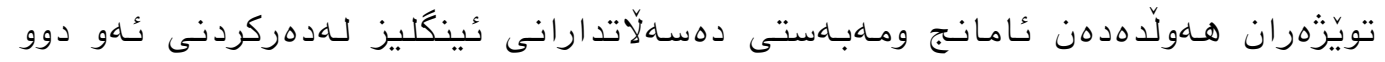

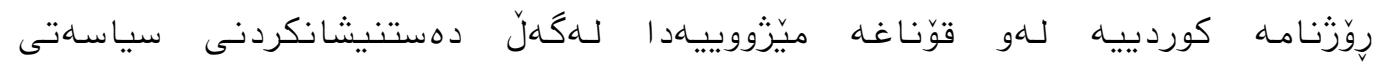

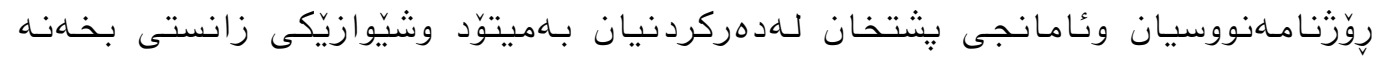




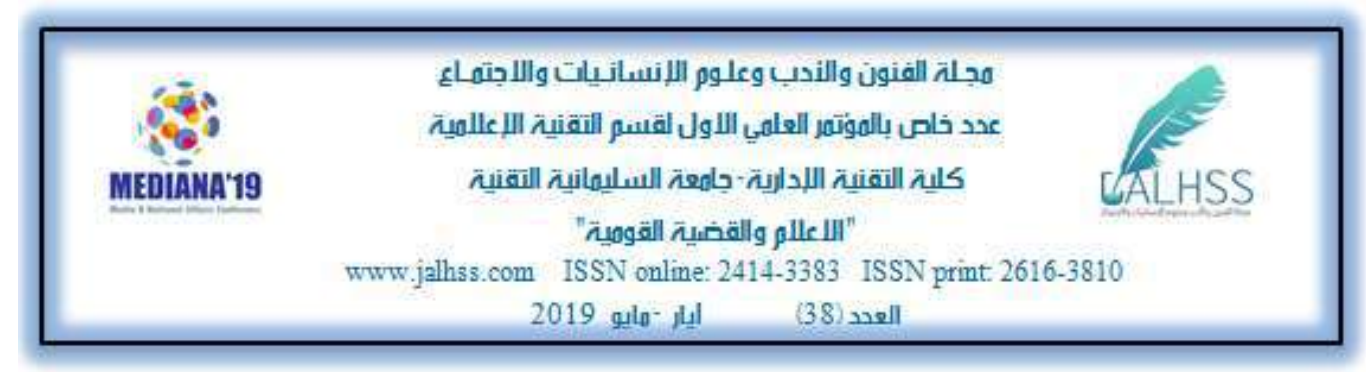

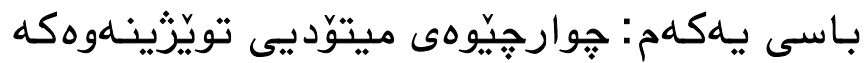

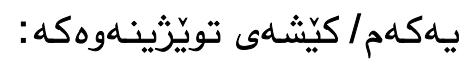

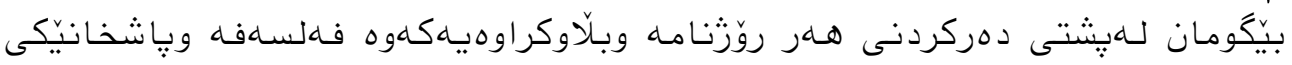

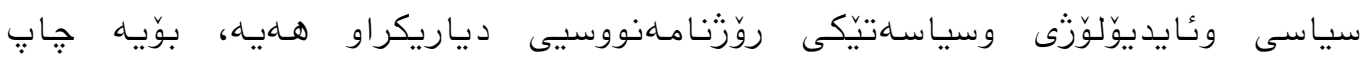

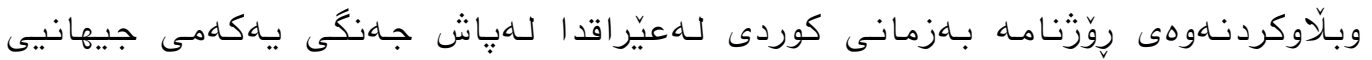

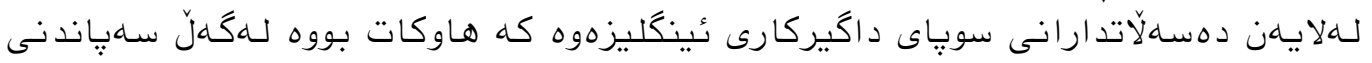

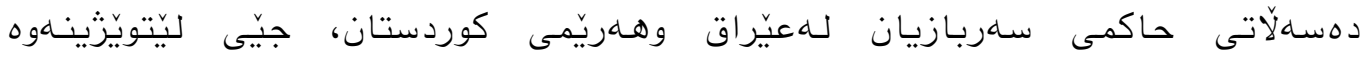

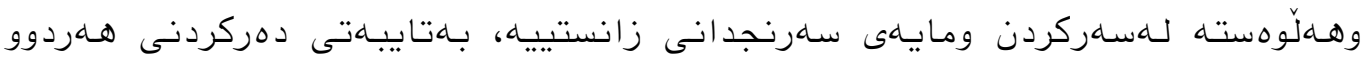

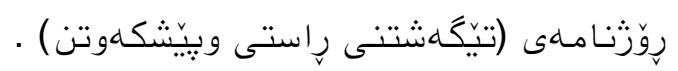

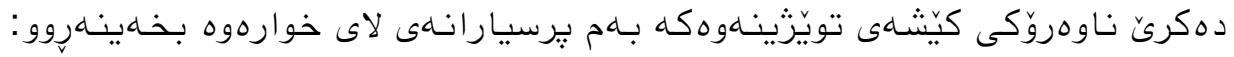

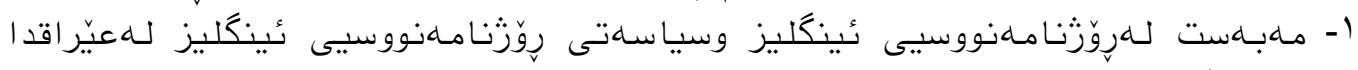

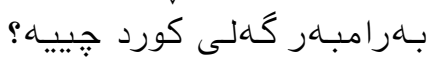

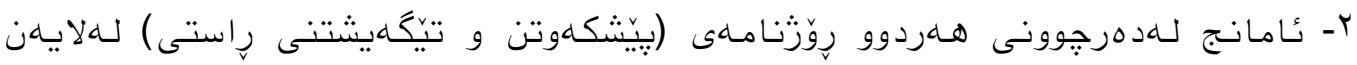

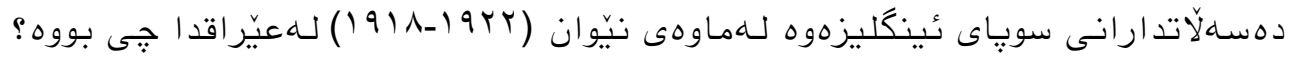

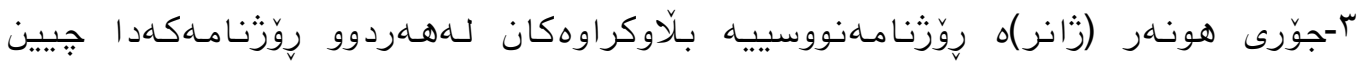

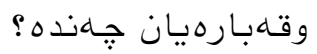

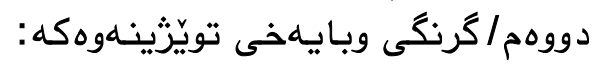

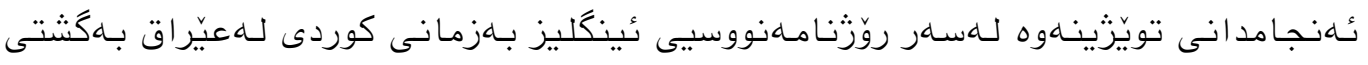

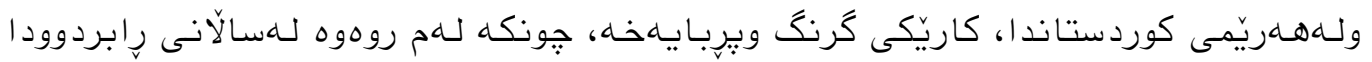

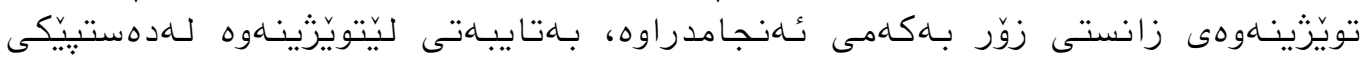

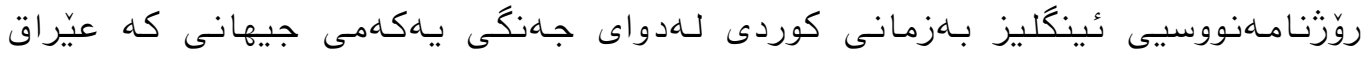

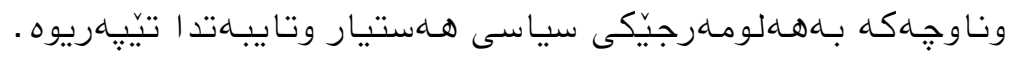

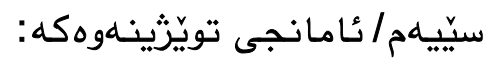

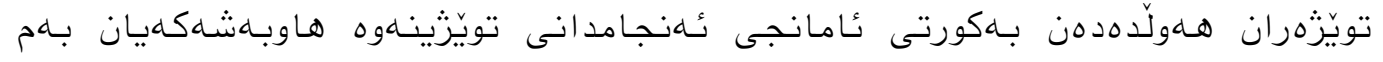

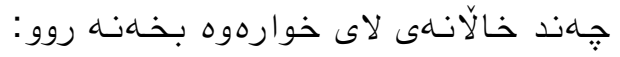

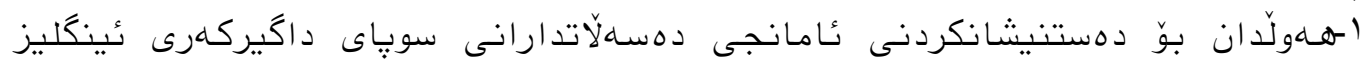

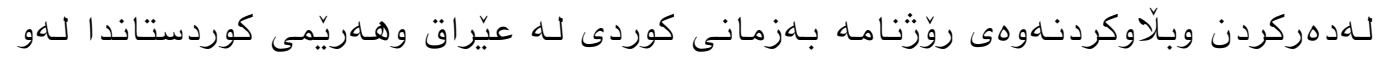

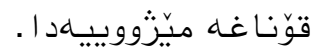

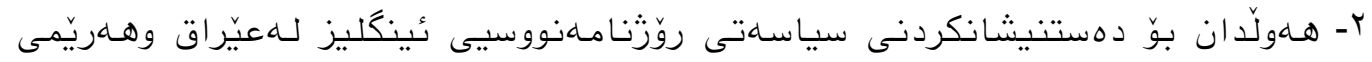

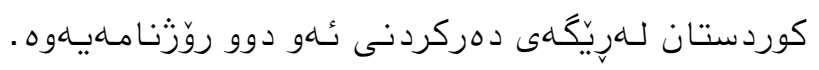

DOI: $10.33193 /$ JALHSS.38.14 


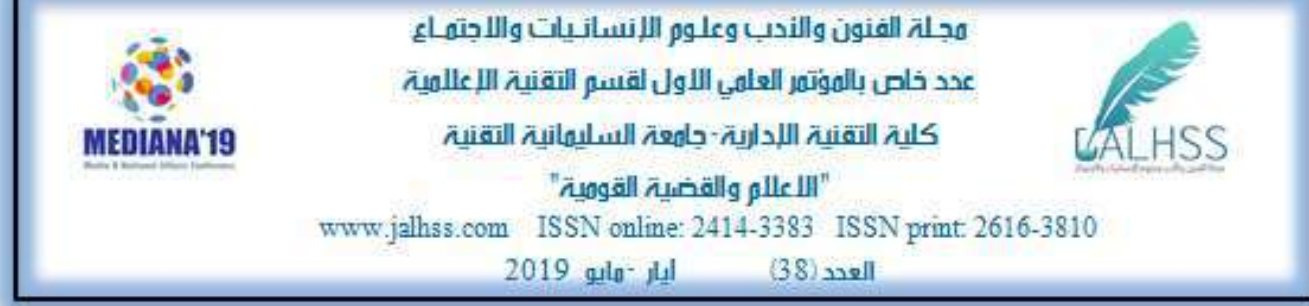

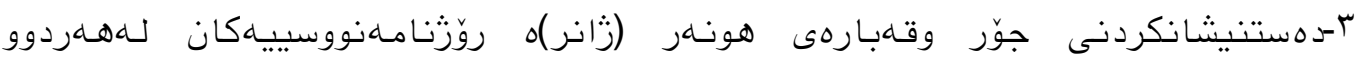

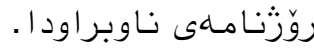

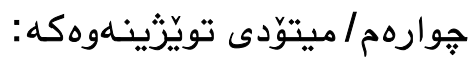

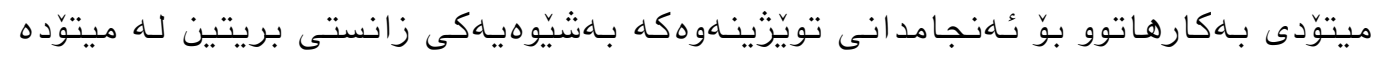

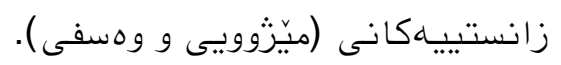

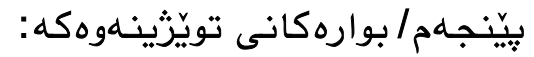

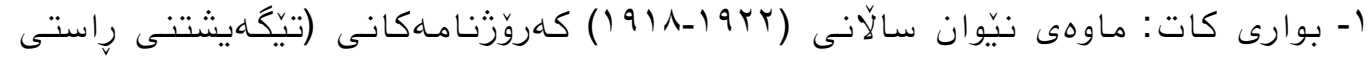

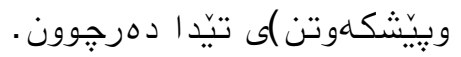

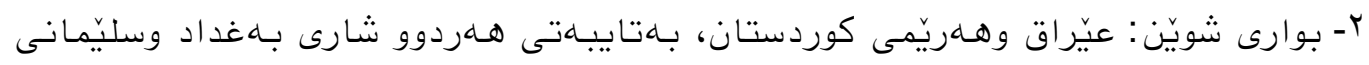

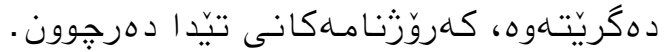

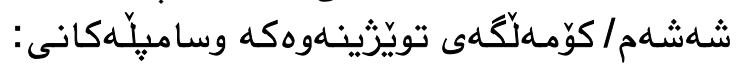

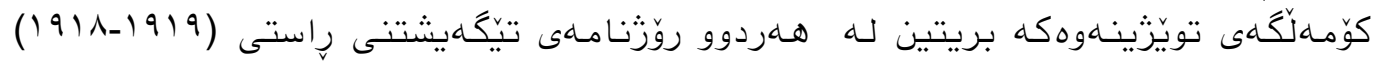

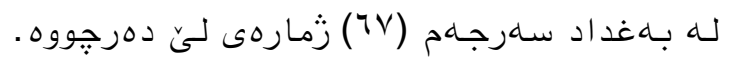

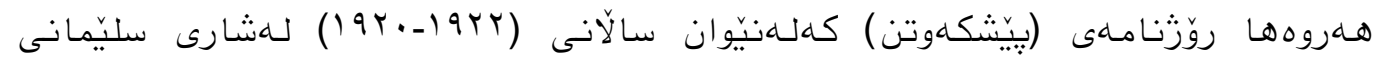

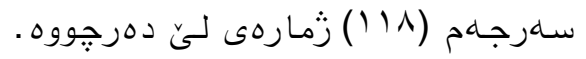

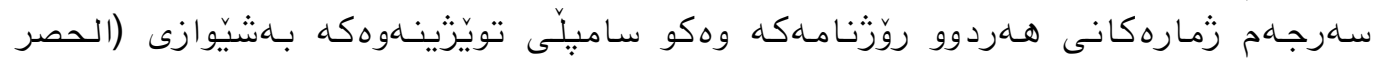

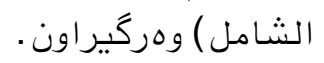

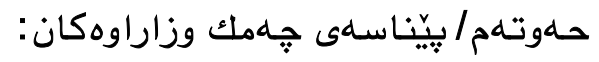

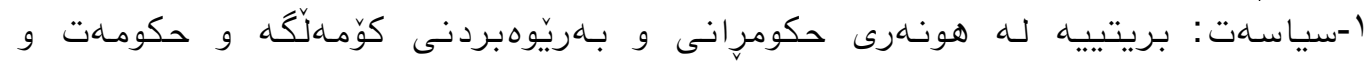

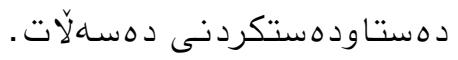

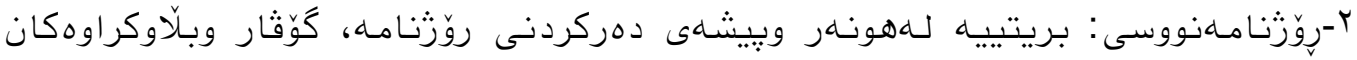

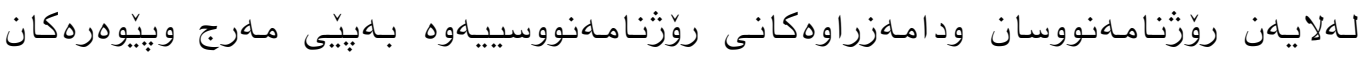

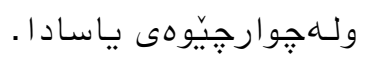

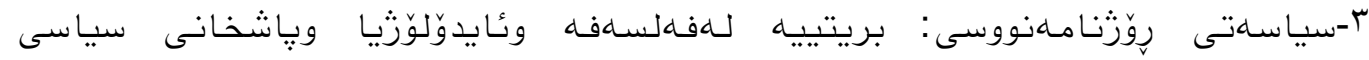

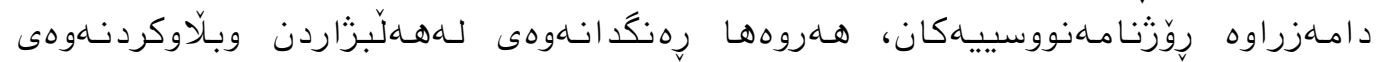

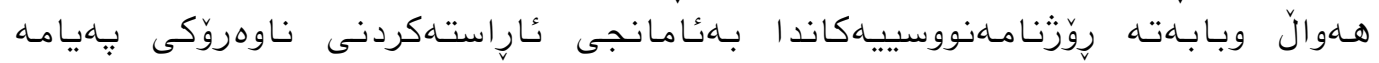

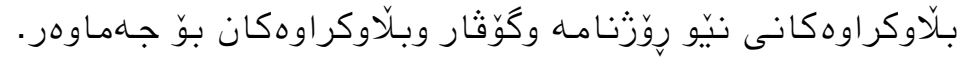

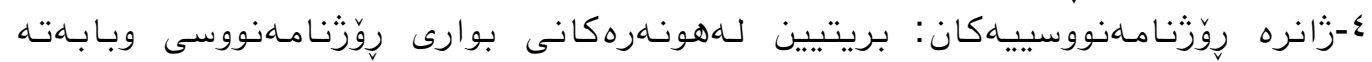

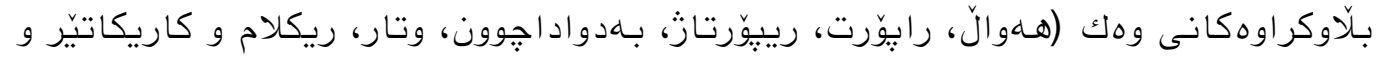
. هـا.... 


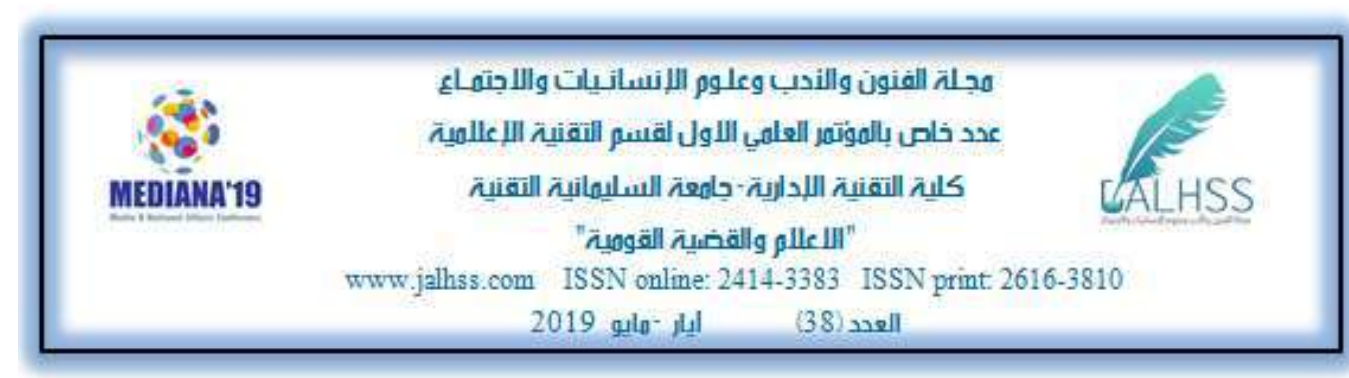

\section{باسى دووهم: بِهيوهندى نيّوان ميديا و كايهى سياسى}

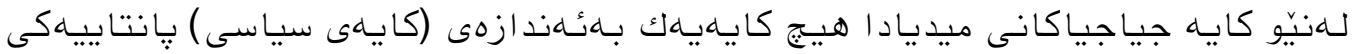

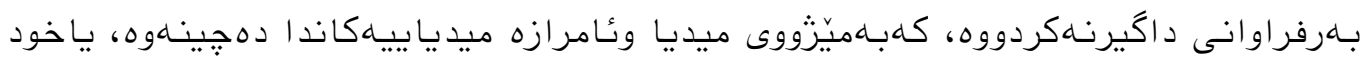

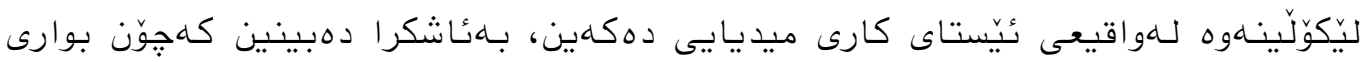

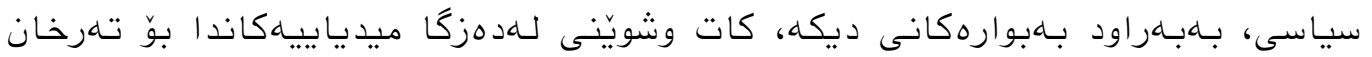

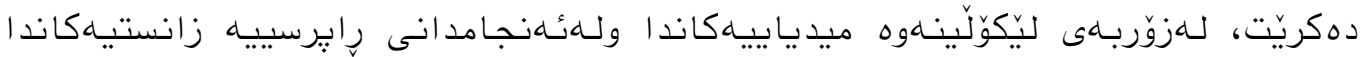

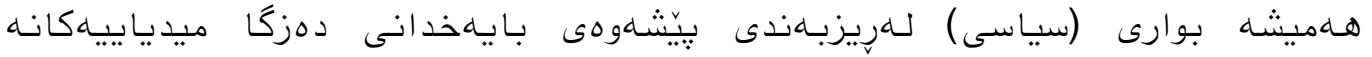

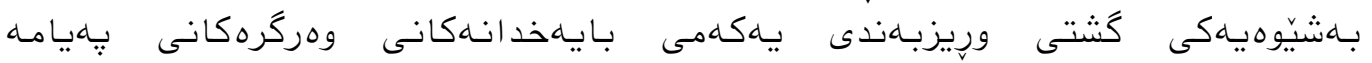

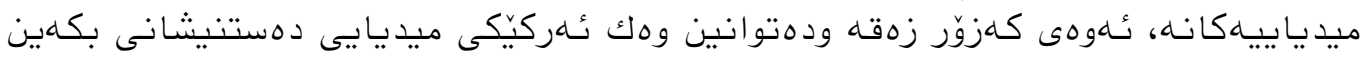

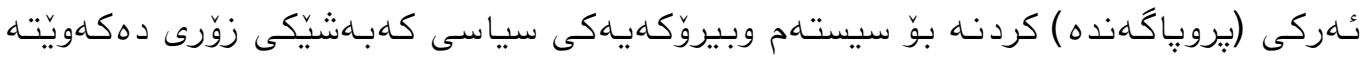

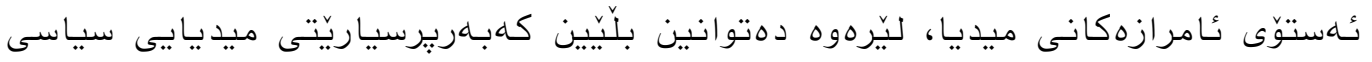

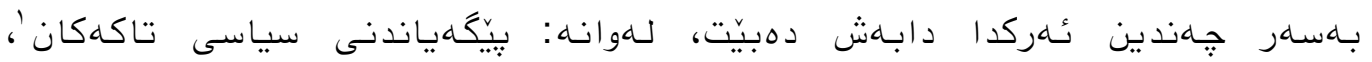

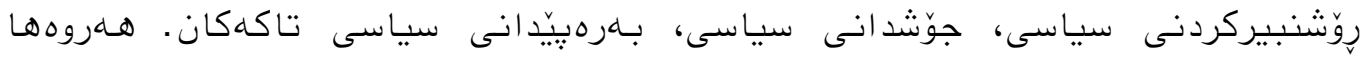

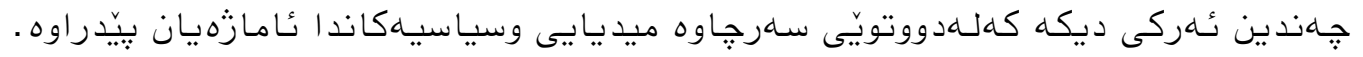

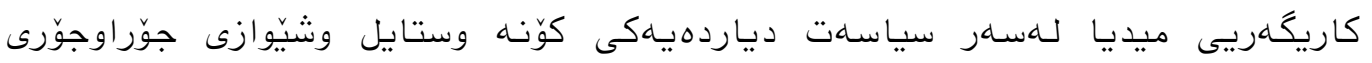

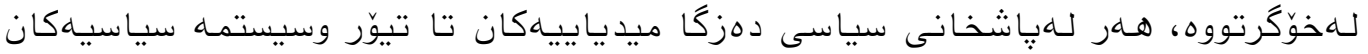

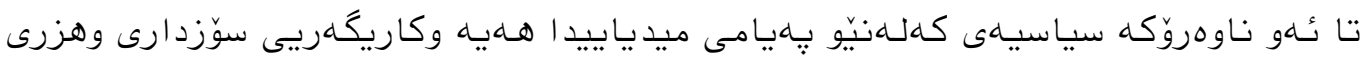

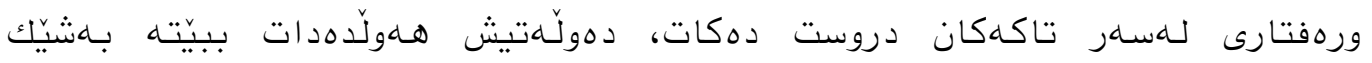

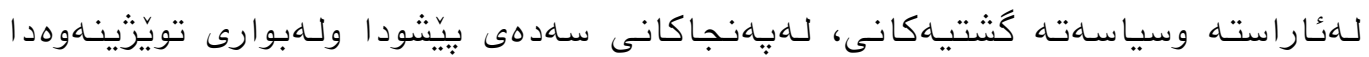

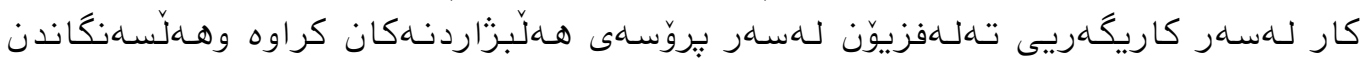

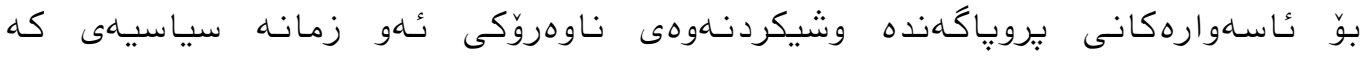

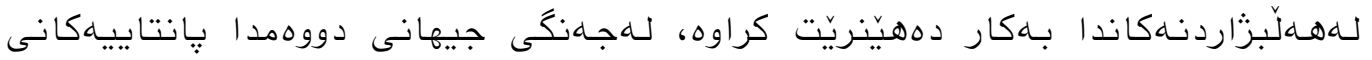

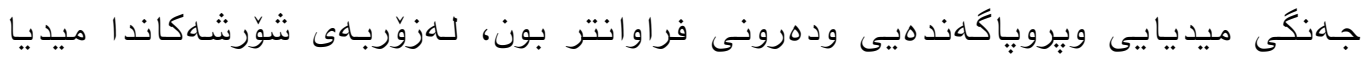

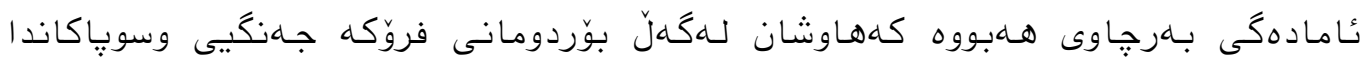

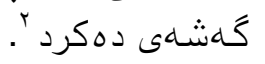

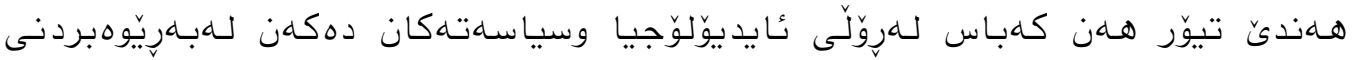

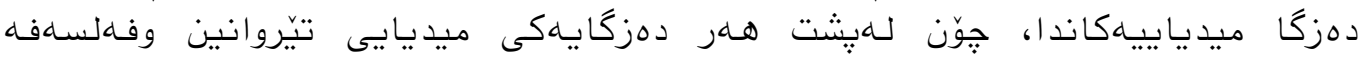

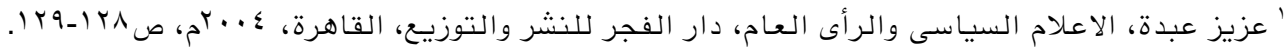

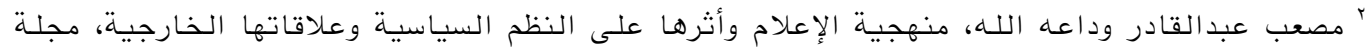

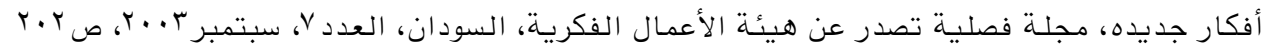




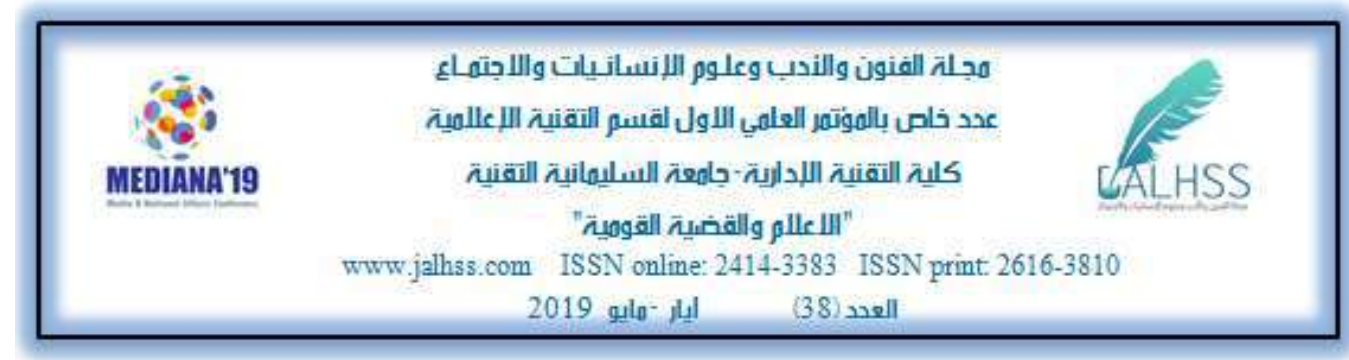

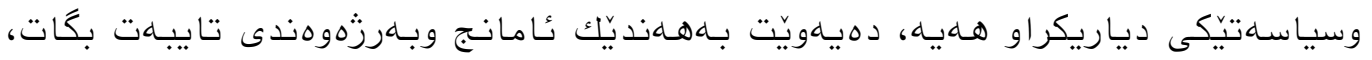

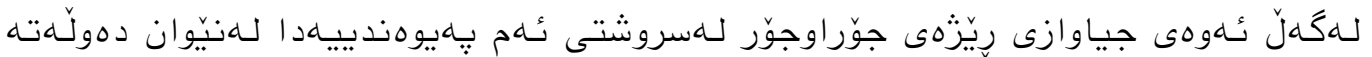

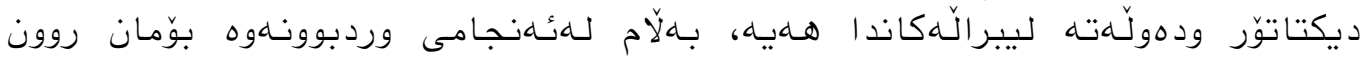

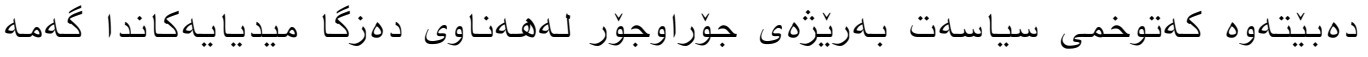

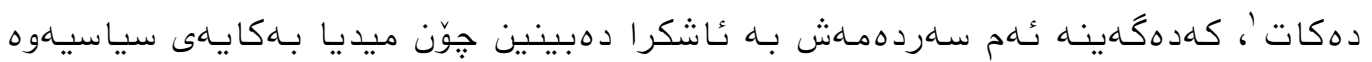

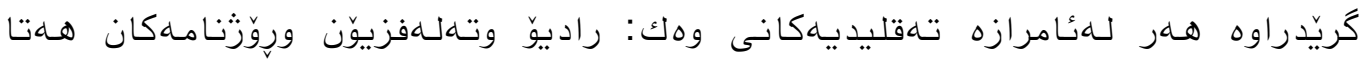

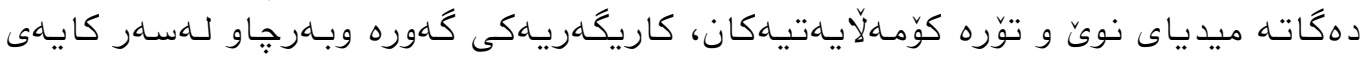

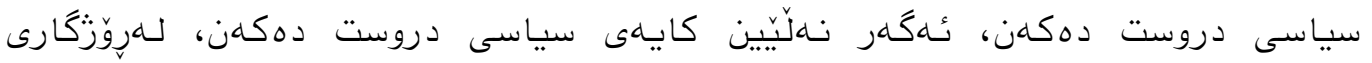

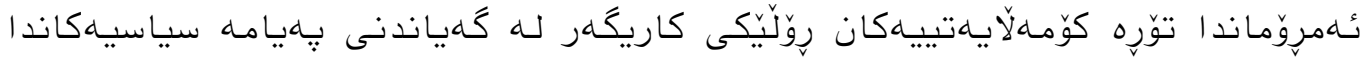

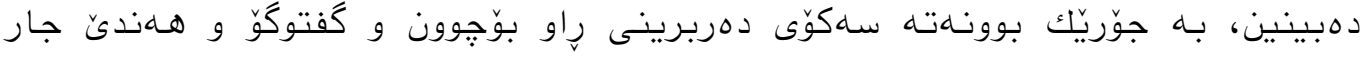

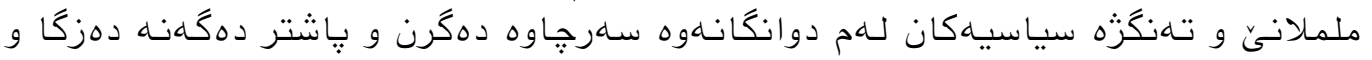

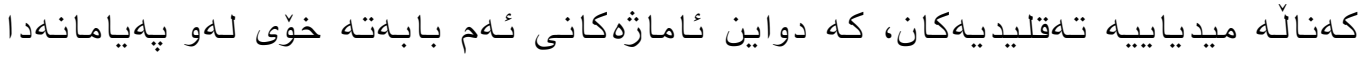

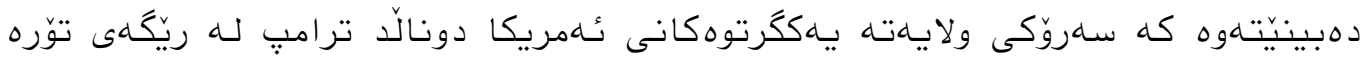

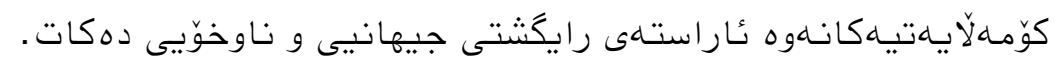

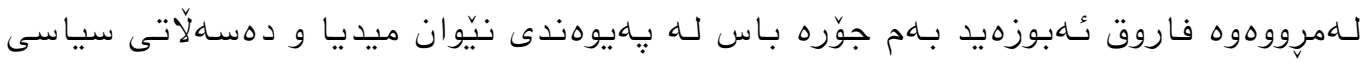

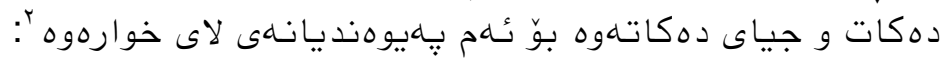

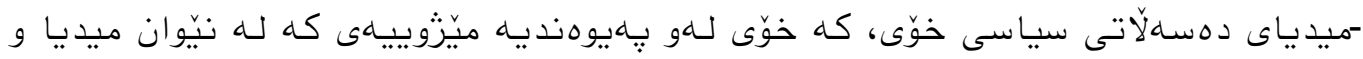

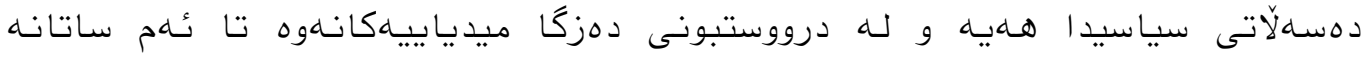

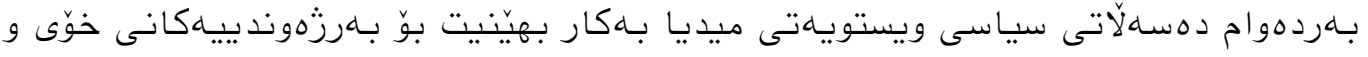

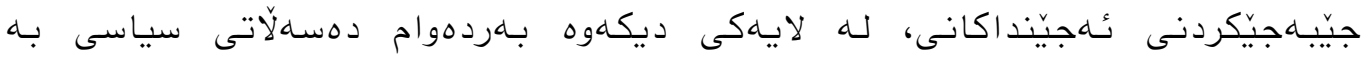

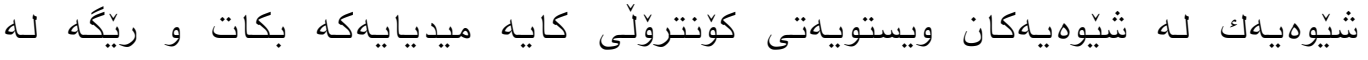

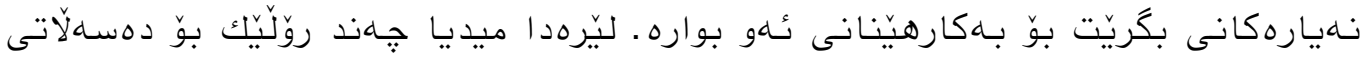

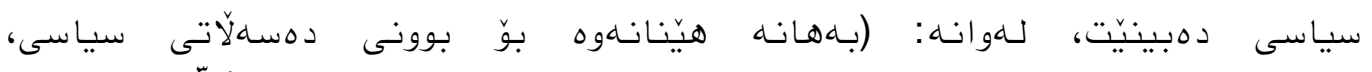

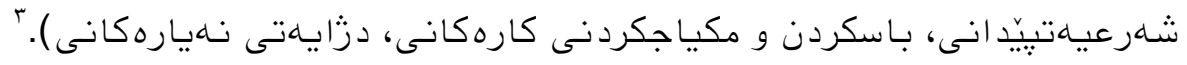

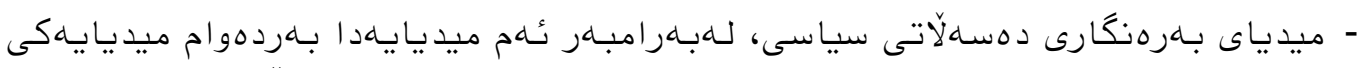

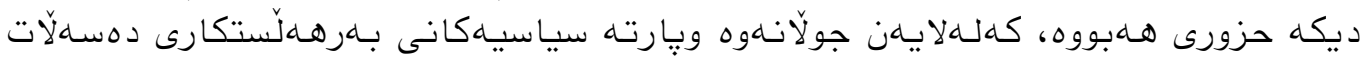

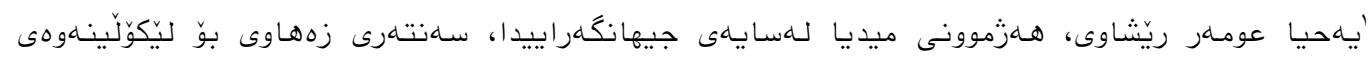

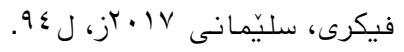

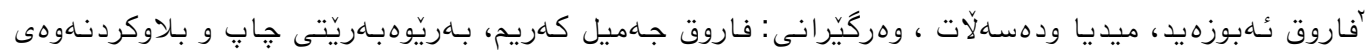

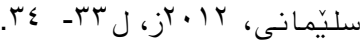
'بسام عبد الرحمن المشاقبة، الاعلام البرلمانى والسياسى، دار أسامة، الاردن، لالـبم، ص 79.

DOI: $10.33193 /$ JALHSS.38.14 


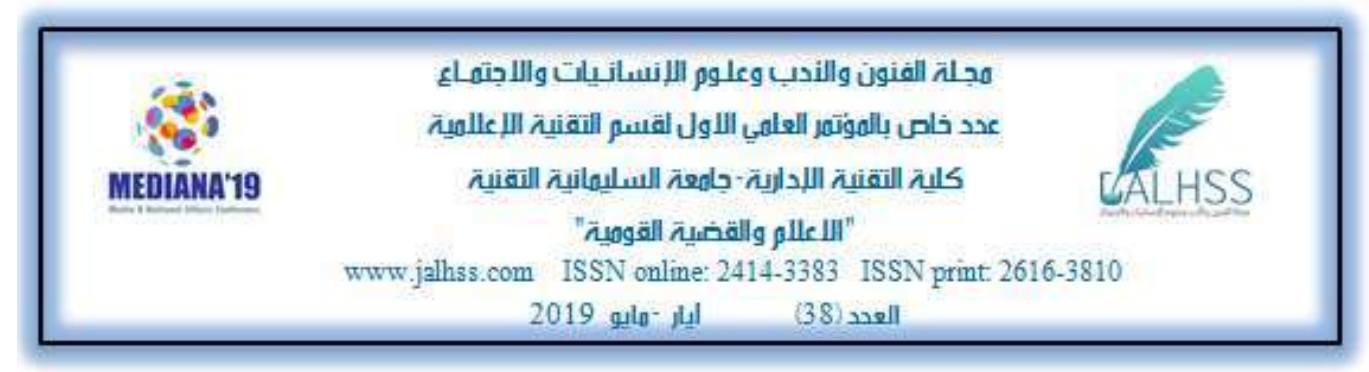

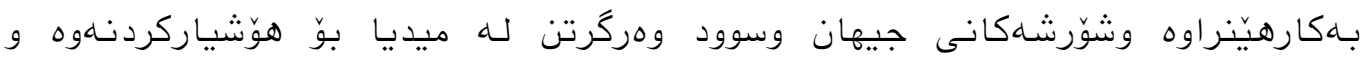

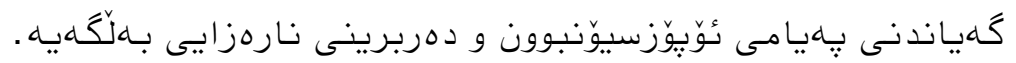

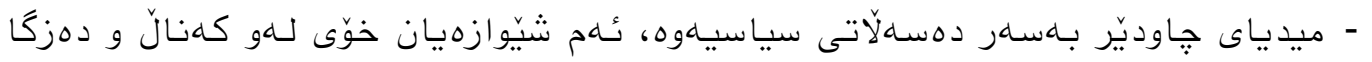

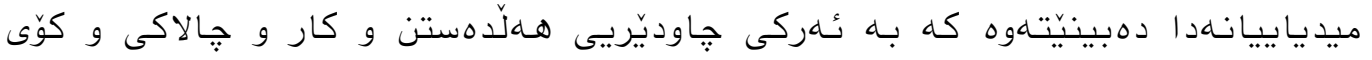

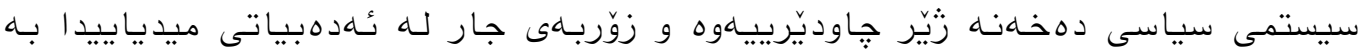

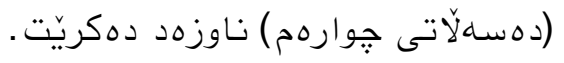

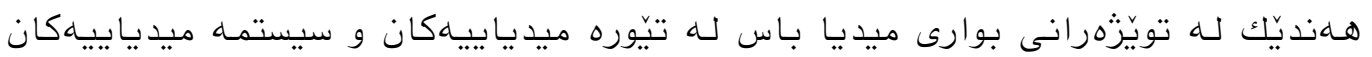

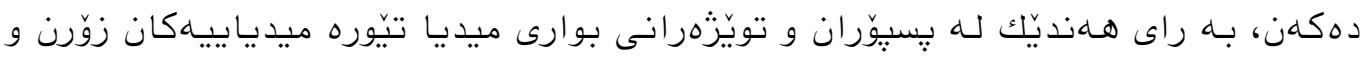

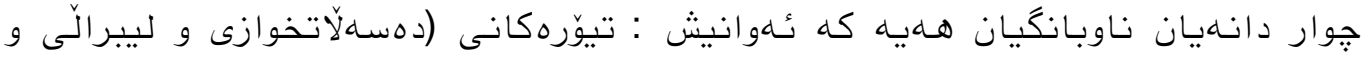

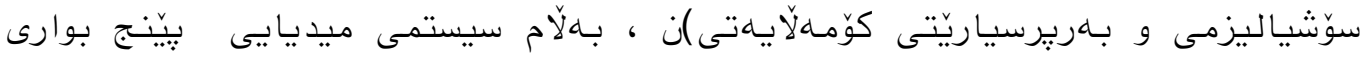

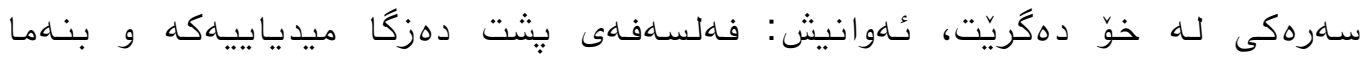

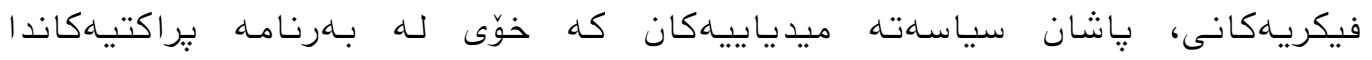

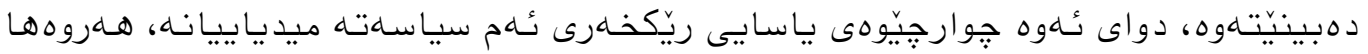

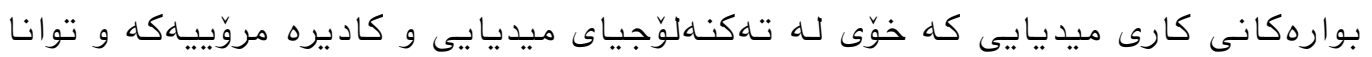

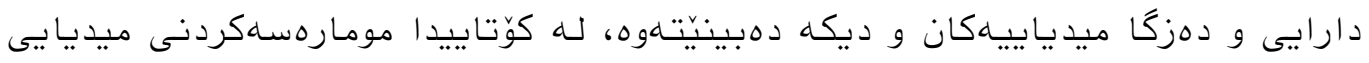
له واقيعى بيراكتيكيدا.

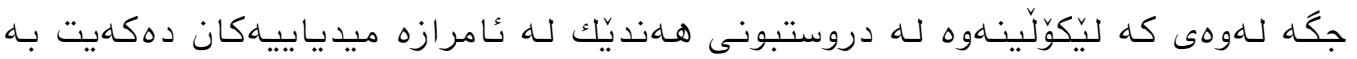

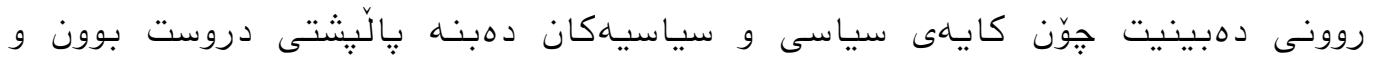

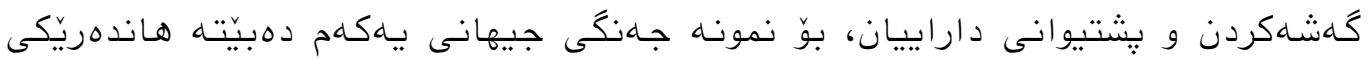

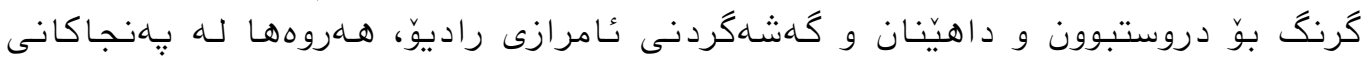

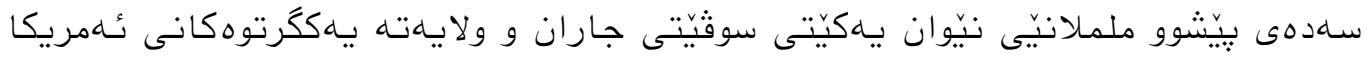

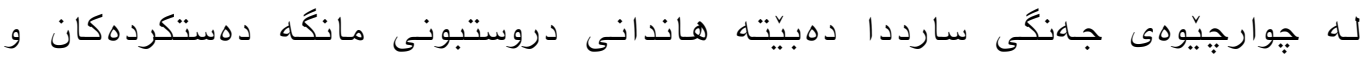

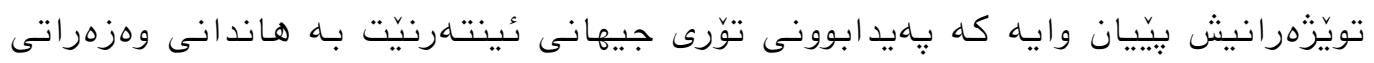

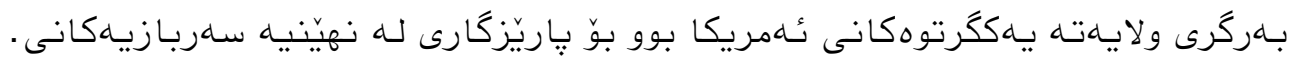

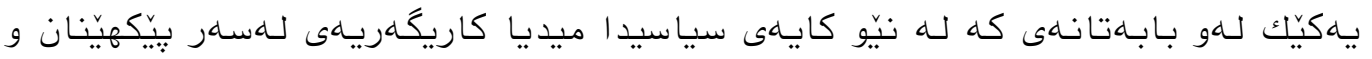

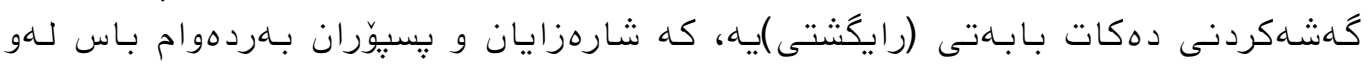

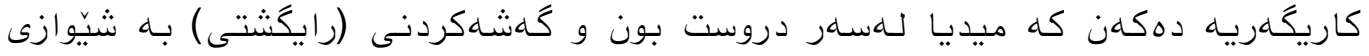

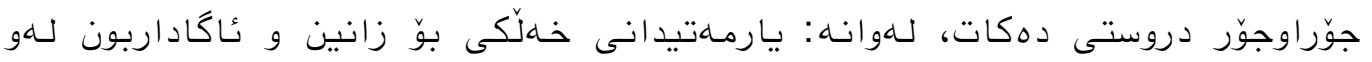

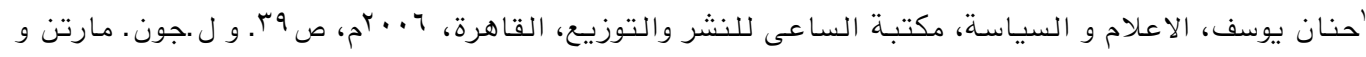

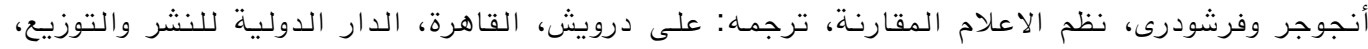

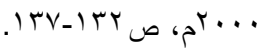




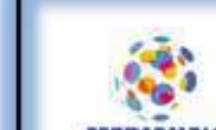

MEDIĀMA'19
هجلة الفنون والندب وعلوم اللإنسانيات واللاجتماعاع

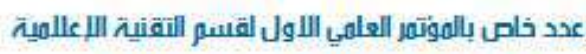
كلية التقنية اللدازية جاهعت السليهانية التقنيت

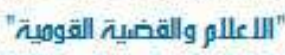

www.jalhss.com ISSN online: $2414-3383$ ISSN print $2616-3810$

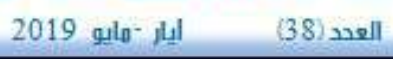

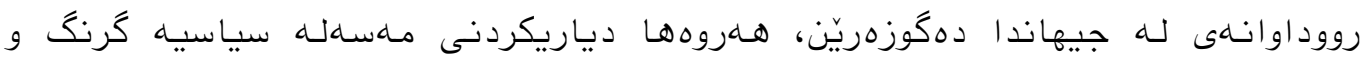

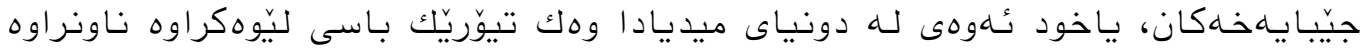

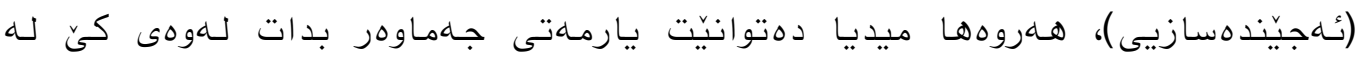

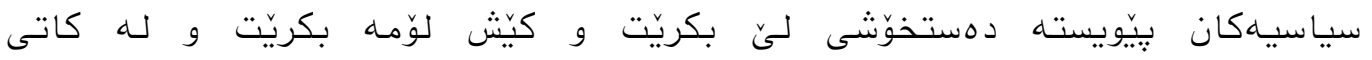

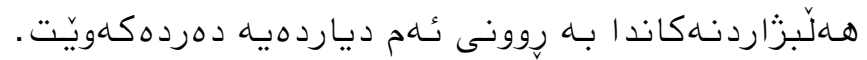

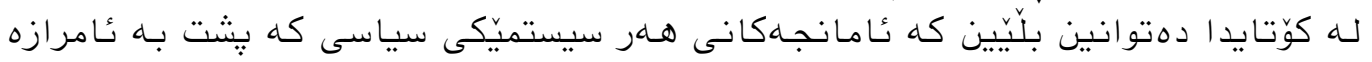

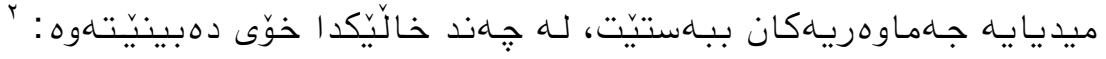

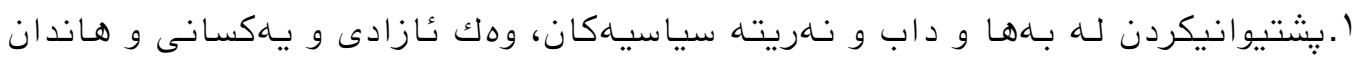

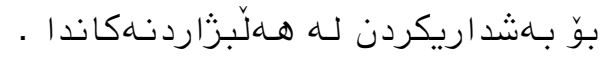

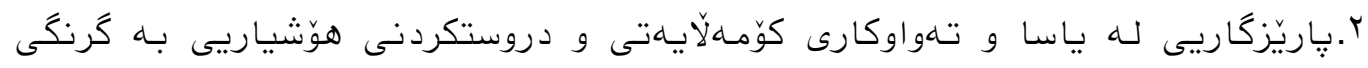

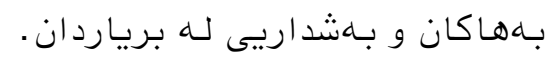

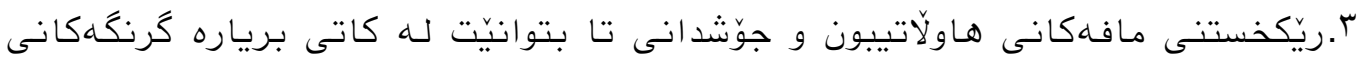

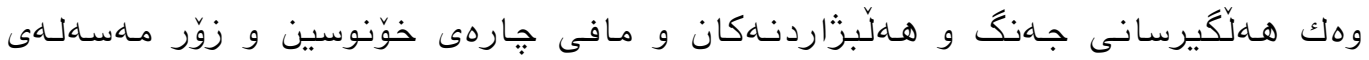

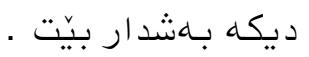

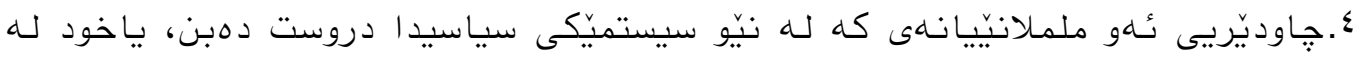

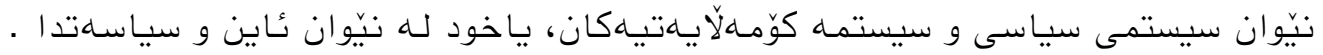

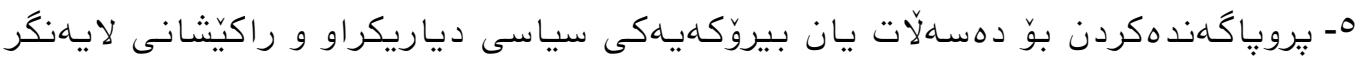

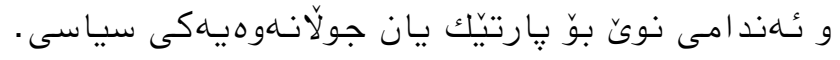

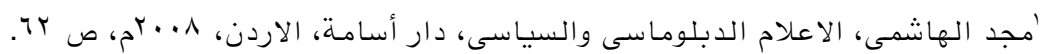

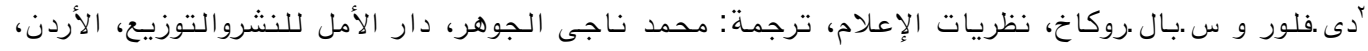

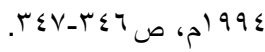

